UNIVERSIDADE DE SÃO PAULO

ESCOLA DE ENGENHARIA DE SÃO CARLOS

DEPARTAMENTO DE ENGENHARIA MECÂNICA

\title{
DESENVOLVIMENTO DE UM SENSOR DE TEMPERATURA INTELIGENTE - COMPENSAÇÃO EM TEMPO REAL DOS EFEITOS DE CONVECÇÃO, ACUMULAÇÃO E RADIAÇÃO
}

\section{Juliana de Oliveira}

Orientador: Prof. Assoc. Paulo Seleghim Junior

Tese apresentada à Escola de
Engenharia de São Carlos da
Universidade de São Paulo, como parte
dos requisitos para a obtenção do
Título de Doutor em Engenharia
Mecânica.


Aos meus pais Ailton e Marilú. 


\section{Agradecimentos}

A Deus, por tudo que sou e por estar sempre ao meu lado, dando força e saúde.

Ao Prof. Paulo Seleghim Junior, pela orientação, ensinamentos, dedicação, incentivo e amizade no desenvolvimento deste trabalho. Neste período de convivência aprendi muito, obrigada por tudo.

Aos meus pais, Ailton e Marilú, pelo amor, apoio e compreensão. As minhas irmãs, Silmara e Suzeli, e ao meu cunhado, Wagner, pelo carinho. Aos meus sobrinhos, Victor e Mateus, por alegrarem minha vida e de minha família.

Ao Prof. Carlos Dias Maciel pelo apoio e amizade.

Aos amigos Alessandra, Cecília, Érica, Graziela, Grazieli, Helton, Ivonete, Paulo, Sônia e Vanessa pela amizade, apoio, incentivo e companheirismo no decorrer deste trabalho.

Aos amigos da pós-graduação, do Cefer e do Coem pelo companheirismo.

Aos técnicos do NETeF Hélio, Jorge, Luchesi, Roberto Lourenço, Roberto Pratavieira, Torres, Zete, pelo suporte nos problemas experimentais e computacionais.

As funcionárias Ana e Lena pelo carinho no laboratório.

Aos colaboradores da secretaria do $\mathrm{NETeF}$, da secretaria de pós-graduação da engenharia mecânica, da secretária de pós-graduação da EESC e das bibliotecas.

A Capes pelo auxílio financeiro. 


\section{Resumo}

OLIVEIRA, J. (2006). Desenvolvimento de um sensor de temperatura inteligente compensação em tempo real dos efeitos de convecção, acumulação e radiação. Tese (doutorado) - Escola de Engenharia de São Carlos, Universidade de São Paulo, São Carlos, 2006.

Esta tese apresenta o desenvolvimento de uma técnica de processamento numérico capaz de reconstruir o sinal da temperatura do processo original a partir do sinal distorcido, atrasado e ruidoso, medido através de uma sonda intrusiva. Uma técnica de regularização foi adotada para contornar o mau condicionamento do modelo numérico inverso da equação de transdução para obter o sinal do processo, que considera o acúmulo térmico e as transferências de calor convectivo e radiativo entre o meio e o sensor térmico. O método dos mínimos quadrados simplificado foi implementado como técnica de regularização, por ser um método rápido e possuir um código computacional pequeno, permitindo, obter os dados em tempo real e desenvolver um sensor térmico inteligente. Testes numéricos demonstraram as discrepâncias introduzidas pela inércia térmica, convecção e radiação, bem como a extrema sensibilidade da presença de ruídos quando o problema inverso é resolvido. Testes experimentais foram conduzidos para validar o algoritmo de reconstrução sob condições práticas com sinais obtidos por um termopar encapsulado.

Palavras-chave: método de regularização, problema inverso, medida em tempo real, sensor de temperatura inteligente. 


\section{Abstract}

OLIVEIRA, J. (2006). Development of an intelligent temperature sensor - on-line compensation of the convection, accumulation and radiation effects. $\mathrm{Ph} . \mathrm{D}$ Thesis Escola de Engenharia de São Carlos, Universidade de São Paulo, São Carlos, 2006.

This thesis presents the development of a numerical processing technique capable of reconstructing the original process temperature signal from distorted, late and noisy measured signal obtained from an intrusive probe. A regularization technique was adopted to palliate the ill conditioning of the inverse numerical model of the transduction equation to obtain the process signal, which considers thermal accumulation and convective and radiative heat transfers between the medium and the thermal sensor. The simplified least square method was implemented as the regularization technique, because it is a fast method and results in a small computational code, which produces on-line information and allow the development an intelligent temperature sensor. Numerical tests demonstrated the discrepancies introduced by thermal inertia, convection and radiation, as well as the extreme sensitivities to the presence of noise when solving the inverse problem. Experimental tests were carried out to validate the reconstruction algorithm under realistic experimental conditions with the signals obtained by the sheathed thermocouple.

Keywords: regularization method, inverse problem, on-line measurement, intelligent temperature sensor. 


\section{Sumário}

Introdução........................................................................................................................................1

Objetivos .............................................................................................................................4

Revisão bibliográfica......................................................................................................................6

3.1 Aplicações dos sistemas com escoamentos multifásicos ..................................... 6

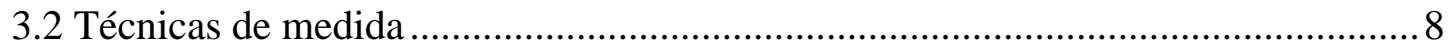

3.3 Técnicas de processamento de sinais ................................................................ 11

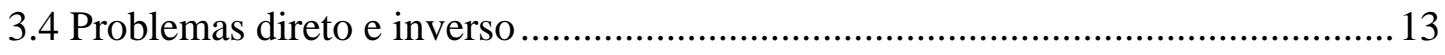

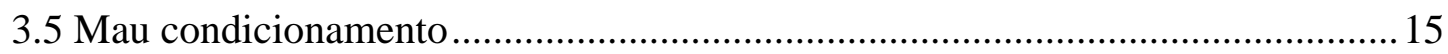

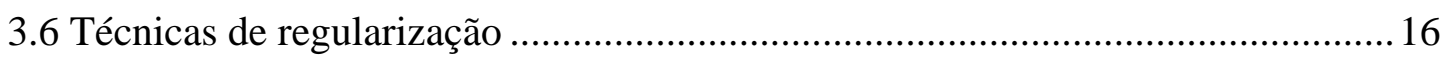

Técnicas de smoothing (alisamento) .........................................................................21

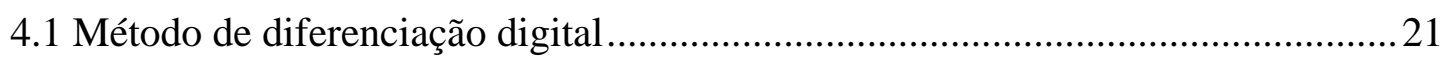

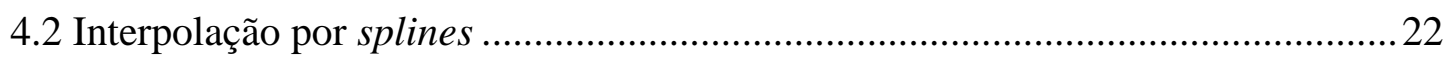

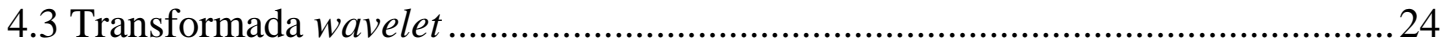

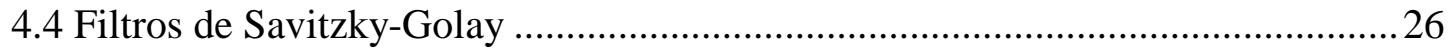

Formulação do problema e algoritmo de reconstrução....................................................29

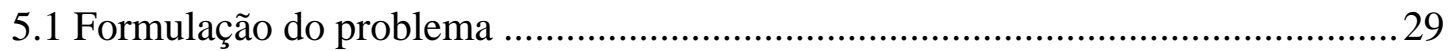

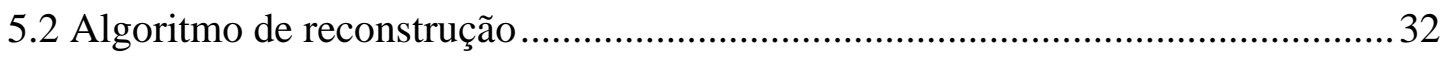

Testes numéricos e experimentais...................................................................................................3 37

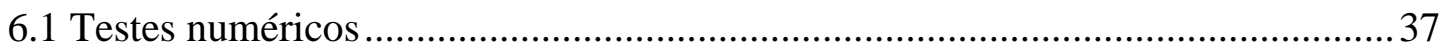

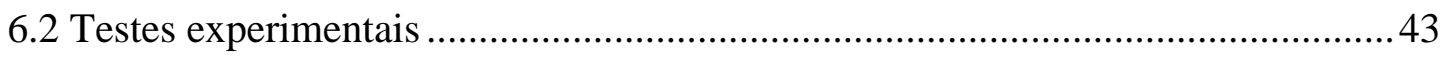

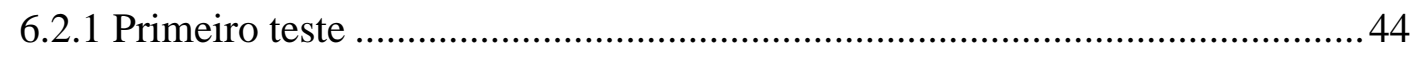

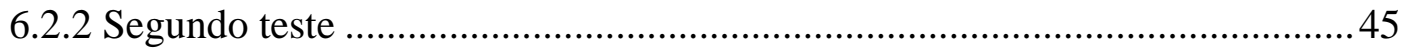

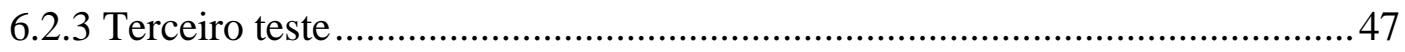


Conclusões e perspectivas..........................................................................................................54

Referência bibliográfica.............................................................................................................57

Apêndice A - Termopar inteligente .........................................................................................66

Apêndice B - LabVIEW ………………...................................................................................68

Apêndice C - Termopar ..............................................................................................................

Anexo A ........................................................................................................................................79

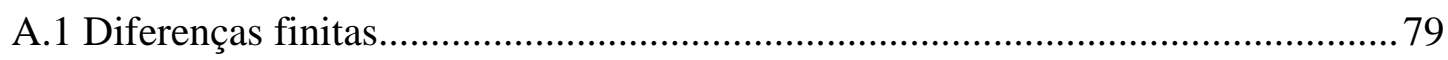

A.2 Função de densidade de probabilidade.............................................................. 80

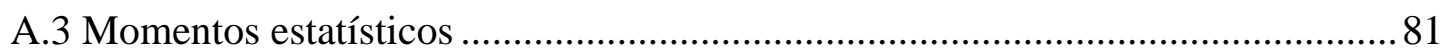




\section{Lista de figuras}

Figura 3. 1: Diferenças entre o sinal obtido por uma sonda ideal e o sinal obtido por uma

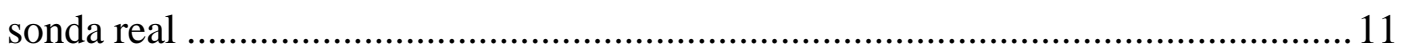

Figura 3. 2: Esquema geral dos problemas direto e inverso ........................................ 14

Figura 5. 1: Uso de uma sonda térmica para detecção de fase num escoamento gás-

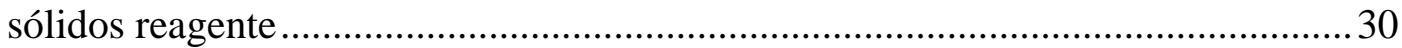

Figura 5. 2: $T_{\text {ind }}$ e $d T_{\text {ind }} / d t$ da equação (5.2) são calculadas através de um polinômio ajustado sobre os últimos $m+1$ pontos de temperatura ......................................33

Figura 6. 1: Temperatura do processo, temperatura indicada e temperatura do processo reconstruída obtida da equação (5.7) sem regularização a priori (o nível de erro da

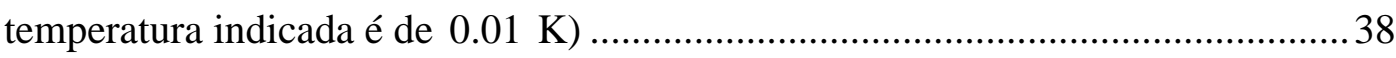

Figura 6. 2: Temperaturas do processo, indicada, reconstruída (equação (5.7)) e regularizada (equação (5.13)) (o nível de ruído da temperatura indicada é $0.1 \mathrm{~K}$ ) 39

Figura 6. 3: Sinais das temperaturas do processo (azul), reconstruída (alaranjado) e regularizada (vermelho) para diferentes números de temperaturas ajustadas (a, b e c) e PDF's da temperatura do processo, regularizada e reconstruída (esquerda, centro e direita)

Figura 6. 4: Desvio padrão do erro entre o sinal do processo real e do sinal reconstruído regularizado em função do número de pontos de temperatura ajustada e por coeficientes de ponderação dada pelas equações (6.1) e (6.2) (pontos quadrados

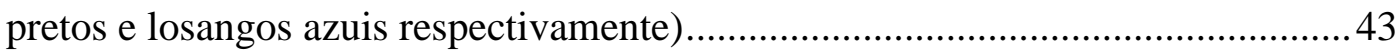

Figura 6. 5: Temperaturas do processo, indicada e reconstruída do teste da chama....... 45

Figura 6. 6: Temperaturas do processo, indicada e reconstruída .................................. 46

Figura 6. 7: Projeto experimental (termopares tipo K estão localizados lado a lado perpendicularmente a direção do escoamento para minimizar os efeitos de rastro) 
Figura 6. 8: Superfície de otimização dada pela equação (6.5) (esquerda = escala linear e direita $=$ escala logarítmica) 48

Figura 6. 9: Sinais experimentais das temperaturas do processo (azul), indicada (preto) e regularizada (vermelho) para diferentes números de temperaturas ajustadas (a, b, c e d) e PDF's das temperaturas do processo, regularizada e reconstruída (esquerda, centro e direta)

Figura A. 1: Hardware dedicado (PIC 18F252) e a eletrônica associada ao sinal condicionado 66

Figura A. 2: Foto da montagem do termopar inteligente no protoboard. 67

Figura B. 1: Painel frontal do programa de aquisição de dados..... 69

Figura B. 2: Diagrama de bloco do programa de aquisição de dados. 69

Figura B. 3: Painel frontal do programa de reconstrução dos sinais e simulação. .70

Figura B. 4: Diagrama de bloco do programa de reconstrução dos sinais e simulação.. 70

Figura B. 5: Diagrama de bloco da subVI "gama" .71

Figura B. 6: Diagrama de bloco da subVI "tau" ............................................................... 71

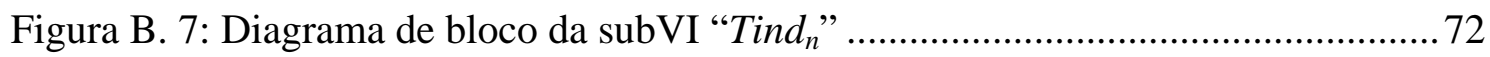

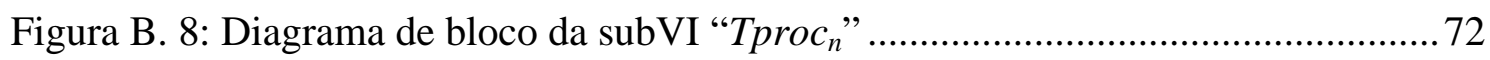

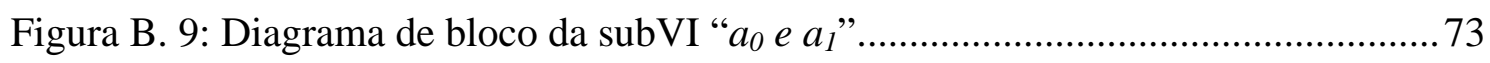

Figura B. 10: Diagrama de bloco da subVI " $G^{-1}$ " ......................................................... 73

Figura B. 11: Diagrama de bloco da subVI "gera vet $b$ " .............................................. 74

Figura C. 1: Circuito simples de termopar (PERRY e CHILTON 1980) ........................ 76

Figura C. 2: Gráfico da relação f.e.m. x temperatura de vários tipos de termopares (TERMOPARES 2005) .77

Figura A.1. 1: Pontos utilizados nas diferenças finitas avançadas, atrasadas e centrais. 80

Figura A.2. 1: Relação entre a PDF e o histograma (METCALFE 1994). 80

Figura A.3. 1: Distribuições cujo terceiro (esquerda) e quarto (direita) momentos são diferentes de uma distribuição normal (PRESS et al. 1992) 82 


\section{Lista de tabelas}

Tabela 3. 1: Exemplos de métodos para a solução de problemas inversos ..................... 17

Tabela 6. 1: Erro médio entre a temperatura do processo real e reconstruída regularizada de acordo com a equação (6.3) em ${ }^{\circ} \mathrm{C}$ (vetor de ponderação: $w_{k}=e^{-k}$ )...............46

Tabela 6. 2: Temperaturas testadas a fim de determinar $\tau_{0}$ e $\lambda$ na equação (6.4).........49

Tabela 6. 3: Momentos estatísticos médios da temperatura de referência e da temperatura reconstruída para diferentes valores de $m+1$ nas equações (5.16) e

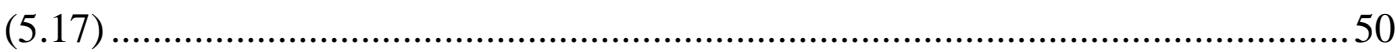

Tabela C. 1: Relação de tipos de materiais utilizados na construção de termopares e suas faixas de atuação 78 


\section{Lista de símbolos}

\section{Revisão bibliográfica}

3.3 Técnicas de processamento de sinais

$$
\begin{aligned}
& X_{k}(x, t): \text { sinal indicador de fase ou função densidade de fase } \\
& k: \text { fase } \\
& x: \text { fluxo } \\
& t: \text { tempo }
\end{aligned}
$$

\section{Técnicas de smoothing (alisamento)}

4.1 Método de diferenciação digital

$n:$ ordem do método de diferenciação digital

$f$ : frequiência instantânea

$\varphi$ : fase instantânea

$a_{-1}, a_{0}, a_{1}$ : coeficientes do filtro binomial de alisamento

$k:$ índice

$t:$ tempo

4.2 Interpolação por splines

$n:$ número de pontos

$y_{i}$ : conjunto de pontos

$i$ : índice 
$Y_{i}$ : polinômio de grau três

$t$ : variável do polinômio

$a_{i}, b_{i}, c_{i}, d_{i}, D_{i}$ : incógnitas

4.3 Transformada wavelet

$\psi(x)$ : wavelet mãe

$x$ : variável

$\psi^{a, b}(x):$ wavelet filha

$a$ : fator de extensão

$b:$ fator de translação

$f(t):$ sinal

$W_{\psi}(f)(a, b)$ : transformada wavelet

$t:$ tempo

$C_{\psi}:$ critério de admissibilidade

4.4 Filtros de Savitzky-Golay

$f_{i}:$ pontos

$t_{i}:$ posição

$\Delta:$ constante

$i:$ índice

$g_{i}:$ combinação linear

$c_{n}$ : coeficientes da combinação linear $g_{i}$

$n$ : índice

$n_{L}$ : número de pontos a esquerda do ponto na posição $i$

$n_{R}$ : número de pontos a direita do ponto na posição $i$

$M$ : grau do polinômio
A : matriz
$j$ : índice
$\mathbf{a}$ : vetor dos coeficientes $c_{n}$ 
f : vetor dos pontos $f_{i}$

$k$ : índice

$\mathbf{e}_{n}$ : vetor unitário

$m:$ índice

Formulação do problema e algoritmo de reconstrução

5.1 Formulação do problema

$T_{p r o c}:$ temperatura do processo

$T_{\text {ind }}:$ temperatura indicada

$M:$ massa $(\mathrm{kg})$

$C:$ calor específico $(\mathrm{J} / \mathrm{kg} / \mathrm{K})$

$A$ : área $\left(\mathrm{m}^{2}\right)$

$h:$ coeficiente de convecção $\left(\mathrm{W} / \mathrm{m}^{2} / \mathrm{K}\right)$

$\varepsilon$ : emissividade (adimensional)

$\sigma$ : constante de Stefan-Boltzmann $\left(=5.670 \cdot 10^{-8} \mathrm{~W} / \mathrm{m}^{2} / \mathrm{K}^{4}\right)$

$T_{\infty}$ : temperatura na qual ocorre a transferência radiativa

$\tau:$ constante de tempo (s)

$\gamma$ : coeficiente de radiação

$\Delta t:$ passo no tempo

$n$ : índice do tempo

$t:$ tempo (s)

5.2 Algoritmo de reconstrução

$N$ : grau do polinômio

$m:$ número de pontos

$T_{\text {suave }}$ : temperatura polinomial

$x$ : eixo de suporte polinomial

$a_{i}:$ coeficientes polinomiais

$i$ : índice 
$w_{k}:$ coeficiente de peso

$k$ : índice do somatório

$[G]$ : matriz de Gram

$[G]^{-1}$ : inversa da matriz de Gram

$A_{i}$ : coeficientes da primeira linha de $[G]^{-1}$

$B_{i}$ : coeficientes da segunda linha de $[G]^{-1}$

\section{Testes numéricos e experimentais}

6.1 Testes numéricos

$\bar{\tau}:$ constante de tempo média

$\bar{\gamma}$ : coeficiente de radiação médio

$\bar{T}_{\text {ind }}:$ temperatura indicada média

$T_{\text {reg }}$ : temperatura reconstruída regularizada

$T_{\text {rec }}$ : temperatura reconstruída

6.2 Testes experimentais

$e:$ função erro

$j$ : índice

$\phi$ : raio do termopar (mm)

$T_{r e f}$ : temperatura de referência ou temperatura do processo real

$\tau_{0}:$ constante de tempo em $317.5 \mathrm{~K}(\mathrm{~s})$

$\lambda$ : medida flutuante térmica $(\mathrm{s} / \mathrm{K})$

mim: mínimo

max: máximo

\section{Apêndice C - Termopar}

A, B: metais do termopar 
$\mathrm{T}_{1}$ : temperatura na junta fria do termopar

$\mathrm{T}_{2}$ : temperatura na junta quente do termopar

$i$ : corrente termoelétrica

\section{Anexo A}

A.1 Diferenças finitas

$f:$ função

$x$ : variável da função

$\Delta x:$ tamanho do passo

$i, k:$ índices

A.2 Função de densidade de probabilidade
$f$ : função
$x$ : variável da função
$F$ : função de distribuição
$\mathbf{x}$ : variável randômica

A.3 Momentos estatísticos

$x_{j}:$ pontos

$\bar{x}:$ média dos pontos

$N$ : número de pontos

$j$ : índice

$\sigma^{2}$ : variância

$\sigma:$ desvio padrão

Skew: skewness

Kurt : kurtosis 


\section{Capítulo 1}

\section{Introdução}

Escoamentos multifásicos têm sido amplamente estudados, impulsionados pelo aumento da demanda das tecnologias atuais, por exemplo, em escoamentos gás-líquido, atendendo as indústrias de petróleo, ou gás-sólidos, em reatores de leitos fluidizados (CARTELLIER e ACHARD 1991).

Os reatores de leitos fluidizados são usados na indústria para várias finalidades, dentre as quais se destacam quebra catalítica de hidrocarboneto e combustão de carvão (FAN 1996). A modelagem desse sistema consiste de uma combinação de bolhas e partículas, ou seja, uma mistura contendo duas fases. Existem também os leitos fluidizados circulantes, nos quais a velocidade da fase contínua é suficiente para transportar pneumaticamente o particulado.

A fase a bolhas da mistura é dispersa dentro da fase continua, formando uma emulsão quando o gás fluidizante é injetado no fundo do leito. Quando as bolhas movem-se para cima arrastam o particulado, podendo coalescer em bolhas maiores, dividir e recoalescer.

Para um escoamento gás-sólidos este fenômeno intrínseco e interdependente resulta em um escoamento extremamente complexo e diferenciado por reações complexas e taxas elevadas de transferência de calor. Uma compreensão de tais fenômenos é de grande importância para o projeto adequado de leitos fluidizados, com operações seguras e eficientes.

A investigação das propriedades e da evolução das bolhas em leitos fluidizados usa técnicas de medida intrusivas e não-intrusivas. Entre as técnicas não-intrusivas mais comuns de medida externa estão: as sondas capacitivas e eletroresistivas, observações 
óticas e raios X (ROCO 1996). Estes métodos não perturbam o processo, mas são limitados a pequenos leitos ou permitem observações somente perto das paredes do leito. Técnicas intrusivas são baseadas em sondas de detecção de fase para medir propriedades físicas locais. As sondas mais usadas são: térmicas, capacitivas, óticas, pressão diferencial e eletroresistivas (CARTELLIER e ACHARD 1991). Embora perturbem o processo, estas sondas são aplicáveis em leitos de qualquer tamanho e constituem a escolha mais adequada em sistemas industriais de grande escala.

Sondas térmicas são uma boa opção para a análise de escoamentos gás-sólidos em reatores de leitos fluidizados, porque possuem baixo custo e robustez intrínseca necessários para um meio experimental extremamente severo. As sondas ficam imersas em um escoamento onde as temperaturas ultrapassam $1000{ }^{\circ} \mathrm{C}$, o material se deteriora por causa do atrito com o particulado fluidizado e por corrosão química.

O princípio de medição das sondas térmicas é baseado na diferença de temperatura entre a fase de dispersão reagente (queima de partículas de carvão, por exemplo) e a fase de bolhas de gás constituída de gás excedente injetado. Conseqüentemente, os sinais obtidos por tais sondas térmicas tendem a concentrarem-se em níveis característicos e podem ser usados para construir o sinal indicador de fase, o qual, por definição, assume valores binários dependendo de qual fase está instantaneamente em contato com o sensor.

O sinal indicador de fases é necessário para a determinação de parâmetros físicos importantes, tais como tempos de residência, diâmetros de bolhas, velocidades, níveis de turbulência e temperatura do escoamento, os quais são difíceis de obter por medição indireta. Numa aplicação industrial, o sinal indicador de fases é importante para obter uma melhor eficácia e controle do processo de fluidização. Num leito fluidizado, a queima de carvão depende da taxa de reação e do controle da temperatura, de valor previamente determinado para minimizar a produção de óxidos de enxofre e de nitrogênio e, assim, obter uma produção de energia eficiente e limpa.

Existem restrições na obtenção de alguns dos parâmetros físicos descritos acima e qualquer distorção nos sinais medidos, por mais insignificante que seja, pode comprometer seriamente os resultados. Já que erros experimentais e distorções na medida são difíceis de serem evitados, técnicas especiais de processamento de sinais devem ser aplicadas parar minimizar erros e obter resultados aceitáveis.

Este trabalho está organizado da seguinte forma: o capítulo 2 apresenta os objetivos; o capítulo 3 contém a revisão da bibliografia dos assuntos abordados neste 
projeto; no capítulo 4 encontram-se alguns métodos de alisamento que suavizam os dados e que são usados nas áreas de processamento e análise de sinais, computação gráfica e processamento de imagens; o capítulo 5 descreve a formulação do problema e o algoritmo de reconstrução; o capítulo 6 expõe os testes numéricos e experimentais e o capítulo 7 discute as conclusões obtidas e apresenta as perspectivas para a continuidade deste trabalho.

Nos apêndices, A, B e C, a fim de complementar o texto, encontram-se respectivamente, um teste realizado pelo protótipo de um sensor térmico inteligente nomeado por termopar inteligente, o software de programação LabVIEW com a listagem completa dos programas e a caracterização do termopar usado como sonda intrusiva de medição de temperatura. No anexo A estão as teorias do método de diferenças finitas, da função de densidade de probabilidade e dos quatro momentos estatísticos. 


\section{Capítulo 2}

\section{Objetivos}

Conforme mencionado na introdução, o estudo do comportamento das bolhas é de grande importância para o desenvolvimento de reatores de leitos fluidizados, de forma a obter uma operação otimizada, implicando em economia energética e material, maior eficiência e segurança no processo.

O sinal indicador de fase é muito importante no monitoramento dos processos de fluidização, pois é uma forma de obter informações básicas sobre o sistema. Porém, o sinal obtido por uma sonda intrusiva apresenta distorções, ruídos e atrasos. Então, técnicas de processamento de sinais devem ser aplicadas para que o sinal indicador de fase possa representar corretamente o fenômeno físico a ser investigado.

Com este intuito, o objetivo global deste trabalho é contribuir para o desenvolvimento de uma técnica de processamento numérico capaz de reconstruir o sinal da temperatura do processo original a partir do sinal distorcido, medido através de uma sonda intrusiva.

No caso de sondas térmicas usadas em reatores de leito fluidizado, tais distorções são causadas principalmente por efeitos não-lineares e atrasos ocasionados pelo encapsulamento de proteção do sensor de temperatura. O método proposto é baseado na deconvolução do sinal medido através de um modelo numérico inverso da equação de transdução para obter o sinal do processo.

O modelo matemático é construído considerando o acúmulo térmico e a transferência de calor (convectivo e radiativo) entre o meio e o sensor térmico. A equação diferencial correspondente é discretizada pelo método de diferenças finitas e regularizada por ajuste polinomial, através do qual derivadas correntes e valores de 
temperatura indicada são extraídos. Esta aproximação é adequada para se obter os dados em tempo real e permite o desenvolvimento de um sensor térmico inteligente, capaz de corrigir atrasos e distorções. Mais especificamente, o objetivo deste trabalho também é compreender alguns problemas peculiares ao modelo adotado, em particular, entender como o mau condicionamento intrínseco do problema se manifesta e, desta forma, desenvolver métodos capazes de contornar os problemas encontrados. 


\section{Capítulo 3}

\section{Revisão bibliográfica}

Este capítulo apresenta uma revisão da bibliografia dos assuntos abordados neste projeto: aplicações dos escoamentos multifásicos; técnicas de medida e processamento de sinais; problemas direto e inverso; mau condicionamento e técnicas de regularização para atenuar os erros na resolução dos problemas inversos.

\subsection{Aplicações dos sistemas com escoamentos multifásicos}

Sistemas com escoamentos multifásicos gás-líquido, gás-sólidos, gás-líquidosólidos tornaram-se uma área em evidência nos últimos anos devido ao aumento de aplicações na área química, mineração, petroquímica, bioquímica, metalúrgica, farmacêutica, nuclear, energética, etc (FAN 1996, ROCO 1996, KANTARCI, BORAK e ULGEN 2005). Nos reatores de leitos fluidizados, a operação de fluidização envolve o escoamento de sólidos em contato com gás, líquido, ou gás e líquido (FAN 1996) e nos reatores de colunas de bolhas a fase gasosa apresenta-se como bolhas dispersas na fase líquida contínua (JOSHI et al. 2002).

A análise da literatura mostra uma grande quantidade de pesquisas com reatores de leitos fluidizados e com reatores de colunas de bolhas, no intuito de obter resultados importantes para uma melhor compreensão e operação destes sistemas. Os trabalhos de Fan (1996), Roco (1996), Joshi et al. (2002) e Kantarci, Borak e Ulgen (2005) são artigos de revisão do estado da arte. São pesquisas voltadas para a hidrodinâmica dos sistemas, teorias e modelagem, mistura, atrito e arrasto dos sólidos, transferência de 
calor e massa, instrumentação, aplicações, microestrutura e organização de macroestruturas no escoamento, técnicas de simulação numérica, tópicos interdisciplinares no processo de escoamento particulado, entre outros.

De acordo com Fan (1996), as aplicações clássicas em reatores de leitos fluidizados gás-sólidos, gás-líquido-sólidos podem ser exemplificados por: reações de síntese (síntese de Fischer-Tropsch); quebra de hidrocarboneto (craqueamento catalítico de fluido e craqueamento térmico); reações de redução e oxidação de minério (redução de minério de ferro); processos de carbonização e gaseificação (gaseificação de carvão e produção de carbono ativado); cristalização em processamento químico e ambiental; processamento petroquímico (conversão de petróleo pesado); processamento eletroquímico; processamento biológico (tratamento de esgoto). Ainda de acordo com o autor as aplicações no estado da arte para leitos fluidizados gás-sólidos em processamento de materiais são: produção de silício, tungstênio, partículas com camadas metálicas, tecnologias para combustível fóssil limpo com o controle de $\mathrm{NO}_{\mathrm{x}}$, $\mathrm{SO}_{2}, \mathrm{~N}_{2} \mathrm{O}$, toxinas do ar, perdas liquidas e sólidas e outras emissões resultantes do uso de carvão e incineradores de leito fluidizado circulante a alta pressão para rejeitos sólidos. As aplicações no estado da arte usando leitos fluidizados gás-líquido-sólidos podem ser exemplificadas por processamento biológico, tal como produção de antibióticos, etanol e vacinas virais.

Para Kantarci, Borak e Ulgen (2005) os reatores de colunas de bolhas são usados especialmente em processos químicos (processo de Fischer-Tropsch, reações de oxidação), processos bioquímicos (fermentação e tratamento de esgoto) e processo de conversão de combustíveis. Segundo Joshi et al. (2002), as aplicações relevantes em reatores de colunas de bolhas incluem oxidação, hidrogenação, reação de FischerTropsch, fermentação, tratamento de esgoto, etc.

Pesquisas recentes tanto em leitos fluidizados quanto em colunas de bolhas estão voltadas para a segurança e eficiência do processo. Os estudos estão freqüentemente focados nos seguintes tópicos: fração de gás; características das bolhas; investigações do regime de escoamento e estudo computacional da dinâmica de fluidos; medida de transferência de calor do meio e local; estudos de transferência de massa. Os efeitos da dimensão e projeto interno da coluna, condições de operação, isto é, pressão e temperatura, propriedades do líquido, os efeitos da velocidade superficial do gás, projeto do distribuidor de gás, tipo e concentração dos sólidos são geralmente investigados nestas pesquisas (KANTARCI, BORAK e ULGEN 2005). 
As propriedades e evolução das bolhas nos reatores têm despertado particular interesse, pois as bolhas sofrem ações do meio, podendo romper-se no movimento de subida, coalescer e se separarem novamente. As características das bolhas são investigadas usando técnicas intrusivas e não-intrusivas de medida. Por exemplo, a distribuição do tamanho das bolhas em reatores de colunas de bolhas sob condições industriais foi determinada por um processamento de imagem não-invasivo (SCHÄFER, MERTEN e EIGENBERGER 2002); e através de técnicas de processamento numérico associado com sondas intrusivas de detecção de fase, o histograma do diâmetro das bolhas foi determinado a partir do histograma de cordas de escoamentos bifásicos com bolhas (SELEGHIM e MILIOLI 2001).

\subsection{Técnicas de medida}

As pesquisas sobre técnicas de medida são de importância fundamental para a compreensão da dinâmica do escoamento na operação de reatores, sejam eles em leitos fluidizados ou colunas de bolhas. Mais precisamente, taxas de reação química e de transporte por convecção e difusão correlacionam-se de maneira muito estreita com a área interfacial, tempos de residência, diâmetro de bolhas e outras variáveis características, isto é, com a maneira pela qual as diferentes fases entram em contato no reator. Estes fatos justificam a importância de se desenvolver instrumentos para a monitoração destas variáveis, bem como dispositivos para seu controle.

Para a análise de sistemas de escoamentos multifásicos, pode-se empregar técnicas de mensuração não-intrusivas e intrusivas. As técnicas de medida nãointrusivas podem ser acústicas, tomografias capacitivas e impedâncias elétricas, velocimetria laser Doppler (LDV), incluindo métodos ópticos (cálculo da velocidade por imagem da partícula, cálculo da velocidade por imagem digital da partícula, holografia, outros) (ROCO 1996). Ainda de acordo com Roco (1996), avanços recentes na instrumentação, como visualização em ressonância magnética nuclear (NMR) e tomografia de Raio-X, e a análise de imagem e a capacidade dos computadores têm propiciado avanços significativos na visualização de escoamentos multifásicos.

Como exemplo de trabalhos que utilizam técnicas de medida não-intrusivas temse: tomografia de Raio-X aplicada em escoamentos gás-sólidos num leito fluidizado 
circulante para determinar a distribuição de sólidos nas tubulações (GRASSLER e WIRTH 2000); caracterização de escoamento ar-água por ressonância magnética nuclear (LEBLOND et al. 1998); desenvolvimento de uma técnica de visualização da distribuição de fase em escoamentos bifásicos com tomografia por impedância elétrica (KIM et al. 2002); anemômetro fase Doppler usado para análise do processo de formação de aerossol de um metal líquido (TILLWICK, UHLENWINKEL e BAUCKHAGE 1999); e discriminação das velocidades entre sólido e líquido de um escoamento em pasta fluida através de um velocímetro laser Doppler (CHEN e KADAMBI 1995).

As técnicas intrusivas são baseadas em sondas de detecção de fase. Tais sondas indicam um sinal binário que caracteriza o fenômeno físico do escoamento em contado com a ponta da sonda. Quatro técnicas foram identificadas, baseadas em índices refrativos, condutividade elétrica ou capacitância, condutividade térmica e difusividade eletroquímica (CARTELLIER e ACHARD 1991).

$\mathrm{Na}$ técnica óptica a sonda laser detecta diferenças de índice de refração ou opacidade dependendo da fase constituinte do escoamento. As sondas de impedância mudam de resistividade ou capacitância de acordo com a fase considerada. A influência de resistividade e capacitância varia com a freqüência da corrente imposta através do sensor. De qualquer forma, uma exigência é que condutividades ou capacitâncias das fases sob estudo sejam significativamente diferentes.

Técnicas baseadas na troca de calor podem medir a velocidade local, turbulência e temperatura local do escoamento. As sondas térmicas mostram as diferenças de temperatura entre as fases quando em contato com o sensor. Já a técnica eletroquímica explora a difusão de íons ao invés da temperatura.

Como exemplos de trabalhos com sondas intrusivas tem-se: o desenvolvimento de uma sonda óptica cônica de detecção de fase para investigar as características e a evolução espacial de aerossol produzido por injetores coaxiais (HONG, CARTELLIER e HOPFINGER 2004); a análise das características das bolhas em leito fluidizado, feita por uma sonda de capacitância (VAN LARE et al. 1997); medidas locais em escoamentos bifásicos extraídas por um anemômetro filme-quente e por um termopar (HOGSETT e ISHII 1997); e o uso de uma sonda eletroquímica para medir tamanhos de bolhas em colunas de bolhas (ESSADKI, NIKOV e DELMAS 1997).

Os métodos não-intrusivos não perturbam o processo, mas são limitados a equipamentos pequenos e permitem observações somente perto das paredes, no caso 
específico de reatores de leitos fluidizados. Para sistemas de escala industrial a melhor opção é as técnicas intrusivas, que trazem alguns distúrbios ao processo em alguma extensão, mas são aplicáveis em reatores de qualquer tamanho.

O principal problema envolvendo a sondagem de escoamentos em reatores de leito fluidizado diz respeito ao meio extremamente severo no qual o sensor é imerso: temperaturas excedendo $800{ }^{\circ} \mathrm{C}$, materiais em deterioração devido à fricção com as partículas fluidizadas, corrosão química, presença de cargas eletrostáticas, etc. Para estudar os escoamentos, uma necessidade básica é que as sondas possam resistir ao ambiente tempo suficiente para a avaliação e tratamento dos sinais medidos.

Das técnicas intrusivas citadas, as sondas ópticas vêm se atualizando desde que Miller e Mitchie (1970) projetaram a primeira sonda óptica em 1970. Desde então, vários sensores foram desenvolvidos, mas as sondas atuais ainda são limitadas suportando uma pressão de poucos bars e uma temperatura por volta de $100{ }^{\circ} \mathrm{C}$ (CARTELLIER e ACHARD 1991). Algumas das limitações no uso destas sondas em altas temperaturas são: as fibras ópticas empregadas nas sondas ópticas são sensíveis demais para meios severos que causam a deterioração da ponta da sonda; o leito em combustão é uma fonte de luz, o qual pode afetar o sinal; e o sistema de detecção tem que ser protegido do meio com altas temperaturas (JOHNSSON e JOHNSSON 2001).

As sondas por impedância trabalham com temperaturas elevadas, mas são sondas que necessitam de constante calibração, são de uso limitado, pois não fazem medida para todo tipo de escoamento e são susceptíveis as influências de ruídos externos. As sondas eletroquímicas são também de aplicação limitada porque a fase líquida deve ter um eletrólito de composição especial e não podem ser aplicadas em escoamentos líquido-líquido (CARTELLIER e ACHARD 1991).

As sondas térmicas medem a diferença de temperatura entre as fases, sendo que a exigência básica para qualquer sonda térmica é a habilidade de identificar cada fase em um sinal original. Essas sondas são uma boa opção em meios severos por causa do baixo custo e robustez intrínseca. A maior dificuldade nesta técnica é que o sinal fornece informações sobre o escoamento (velocidade, turbulência e temperatura do escoamento), mas também há ruído embutido no sinal (CARTELLIER e ACHARD 1991). Técnicas em processamento de sinais são utilizadas para minimizar a influência dos ruídos nos sinais e serão discutidas a seguir. 


\subsection{Técnicas de processamento de sinais}

Os sinais obtidos pelas sondas térmicas tendem a apresentar níveis característicos e podem ser usados para construir o assim chamado sinal indicador de fase ou função densidade de fase, o qual por definição assume valores binários dependendo de qual fase está instantaneamente em contato com o sensor, equação (3.1) (CARTELLIER e ACHARD 1991).

$$
X_{k}(x, t)= \begin{cases}1 & \text { se } x \text { está na fase } k \text { no tempo } t \\ 0 & \text { caso contrário }\end{cases}
$$

O sinal obtido por uma sonda real não é perfeitamente binário, como ilustra a Figura 3.1. As imperfeições aparecem devido aos ruídos e ao tempo de resposta da sonda.

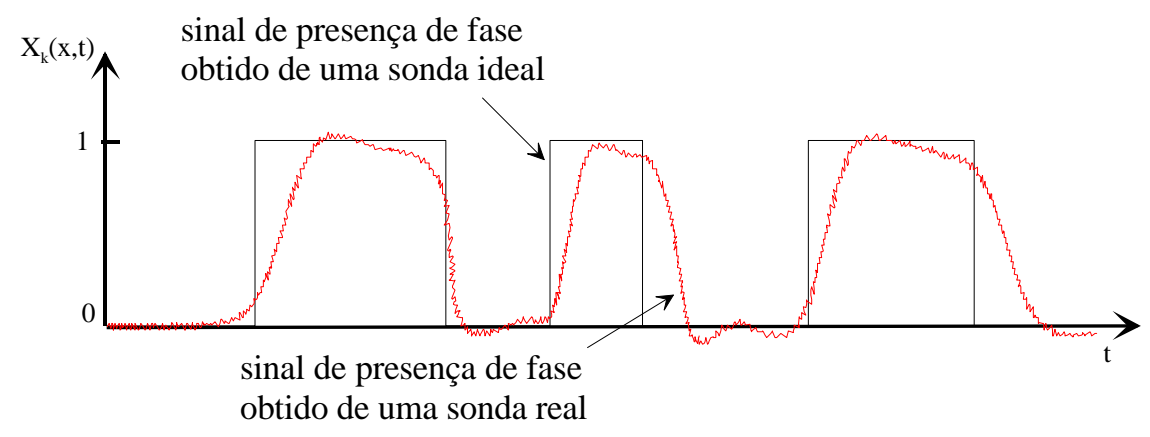

Figura 3. 1: Diferenças entre o sinal obtido por uma sonda ideal e o sinal obtido por uma sonda real

O tempo de resposta depende do sistema de medida, que introduz atrasos entre a ocorrência e a detecção do evento, e também da interferência da sonda, que pode alterar ou desviar o escoamento (ZUN et al. 1995 e SELEGHIM 2002).

Ruídos presentes no sinal também devem ser considerados, pois podem comprometer os resultados. Erros insignificantes na medida podem levar a uma discriminação de fase incorreta.

Para diferenciar as fases existe a técnica de processamento de sinais conhecida como níveis de corte (corte simples, corte duplo, cortes múltiplos (ZUN et al. 1995)) usados para converter o sinal original num sinal binário. Nesse caso, uma escolha 
adequada dos níveis de corte é importante para o bom funcionamento do método. $\mathrm{O}$ problema que ocorre é que é difícil definir critérios objetivos para essa escolha, e a consequiência é a existência de uma quantidade grande de soluções empíricas, cuja aplicação freqüentemente se restringe às condições experimentais em que foi definida (SELEGHIM 2002).

Kataoka, Ishii e Serizawa (1994) determinaram valores de cortes adequados após analisarem a função densidade de probabilidade dos sinais obtidos através de uma sonda de resistividade elétrica quando os níveis de ruído estavam altos. Zun et al. (1995) desenvolveram um algoritmo de processamento capaz de transformar ruídos medidos em um sinal indicador de fases, usando uma técnica de discriminação de fase baseada nos níveis de corte, previamente otimizados por um algoritmo genético.

Outro método denominado técnica de diferenciação propõe que o sinal original seja primeiramente delimitado para eliminar o ruído e então seja diferenciado (CARTELLIER e ACHARD 1991). Uma derivada positiva do sinal determina o início da onda retangular e uma derivada negativa do sinal define o término da onda retangular de valor previamente determinado quando o sinal foi delimitado para eliminar o ruído. Uma das vantagens deste método é que pequenas variações na amplitude do sinal são consideradas, assim pequenas frações de vazios podem ser detectadas (CARTELLIER e ACHARD 1991 e VINCE, MOREIRA e LAHEY 1980). Vince, Moreira e Lahey (1980) usaram a técnica de diferenciação para medir fração de vazio local através de uma sonda de impedância, pois esta técnica é capaz de detectar pulsos rápidos, de curta duração e vazios, ao contrário da técnica de nível de corte simples. Assim, a técnica pôde discriminar baixa freqüência relacionada a pequenas frações de vazio e alta freqüência associada com ruído.

Gabor (1946) e Ville (1948) propuseram a análise da freqüência instantânea do sinal analítico extraído do sinal fornecido pelo sensor como outra forma de tratamento de sinais. O sinal analítico do sinal original pode ser calculado e com isso suas amplitude e fase instantâneas podem ser calculadas. Sendo assim, a freqüência instantânea pode ser determinada, cujo significado está ligado à evolução temporal do conteúdo em freqüência do sinal. As propriedades da amplitude e da freqüência instantânea são bastante interessantes, principalmente quando se têm sinais com amplitudes e freqüências distintas. Seleghim e Milioli (2001) apresentaram um novo algoritmo de discriminação de fase usando filtragem wavelet associado com a 
freqüência instantânea de Ville (1948) para suavizar os efeitos da presença de ruído no sinal.

Embora vários trabalhos venham a contribuir na detecção de fase, o problema persiste, especialmente em processamentos em tempo real, por causa do procedimento de reconstrução do sinal original ser fortemente dependente dos fenômenos físicos do escoamento e de sua interação com a sonda.

O sinal de detecção de fase é muito importante no monitoramento dos processos de fluidização, pois é uma informação básica importante através da qual pode-se definir parâmetros importantes tais como tempos de residência, histogramas de diâmetro de bolhas, temperatura, pressão, etc. Tendo um controle mais preciso sobre estas informações a operação dos reatores pode ser otimizada, implicando em economia energética, de material, eficiência e segurança no processo.

Para desenvolver uma técnica de reconstrução do sinal original, deve-se levar em consideração que todo o processo de detecção de fase é um problema inverso. Os dados obtidos pela sonda não refletem diretamente o evento ocorrido, devido a quaisquer distorções, ruídos e atrasos nos sinais medidos, podendo comprometer seriamente os resultados. Então, um conhecimento sobre os problemas inversos e suas implicações é necessário.

\subsection{Problemas direto e inverso}

Os problemas inversos constituem uma área de pesquisa que tem crescido consideravelmente nos últimos anos, por ser uma área multidisciplinar que une a análise matemática dos problemas aos dados experimentais. As aplicações dos problemas inversos estão em várias áreas como engenharia, medicina, geofísica, astrofísica e outros ramos da ciência (SILVA NETO e MOURA NETO 2000).

Como exemplo de aplicações práticas de problemas inversos, Seleghim e Milioli (2001) determinaram o histograma de diâmetro de bolhas a partir do histograma de cordas de escoamentos bifásicos com bolhas. Malinen, Huttnen e Kaipio (2002) propuseram um controlador para um ultra-som de aquecimento induzido de um tumor, cujo principal objetivo é obter uma distribuição de temperatura desejada com o ultrasom pré-focado para destruir o tecido cancerígeno. Chalhoub e Campos Velho (2002) 
apresentaram uma análise inversa para a avaliação de nascente em águas naturais usando dados de sensoriamento remoto. Rolnik e Seleghim (2002) desenvolveram um procedimento de calibração local da medida de fração de fase por uma técnica inversa.

O tratamento dos dados do problema pode ser feito de três maneiras, dependendo dos dados que se tem a priori. Considere um problema composto por três partes: dados de entrada, dados de saída e um operador que é uma função que caracteriza o problema físico e que transforma os dados de entrada em dados de saída, a Figura 3.2 ajuda a exemplificar. Então as três categorias de problemas são:

- direto: conhecendo-se os dados de entrada e o operador, a finalidade é obter os dados de saída;

- inverso: tendo-se os dados de saída e o operador, a meta é encontrar os dados de entrada;

- $\quad$ inverso tomográfico ou de identificação: sabendo-se os dados de entrada e saída, o objetivo é determinar o operador.

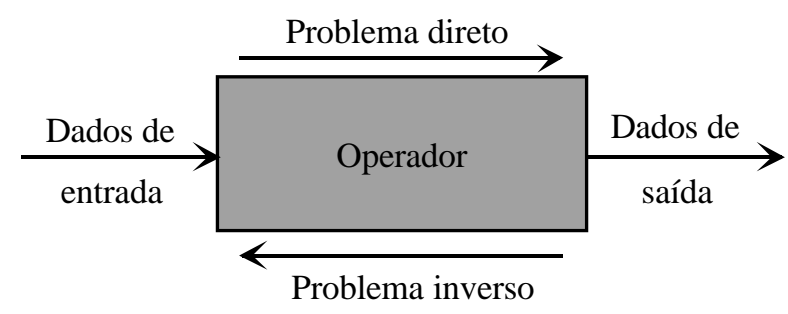

Figura 3. 2: Esquema geral dos problemas direto e inverso

Numa aplicação prática, os dados de entrada (estímulo) são o sinal do processo, aquele que representa o escoamento, já os dados de saída (resposta) constituem o sinal obtido pela sonda, com ruídos e atrasos na medida, e o operador é a interação física entre a sonda e o escoamento.

Problemas inversos são intrinsecamente mal condicionados, significando que o processo será extremamente sensível a erros experimentais e numéricos a ponto de comprometer completamente os resultados obtidos. Por causa desta instabilidade, a solução dos problemas inversos deixa de ser simples e passa a ser complexa, motivo este de constantes estudos na área. 


\subsection{Mau condicionamento}

Os problemas inversos devem ser tratados de forma a minimizar a introdução de erros que podem corromper os resultados.

Em situações práticas, o mau condicionamento intrínseco dos problemas inversos traz problemas quando não se tem controle suficiente dos níveis de ruído do sinal ou quando a presença da sonda altera localmente a interface entre as diferentes fases do escoamento e conseqüentemente não se tem uma frente de transição suficientemente clara no sinal de presença de fase.

O trabalho de Seleghim e Milioli (2001) mostra que erros quase imperceptíveis nos dados de entrada (menos do que $1 \%$ do valor máximo) corromperam completamente os dados de saída. Conseqüentemente, determinar o histograma de diâmetro de bolhas diretamente do histograma de cordas obtido de uma sonda de detecção de fase imersa, em um escoamento a bolhas, é impraticável sem um algoritmo específico de processamento de sinais para controlar a influência de ruído.

Matematicamente, problemas inversos pertencem à classe de problemas malpostos. No início do século passado (1902) o matemático francês Jacques Hadamard definiu um problema bem-posto como sendo aquele que cumpre as três condições abaixo:

- $\quad$ existe solução (existência);

- $\quad$ a solução é única (unicidade);

- a solução tem uma dependência contínua (suave) com os dados de entrada (regularidade).

Assim, o problema é dito mal-posto se alguma das condições acima não é satisfeita. Problemas discretos e finitos são chamados mal condicionados, se a terceira condição não se cumpre. Em geral, nenhuma das condições de Jacques Hadamard é satisfeita num problema inverso (CAMPOS VELHO 2001 e SILVA NETO e MOURA NETO 2000).

Quando a primeira condição não é satisfeita, por ser impossível interpolar os dados, faz-se uma flexibilização da noção de solução procurando-se uma aproximação ao invés de uma solução interpolante. Quando a segunda condição não é satisfeita, 
procura-se por restrições adicionais para garantir a unicidade. Já a terceira condição é mais difícil tecnicamente. As técnicas de regularização procuram contornar as dificuldades associadas ao problema da não dependência suave da solução nos dados de entrada (SILVA NETO e MOURA NETO 2000).

\subsection{Técnicas de regularização}

Existem vários métodos de solução de problemas inversos, cada um com um algoritmo proposto com o objetivo de atenuar os problemas provocados pelo mau condicionamento da função.

A função em um dado ponto pode ser bem ou mal condicionada. De forma qualitativa uma avaliação da função é bem condicionada quando um pequeno erro no ponto de análise não altera significativamente o valor da função. Caso contrário, se um pequeno erro no ponto de observação corromper o valor da função, então a avaliação é mal condicionada (SILVA NETO e MOURA NETO 2000).

O cálculo da avaliação da função inversa em pontos contaminados por pequenos erros é mais sensível a certas perturbações que a outras. Algumas destas perturbações acabam por ser ampliadas de forma demasiada.

No caso da avaliação de funções, algoritmos diferentes para o mesmo problema podem ter propriedades e comportamentos completamente distintos. Em particular, alguns são instáveis (quando os erros, que se propagam através dos cálculos intermediários, são amplificados), enquanto outros são estáveis. Por outro lado, formulações diferentes para o mesmo problema, mesmo que matematicamente equivalentes, dão origem a algoritmos diferentes (SILVA NETO e MOURA NETO 2000).

Uma primeira idéia sugerida para trabalhar com o mau condicionamento de um problema foi dada por Tikhonov e Arsenin (1977), chamada de regularização. A regularização de problemas mal condicionados consiste em alterar um pouco o problema a resolver para amenizar as dificuldades encontradas pela não dependência suave da solução nos dados de entrada, limitando, na solução, o efeito do aumento do erro proveniente dos dados, através de uma alteração na condição do problema. 
Então, ao invés de resolver o problema inverso original, resolve-se um problema levemente alterado por um parâmetro de regularização, perturbando os dados de tal forma que o problema mantenha tanto quanto possível o comportamento do problema original. Diz-se que este novo problema levemente alterado é uma regularização do problema original. Entretanto, existe o problema de escolher o melhor parâmetro de regularização, sabendo que para resolver problemas mal condicionados, informações adicionais e de boa qualidade contribuem para uma melhor determinação da solução.

Uma forma de avaliar se o parâmetro de regularização é apropriado é calcular um funcional de erro entre o problema original e o problema regularizado. Quando este funcional se aproximar de zero a solução do problema regularizado se aproxima da solução do problema original. Nem sempre é aconselhável a obtenção do funcional de erro igual a zero, uma vez que, na presença inevitável de erros, os erros na solução do problema inverso podem ser minimizados por uma escolha criteriosa do valor de regularização. Deve-se, portanto, buscar o parâmetro de regularização ótimo, de forma a se ter à mínima alteração do problema original, mas com a desejada estabilidade da solução.

Há muitos métodos para a solução de problemas inversos, como os métodos de otimização, decomposição em valores singulares, mínimos quadrados e variantes, métodos variacionais, molificação, métodos bayesianos, filtros digitais, redes neurais e outras novas metodologias (CAMPOS VELHO 2001). A seguir, na Tabela 3.1, estão alguns métodos para a solução de problemas inversos com exemplos de aplicação.

Tabela 3. 1: Exemplos de métodos para a solução de problemas inversos

\begin{tabular}{|c|c|c|}
\hline Método & Descrição & Aplicação \\
\hline $\begin{array}{l}\text { Método da } \\
\text { descida } \\
\text { máxima }\end{array}$ & $\begin{array}{l}\text { Determina o mínimo local interativamente } \\
\text { construindo uma seqüência que minimiza a } \\
\text { função que converge para a solução do } \\
\text { problema. }\end{array}$ & $\begin{array}{l}\text { Huang, Yuan e Ay (2003) resolveram um problema } \\
\text { inverso tridimensional de condução de calor para } \\
\text { especificar a superfície do fluxo de calor de uma } \\
\text { chapa com tubos para estabilizar a troca de calor. O } \\
\text { método da descida máxima combinado com o } \\
\text { código comercial CFX4.4 determinaram os } \\
\text { coeficientes de transferência de calor baseado na } \\
\text { temperatura simulada por um método termográfico } \\
\text { infravermelho. }\end{array}$ \\
\hline $\begin{array}{l}\text { Método de } \\
\text { Landweber }\end{array}$ & $\begin{array}{l}\text { É obtido a partir de uma modificação do } \\
\text { método de descida máxima, sendo que em } \\
\text { cada passo tem-se uma solução sub-ótima. }\end{array}$ & $\begin{array}{l}\text { Doicu, Schreier e Hess (2004) usaram o método de } \\
\text { Landweber para resolver um problema inverso de } \\
\text { sensoriamento atmosférico remoto, isto é, sondagem } \\
\text { de temperatura com um espectrômetro } \\
\text { infravermelho de alta resolução transportado pelo ar. }\end{array}$ \\
\hline $\begin{array}{l}\text { Método de } \\
\text { Newton }\end{array}$ & $\begin{array}{l}\text { Obtém os zeros de uma função. É um } \\
\text { método interativo que em determinadas } \\
\text { condições converge para a solução. }\end{array}$ & $\begin{array}{l}\text { Sharma (2002) usou o método de Newton para } \\
\text { resolver um problema inverso com um sistema de } \\
\text { duas equações não-lineares, proveniente do estudo } \\
\text { da propagação de uma onda tridimensional em um } \\
\text { meio anisotrópico. }\end{array}$ \\
\hline
\end{tabular}


Tabela3.1: Continuação

\begin{tabular}{|c|c|c|}
\hline Método & Descrição & Aplicação \\
\hline $\begin{array}{l}\text { Método de } \\
\text { Levenberg- } \\
\text { Marquardt }\end{array}$ & $\begin{array}{l}\text { Consiste em uma variante do método de } \\
\text { Newton para a solução de sistemas de } \\
\text { equações não-lineares. Em etapa } \\
\text { intermediária, este método inclui uma } \\
\text { regularização que apresenta equivalência } \\
\text { com a regularização de Tikhonov. O } \\
\text { problema inverso é resolvido como um } \\
\text { problema de otimização, de dimensão finita, } \\
\text { onde se busca minimizar o funcional dos } \\
\text { resíduos quadrados. }\end{array}$ & $\begin{array}{l}\text { Silva Neto e Özisik (1995) usaram o método de } \\
\text { Levenberg-Marquard de minimização para resolver } \\
\text { o sistema de equações não-lineares do problema } \\
\text { inverso de estimar simultaneamente os coeficientes } \\
\text { de uma função de fase, albedo de espalhamento } \\
\text { simples e a espessura óptica de um meio paralelo } \\
\text { plano de escala anisotrópica. }\end{array}$ \\
\hline $\begin{array}{l}\text { Método dos } \\
\text { gradientes } \\
\text { conjugados }\end{array}$ & $\begin{array}{l}\text { Considera diretamente o problema de } \\
\text { minimização do funcional construindo uma } \\
\text { sequêencia minimizante. O método tem sido } \\
\text { usado com sucesso na solução de problemas } \\
\text { inversos de estimativa de funções, pois } \\
\text { possui duas qualidades muito importantes, } \\
\text { uma é que a regularização está embutida na } \\
\text { construção do mesmo e outra é que o } \\
\text { método possui boa eficiência computacional. }\end{array}$ & $\begin{array}{l}\text { Bokar e Özisik (1995) usaram o método dos } \\
\text { gradientes conjugados de minimização com } \\
\text { problema adjunto para resolver um problema } \\
\text { inverso de estimar a temperatura de entrada de um } \\
\text { escoamento laminar dentro de um duto de placas } \\
\text { paralelas usando temperaturas transientes medidas } \\
\text { por um termopar simples localizado na jusante de } \\
\text { entrada. }\end{array}$ \\
\hline $\begin{array}{l}\text { Método } \\
\text { simplex }\end{array}$ & $\begin{array}{l}\text { Encontra o mínimo de uma função sujeita a } \\
\text { satisfazer um sistema de restrições. }\end{array}$ & $\begin{array}{l}\text { Martins e Silva (2004) trabalharam com o método } \\
\text { simplex para minimizar um funcional de erro do } \\
\text { problema inverso de estimar as propriedades } \\
\text { térmicas do equacionamento modelado para simular } \\
\text { a fase de descongelamento de feijões verdes. }\end{array}$ \\
\hline $\begin{array}{l}\text { Algoritmos } \\
\text { genéticos }\end{array}$ & $\begin{array}{l}\text { Segue a teoria de Charles } \\
\text { evolução das } \begin{array}{c}\text { Darwin da } \\
\text { espécies. }\end{array} \\
\text { computacionentos } \\
\text { minimizantes para, no final, sobreviverem os } \\
\text { mais aptos. Inicia-se com uma população de } \\
\text { indivíduos (configurações iniciais de um } \\
\text { problema). Faz-se avaliação de cada um } \\
\text { (aplicação da função objetivo). Selecionam- } \\
\text { se os melhores (escolha daqueles cujo valor } \\
\text { da função objetivo tenham os menores } \\
\text { valores) e promovem-se manipulações } \\
\text { genéticas como cruzamento e mutação } \\
\text { (correspondente às perturbações) a fim de } \\
\text { criar uma nova população. }\end{array}$ & $\begin{array}{l}\text { Rolnik (2003) desenvolveu uma nova técnica de } \\
\text { reconstrução numérica do problema de tomografia } \\
\text { por impedância elétrica. O mínimo global do } \\
\text { funcional de erro definido está relacionado com a } \\
\text { imagem do escoamento sensoriado. O mau } \\
\text { condicionamento do funcional de erro prejudica os } \\
\text { métodos de otimização na obtenção do mínimo, } \\
\text { então para contornar os problemas encontrados, } \\
\text { algoritmos genéticos foram utilizados uma vez que } \\
\text { eles escapam de mínimos locais e não dependem da } \\
\text { solução inicial. }\end{array}$ \\
\hline $\begin{array}{l}\text { Método de } \\
\text { decomposição } \\
\text { em valores } \\
\text { singulares }\end{array}$ & $\begin{array}{l}\text { Usado quando um sistema de equações ou } \\
\text { matrizes são singulares ou numericamente } \\
\text { perto de ser singular. A matriz original passa } \\
\text { a ser representada pelo produto de três } \\
\text { matrizes, duas ortogonais (possuem seus } \\
\text { vetores ortogonais entre si e com módulos } \\
\text { unitários) e uma diagonal (possui os vetores } \\
\text { singulares da matriz original). } \\
\end{array}$ & $\begin{array}{l}\text { Lagier, Lemonnier e Coutris (2004) usaram o } \\
\text { método de decomposição em valores singulares para } \\
\text { resolver o sistema linear mal condicionado do } \\
\text { problema inverso de condução de calor variável. O } \\
\text { problema físico consiste em identificar o fluxo de } \\
\text { calor de uma chapa exposta a um fluido quente com } \\
\text { temperaturas coletadas por termopares do lado } \\
\text { oposto da chapa. }\end{array}$ \\
\hline $\begin{array}{l}\text { Método dos } \\
\text { mínimos } \\
\text { quadrados }\end{array}$ & $\begin{array}{l}\text { Encontra a melhor curva de aproximação de } \\
\text { um conjunto de pontos, minimizando a soma } \\
\text { dos quadrados do resíduo dos pontos à } \\
\text { curva. Pode-se colocar pesos no conjunto de } \\
\text { pontos. }\end{array}$ & $\begin{array}{l}\text { Sgura e Bozzini (2005) determinaram parâmetros do } \\
\text { modelo de espectroscopia por impedância } \\
\text { eletroquímica calculados pelo método dos mínimos } \\
\text { quadrados não-linear. }\end{array}$ \\
\hline $\begin{array}{c}\text { Métodos } \\
\text { variacionais }\end{array}$ & $\begin{array}{l}\text { Minimiza uma função resíduo formada entre } \\
\text { a solução exata e a solução aproximada do } \\
\text { problema. }\end{array}$ & $\begin{array}{l}\text { Tessler e Spangler (2005) formularam um princípio } \\
\text { variacional para resolver um problema inverso de } \\
\text { reconstrução das deformações de uma placa } \\
\text { tridimensional das tensões de superfície } \\
\text { experimentalmente medidas. A formulação é } \\
\text { baseada na minimização de um funcional dos } \\
\text { mínimos quadrados. }\end{array}$ \\
\hline Molificação & $\begin{array}{l}\text { É um procedimento de filtragem dos ruídos } \\
\text { por convolução com um } \\
\text { apropriado e e entâme r r esolve-se } \\
\text { numericamente o problema bem-comportado } \\
\text { associado. }\end{array}$ & $\begin{array}{l}\text { Mejía e Murio (1996) resolveram o problema } \\
\text { inverso de condução de calor pelo método de } \\
\text { molificação discreta e o parâmetro de molificação } \\
\text { foi selecionado por uma técnica automática que } \\
\text { fornece o grau correto para filtrar os ruídos dos } \\
\text { dados. }\end{array}$ \\
\hline
\end{tabular}


Tabela3.1: Continuação

\begin{tabular}{|c|c|c|}
\hline Método & Descrição & Aplicação \\
\hline $\begin{array}{c}\text { Métodos } \\
\text { bayesianos }\end{array}$ & $\begin{array}{l}\text { São procedimentos estatísticos para estimar } \\
\text { parâmetros de uma informação obtida } \\
\text { anteriormente. }\end{array}$ & $\begin{array}{l}\text { Wang e Zabaras (2004) usaram a inferência } \\
\text { bayesiana aproximada para solucionar o problema } \\
\text { inverso de condução de calor, a função densidade de } \\
\text { probabilidade posterior da superfície do fluxo de } \\
\text { calor é calculada dando a medida da temperatura } \\
\text { dentro de um sólido condutor e o problema inverso é } \\
\text { regularizado estatisticamente através do modelo de } \\
\text { distribuição obtido a priori. }\end{array}$ \\
\hline Wavelet & $\begin{array}{l}\text { São uma classe de funções com } \\
\text { determinadas propriedades que as tornam } \\
\text { adequadas a servirem de base para } \\
\text { decomposição de outras funções. }\end{array}$ & $\begin{array}{l}\text { Seleghim e Milioli (2001) propuseram uma técnica } \\
\text { de eliminação de ruído usando wavelet como } \\
\text { ferramenta para restaurar sinais de fases, como } \\
\text { resultado tem-se a precisão dos tempos de residência } \\
\text { o qual produz histograma de cordas e raios menos } \\
\text { distorcidos. }\end{array}$ \\
\hline Redes neurais & $\begin{array}{l}\text { Baseia-se no cérebro humano, assim os } \\
\text { elementos de processamento (neurônios) } \\
\text { realizam tarefas de maneira paralelas e são } \\
\text { aptos para aprender e tomar decisões } \\
\text { baseadas na aprendizagem. }\end{array}$ & $\begin{array}{l}\text { Dolenko et al. (2003) usaram redes neurais para } \\
\text { resolver o problema inverso de determinação de } \\
\text { temperatura de um espectro de emissão óptica. } \\
\text { Resultados do modelo de espectro em diferentes } \\
\text { temperaturas, pré-processadas por outra rede neural } \\
\text { trabalhando como uma memória auto-associativa, } \\
\text { foram usados para treinar a rede principal. }\end{array}$ \\
\hline
\end{tabular}

Muitos métodos surgem a cada dia, mas na sua maioria são técnicas que tratam os dados a posteriori. Outros que trabalham com os sinais em tempo real, mas têm códigos computacionais longos impossibilitando a implementação em hardware dedicado. Assim, uma técnica de regularização para a determinação da temperatura de um escoamento, medida por uma sonda intrusiva e que possa ser implementada em um micro-controlador, é proposta neste trabalho.

A técnica de regularização utilizada neste trabalho foi o método dos mínimos quadrados simplificado ou polinomial, pois possui um código computacional curto, o qual permite a implementação em um hardware dedicado (como pode ser observado no Apêndice A), e é um método rápido o que admite a regularização em tempo real.

O método dos mínimos quadrados simplificado é uma técnica usada para reduzir ruídos de alta freqüência, melhorar a razão sinal-ruído dos dados originais (PALACIO et al. 2002). Este método foi primeiramente aplicado por Savitzky e Golay (1964) para alisar (smoothing) dados em análise espectroscópica e mais tarde foi aperfeiçoado por Proctor e Sherwood (1980) para estimar valores nos pontos normalmente perdidos pelo método de Savitzky-Golay que faz o alisamento pelo ponto central. Porém, o uso do método dos mínimos quadrados simplificado com sequiências longas conduz para transmissões de zeros, fase reversa e limites excedidos o que são desvantagens em algumas aplicações (MARCHAND e MARMET 1983).

Quanto aos sensores inteligentes, o termo sensor inteligente se refere a sensores nos quais a sonda é combinada com alguma forma de processamento inteligente no 
micro-controlador (MEIJER 1994). As principais propriedades dos projetos inteligentes são: adaptabilidade, precisão, variação dinâmica, velocidade, consumo de potência, confiabilidade e custos (MEIJER 1994). Para os sensores de temperatura inteligente pode-se acrescentar as seguintes propriedades: sensibilidade, linearidade, variação da temperatura, estabilidade em longo prazo, independência dos processos, nível do sinal, calibração absoluta, imunidade aos ruídos (BIANCHI et al. 1998).

Os sensores de temperatura inteligentes estão presentes nas mais diversas aplicações como biomédicas, espaciais, automotivas, industriais, alimentícia e outras (BIANCHI et al. 1998). Os pesquisadores, em sua maioria, não revelam quais são os métodos implementados nos micro-controladores, simplesmente descrevem quais propriedades foram aprimoradas.

Meijer, Kerkvliet e Toth (1994) desenvolveram um método não-invasivo que detecta, pelo uso de um calorímetro e processamento de sinal inteligente, certos tipos de micro-organismos devido a sua pequena produção de calor. Os teste mostraram que uma produção relativamente pequena de calor pode ser detectada facilmente e com segurança, outras características são que o valor médio dos dados de saída do sinal é linearmente associado à temperatura e o fluxo de dados é reduzido por média, o qual reduz o ruído para um valor insignificante. García-Guzmán et al. (2003) projetaram e simularam um sensor de gás inteligente usando um circuito integrado numa configuração radiométrica para monitoramento de componentes voláteis ou gases. $\mathrm{O}$ micro-controlador compensa as variações de temperatura e umidade e o circuito inteligente também é capaz de autocalibração e compensação automática do sinal das variações da voltagem e temperatura ambiente. Mcllroy e Evans (1994) desenvolveram um telêmetro codificado para monitoramento da temperatura climática usando um micro-controlador. As principais características deste sistema são a transmissão dos dados por radio e monitoramento remoto do sistema.

O sensor de temperatura inteligente desenvolvido neste trabalho lê a temperatura indicada por um termopar e pelo método de regularização a temperatura é reconstruída. Não é preciso fazer nenhum tipo de compensação e os ruídos são atenuados pelo método na reconstrução do sinal. Outra vantagem do sensor de temperatura inteligente é a velocidade do tempo de resposta, permitindo, assim, correções, se necessário, nos parâmetros de entrada. 


\section{Capítulo 4}

\section{Técnicas de smoothing (alisamento) ${ }^{1}$}

Técnicas de alisamento são processos que modificam um conjunto de dados com o objetivo de suavizar ruídos. O processo de alisamento emprega um número de coeficientes, normalmente menor do que o número de pontos dos dados, para ajustar um polinômio através das médias dos pontos vizinhos.

O intuito das técnicas de alisamento de dados é o de avaliar uma variável que se altera devagar e que está corrompida por ruídos aleatórios. Então, algumas vezes pode ser útil substituir cada ponto por um tipo de média local dos pontos adjacentes. A média pode reduzir o nível de ruído sem muita alteração do valor obtido.

A seguir estão algumas destas técnicas que suavizam os ruídos nos dados e são usadas nas áreas de processamento e análise de sinais, computação gráfica, processamento de imagens, química analítica, etc.

\subsection{Método de diferenciação digital}

A diferenciação digital tem sido extensamente usada nas áreas de processamento de sinais de radar e biologia. Um método de diferenciação digital de ordem $n$, que usa métodos algébricos, foi proposto por Chen e Yang (1992), onde o sinal e o ruído são descritos como modelos estocásticos.

\footnotetext{
${ }^{1}$ Doravante neste texto será usado o termo alisamento.
} 
Seleghim (1993) utilizou a técnica apresentada por Chen e Yang (1992) para quantificar a freqüência instantânea $(f)$ de um sinal. Em um primeiro momento, a derivação da fase instantânea $(\varphi)$ do sinal analítico associado ao sinal analisado tem as vantagens de velocidade dos cálculos e simplicidade numérica de implementação. Mas os gráficos mostraram que a derivação numérica da fase instantânea do sinal torna impossível a identificação da freqüência instantânea dominante. Portanto a operação de derivação apresentou a desvantagem de amplificar os componentes com altas freqüências contidos na fase instantânea do sinal. Então, a fase instantânea do sinal foi suavizada por aplicações recursivas do filtro binomial de alisamento com três pontos, definidos pelos coeficientes $\left\{a_{-1}=1 / 4, a_{0}=1 / 2, a_{1}=1 / 4\right\}$ :

$$
\varphi^{n}\left(t_{k}\right)=\frac{1}{4} \varphi^{n-1}\left(t_{k-1}\right)+\frac{1}{2} \varphi^{n-1}\left(t_{k}\right)+\frac{1}{4} \varphi^{n-1}\left(t_{k+1}\right)
$$

Assim, a fase instantânea foi suavizada após $n$ aplicações do filtro e a frequiência instantânea foi obtida por derivação numérica do sinal alisado.

\subsection{Interpolação por splines}

Spline é uma função polinomial discreta que pode ter, localmente, uma forma simples e ao mesmo tempo ser, globalmente, flexível e suave.

A spline mais conhecida é a cúbica e produz uma função de interpolação que é contínua até a segunda derivada. O objetivo da interpolação por splines cúbicas é obter uma fórmula de interpolação que seja suave na primeira e contínua na segunda derivadas, ambas dentro do intervalo e fronteiras.

Uma spline cúbica é uma spline construída com partes de polinômios de grau três os quais passam por um conjunto de $n$ pontos controlados. A segunda derivada de cada polinômio é geralmente zero nos pontos finais, desde que isto forneça as condições de fronteira que complete o sistema de $n-2$ equações. Assim, estas condições produzem as chamadas splines cúbicas naturais e conduzem para um sistema tridiagonal o qual pode ser resolvido facilmente dando os coeficientes dos polinômios. Porém, se esta escolha não for possível, outras condições podem ser usadas no lugar. 
O método descrito abaixo foi baseado em Press et al. (1992), Bartels, Beatty e Barsky (1987) e Weisstein (2005a). Considere uma spline unidimensional para um conjunto de $n+1$ pontos $\left(y_{0}, y_{1}, \ldots, y_{n}\right)$. Seja a i-ésima parte da spline representada pelo polinômio de grau três

$$
Y_{i}(t)=a_{i}+b_{i} t+c_{i} t^{2}+d_{i} t^{3}
$$

onde $t \in[0,1]$ e $i=0, \ldots, n-1$ pontos interiores. Então

$$
\begin{aligned}
& Y_{i}(0)=y_{i}=a_{i} \\
& Y_{i}(1)=y_{i+1}=a_{i}+b_{i}+c_{i}+d_{i}
\end{aligned}
$$

Tomando a derivada de $Y_{i}(t)$ em cada intervalo tem-se

$$
\begin{aligned}
& Y_{i}^{\prime}(0)=D_{i}=b_{i} \\
& Y_{i}^{\prime}(1)=D_{i+1}=b_{i}+2 c_{i}+3 d_{i}
\end{aligned}
$$

e resolvendo estas quatro últimas equações obtém-se

$$
\begin{aligned}
& a_{i}=y_{i} \\
& b_{i}=D_{i} \\
& c_{i}=3\left(y_{i+1}-y_{i}\right)-2 D_{i}-D_{i+1} \\
& d_{i}=2\left(y_{i}-y_{i+1}\right)+D_{i}+D_{i+1}
\end{aligned}
$$

Agora com a segunda derivada igualando os pontos, têm-se quatro condições:

$$
\begin{aligned}
& Y_{i-1}(1)=y_{i} \\
& Y_{i-1}^{\prime}(1)=Y_{i}^{\prime}(0) \\
& Y_{i}(0)=y_{i} \\
& Y_{i-1}^{\prime \prime}(1)=Y_{i}^{\prime}(0)
\end{aligned}
$$

e desde que pontos interiores e finais satisfaçam 


$$
\begin{aligned}
& Y_{0}(0)=y_{0} \\
& Y_{n-1}(1)=y_{n}
\end{aligned}
$$

Tem-se assim, um total de $4(n-1)+2=4 n-2$ equações para determinar $4 n$ incógnitas. São necessárias mais duas condições. O caminho mais comum é simplesmente exigir que a segunda derivada nos pontos finais seja zero, então:

$$
\begin{aligned}
& Y_{0}^{\prime \prime}(0)=0 \\
& Y_{n}^{\prime \prime}(0)=0
\end{aligned}
$$

Estas duas últimas condições dão a chamada splines cúbicas naturais. A razão que torna as splines cúbicas na prática tão especiais é que o conjunto de equações junto com estas duas últimas condições de fronteira deixa o sistema linear e também tridiagonal.

Então agora com $n+1$ equações e $n+1$ incógnitas tem-se o seguinte sistema simétrico tridiagonal

$$
\left[\begin{array}{cccccccc}
2 & 1 & & & & & & \\
1 & 4 & 1 & & & & & \\
& 1 & 4 & 1 & & & & \\
& & 1 & 4 & 1 & & & \\
& & & \ldots & & & & \\
& & & & & 1 & 4 & 1 \\
& & & & & & 1 & 2
\end{array}\right]\left[\begin{array}{c}
D_{0} \\
D_{1} \\
D_{2} \\
D_{3} \\
\vdots \\
D_{n-1} \\
D_{n}
\end{array}\right]=\left[\begin{array}{c}
3\left(y_{1}-y_{0}\right) \\
3\left(y_{2}-y_{0}\right) \\
3\left(y_{3}-y_{1}\right) \\
3\left(y_{4}-y_{2}\right) \\
\vdots \\
3\left(y_{n-1}-y_{n-2}\right) \\
3\left(y_{n}-y_{n-1}\right)
\end{array}\right]
$$

As splines têm vantagens ao modelar funções arbitrárias e são usadas extensivamente em computação gráfica.

\subsection{Transformada wavelet}

As wavelets têm sido usadas nas áreas de análise e síntese de sinais como: reconhecimento padrão, compressão de dados, análise numérica, teoria do campo 
quântico e acústico. Morlet et al. (1982) introduziram a transformada wavelet como ferramenta para análise de sinal de origem sísmica. Posteriormente, Grossman, Morlet e Paul (1985) publicaram uma nova transformada para análise freqüência de sinais. Esta nova transformada conhecida como transformada wavelet foi introduzida porque os métodos clássicos de análise em frequiência baseados na transformada de Fourier têm consideráveis desvantagens quanto à teoria do sinal. Nos círculos matemáticos, a transformada wavelet contínua foi conhecida por algum tempo como fórmula de Calderón (SELEGHIM 1992 e LOUIS, MAAB e RIEDER 1997).

Uma das maiores desvantagens da transformada de Fourier é que ela considera o fenômeno num intervalo infinito, não retratando a realidade. Além disso, decompõe o sinal em funções trigonométricas, as quais oscilam infinitamente com o mesmo período, e isto não tem um caráter local. Uma falha da análise Fourier é ela descrever separadamente tempo e freqüência. Já a transformada wavelet permite mais flexibilidade, uma vez que funções arbitrárias podem ser escolhidas (LOUIS, MAAB e RIEDER 1997).

As wavelets são uma classe de funções usadas para localizar uma função no tempo e escala (dimensão). Uma família de wavelets pode ser construída de uma função $\psi(x)$, algumas vezes conhecida como uma "wavelet mãe", a qual pode ser limitada em um intervalo finito. As "wavelets filhas" $\psi^{a, b}(x)$ são então transladadas no ponto $b$ e estendidas por um fator $a$.

Uma wavelet individual pode ser definida por

$$
\psi^{a, b}(x)=|a|^{1 / 2} \psi\left(\frac{x-b}{a}\right)
$$

Então calcula-se o produto interno do sinal $f$ com a função assim obtida e temse a transformada wavelet

$$
W_{\psi}(f)(a, b)=\frac{1}{\sqrt{a}} \int_{-\infty}^{\infty} f(t) \psi\left(\frac{t-b}{a}\right) d t
$$

E a transformada wavelet inversa é 


$$
f(x)=C_{\psi} \int_{-\infty}^{\infty} \int_{-\infty}^{\infty}\left\langle f, \psi^{a, b}\right\rangle \psi^{a, b}(x) a^{-2} d a d b
$$

A transformada wavelet é baseada em um operador matricial, o qual pode ser calculado mais rapidamente do que a matriz de Fourier análoga. Wavelets são especialmente úteis para comprimir dados de imagem, desde que uma transformada wavelet tenha propriedades as quais a torne superior com relação a transformada de Fourier convencional.

\subsection{Filtros de Savitzky-Golay}

Um tipo particular de filtros passa-baixa, adequado para suavizar dados é o chamado Savitzky-Golay (SAVITZKY e GOLAY 1964), que deriva diretamente de uma formulação particular do problema de alisar os dados no domínio do tempo e é o método dos mínimos quadrados simplificado.

Os filtros Savitzky-Golay foram inicialmente, e ainda são, usados em análise espectroscópica para verificar a largura e altura de linhas espectrais em dados espectrométricos com ruído (ZIEGLER 1981 e BROMBA e ZIEGLER 1981), mas também são usados em outros campos como processamento de sinais, processamento de imagens e química analítica (LUO, YING e BAI 2005).

O método descrito abaixo foi baseado em Press et al. (1992). Um filtro digital é aplicado para uma série de dados igualmente espaçados $f_{i} \equiv f\left(t_{i}\right)$, onde $t_{i} \equiv t_{0}+i \Delta$ para alguma constante $\Delta$ e $i=\ldots-2,-1,0,1,2, \ldots$. Pode-se substituir cada valor de $f_{i}$ por uma combinação linear de $g_{i}$ e alguns pontos vizinhos,

$$
g_{i}=\sum_{n=-n_{L}}^{n_{R}} c_{n} f_{i+n}
$$

Aqui $n_{L}$ é o número de pontos usados a esquerda do ponto $i$, enquanto $n_{R}$ é o número de pontos usados a direta. O filtro chamado de causal deve ter $n_{R}=0$. 
Para $n_{L}=n_{R}$ o cálculo de cada $g_{i}$ tem a média entre os pontos $f_{i-n_{L}}$ e $f_{i+n_{R}}$, chamada de janela média móvel e corresponde à equação (4.13) com a constante $c_{n}=1 /\left(n_{L}+n_{R}+1\right)$.

Se a função básica é constante ou varia linearmente com o tempo, então nenhuma inclinação é introduzida no resultado. Pontos mais altos no final do intervalo médio são na média equilibrados por pontos mais baixos no outro final. Portanto uma inclinação é introduzida se a função básica tem uma derivada segunda nula. No máximo local, por exemplo, a janela média móvel sempre reduz o valor da função.

A idéia básica da filtragem Savitzky-Golay é encontrar os coeficientes $c_{n}$ que preservem os momentos mais altos. Equivalentemente, a idéia é aproximar a função básica dentro da janela móvel não por uma constante, mas por um polinômio de grau mais elevado: para cada ponto $f_{i}$, ajusta-se um polinômio por mínimos quadrados para todos os pontos $n_{L}+n_{R}+1$ da janela móvel, e então o conjunto de $g_{i}$ será composto dos valores do polinômio nas posições $i$. O valor do polinômio não é usado em nenhum outro ponto. Quando se mover para o próximo ponto $f_{i+1}$, faz-se um novo ajuste por mínimos quadrados usando uma nova janela.

Para acelerar o método dos mínimos quadrados levou-se em consideração que o processo envolve somente a inversa de uma matriz linear e os coeficientes do polinômio ajustados são também lineares. O que significa que se pode fazer um avanço no ajuste, por dados artificiais consistindo de todos os valores zero exceto por um único valor unitário, e então se faz o ajuste nos dados reais por combinação linear.

Então há um conjunto particular de coeficientes $c_{n}$ para o qual a equação (4.13) “automaticamente" executa o processo de ajuste polinomial por mínimos quadrados dentro da janela móvel.

Pelo método dos mínimos quadrados a função $g_{0}$ pode ser obtida desde que os coeficientes $c_{n}$ possam ser calculados. Portanto, deve-se aproximar os valores de $f_{-n_{L}}, \ldots, f_{n_{R}}$ pelo polinômio $a_{0}+a_{1} i+\cdots+a_{M} i^{M}$, de grau $M$ em $i$. Então $g_{0}$ será o valor do polinômio em $i=0$, ou seja, $a_{0}$.

O cálculo da matriz deste problema é:

$$
A_{i j}=i^{j} \quad i=-n_{L}, \ldots, n_{R}, j=0, \ldots, M
$$


e as equações normais para os vetores dos $a_{j}$ 's em termos dos vetores dos $f_{i}$ 's é em notação matricial

$$
\left(\mathbf{A}^{t} \mathbf{A}\right) \cdot \mathbf{a}=\mathbf{A}^{t} \cdot \mathbf{f} \text { ou } \mathbf{a}=\left(\mathbf{A}^{t} \cdot \mathbf{A}\right)^{-1} \cdot\left(\mathbf{A}^{t} \cdot \mathbf{f}\right)
$$

As formas específicas são

$$
\left\{\mathbf{A}^{t} \cdot \mathbf{A}\right\}_{i j}=\sum_{k=-n_{L}}^{n_{R}} A_{k i} A_{k j}=\sum_{k=-n_{L}}^{n_{R}} k^{i+j}
$$

e

$$
\left\{\mathbf{A}^{t} \cdot \mathbf{f}\right\}_{j}=\sum_{k=-n_{L}}^{n_{R}} A_{k i} f_{k}=\sum_{k=-n_{L}}^{n_{R}} k^{j} f_{k}
$$

Os coeficientes $c_{n}$ é o componente $a_{0}$ quando f é substituído por um vetor unitário $\mathbf{e}_{n},-n_{L} \leq n<n_{R}$, tem-se

$$
c_{n}=\left\{\left(\mathbf{A}^{t} \cdot \mathbf{A}\right)^{-1} \cdot\left(\mathbf{A}^{t} \cdot \mathbf{e}_{n}\right)\right\}_{0}=\sum_{m=0}^{M}\left\{\left(\mathbf{A}^{t} \cdot \mathbf{A}\right)^{-1}\right\}_{0 m} n^{m}
$$

Note que a equação (4.18) mostra ser necessário somente uma linha da matriz inversa.

Dentro dos limites, a filtragem de Savitzky-Golay fornece um alisamento sem perda de resolução. Entretanto, o subconjunto de dados é um número impar de pontos, $2 n+1$. Luo, Ying e Bai (2005) estenderam os filtros de Savitzky-Golay para um número par de pontos, $2 n$, que é de interesse de espectroscopistas e engenheiros. 


\section{Capítulo 5}

\section{Formulação do problema e algoritmo de reconstrução}

Neste capítulo mostra-se na primeira seção a formulação do problema, com toda a implicação física existente em problemas de condução de calor. Na segunda seção são apresentados o algoritmo de reconstrução e o método de regularização utilizado, que ameniza as interferências dos ruídos e o mau condicionamento do problema inverso.

\subsection{Formulação do problema}

Considere uma sonda térmica encapsulada imersa num escoamento bifásico reagente como indicado na Figura 5.1. A temperatura real do processo é chamada por $T_{\text {proc }}$ e representa a temperatura local instantânea, já a temperatura indicada pela sonda térmica, que corresponde à temperatura do escoamento, será nomeada por $T_{\text {ind }}$.

A diferença entre a temperatura do processo e indicada está associada ao acúmulo térmico, devido ao revestimento do sensor, o que provoca distorção, e às razões de transferência de calor, devidas à convecção e radiação, ocasionando atrasos na medida do sinal. Adicionalmente, a transferência radiativa ocorrendo no interior das bolhas de gás tende a deslocar a temperatura indicada para a temperatura mais alta da emulsão reagente. 


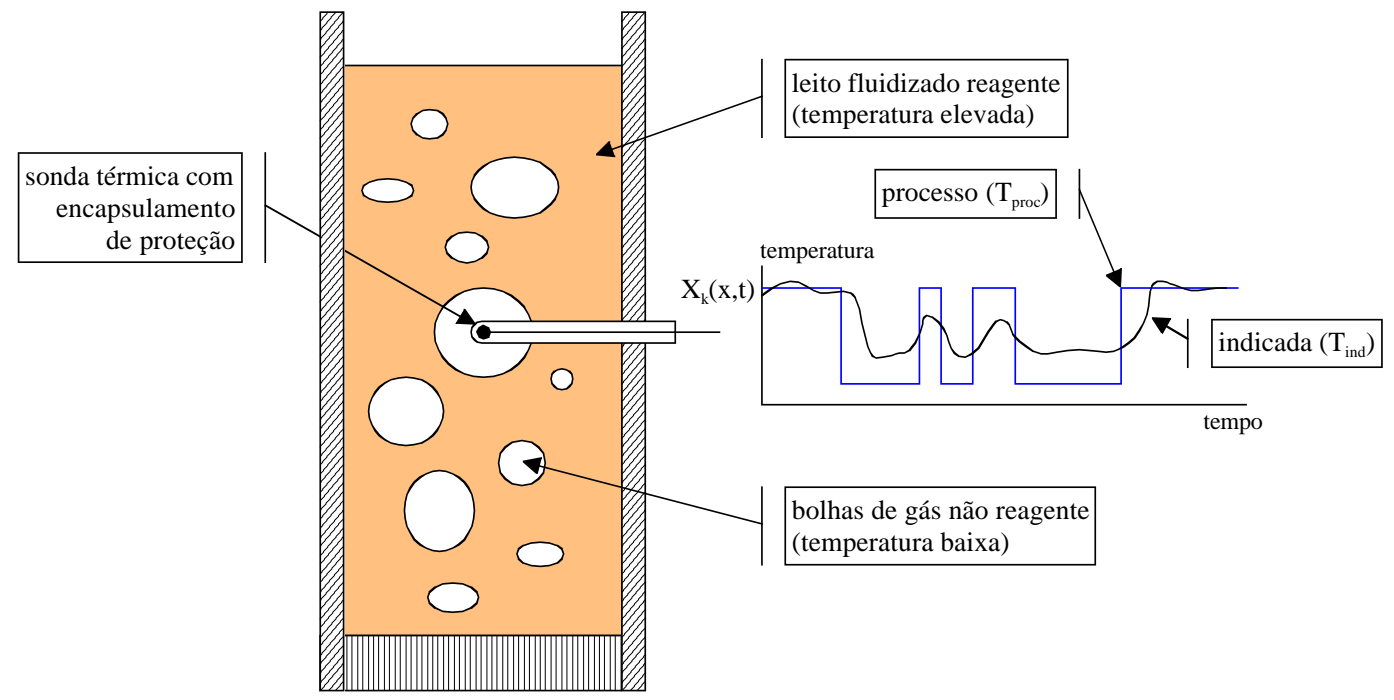

Figura 5. 1: Uso de uma sonda térmica para detecção de fase num escoamento gássólidos reagente

$\mathrm{O}$ acúmulo térmico é caracterizado pela massa $M(\mathrm{~kg})$ do encapsulamento e pelo calor específico $C(\mathrm{~J} / \mathrm{kg} / \mathrm{K})$. As propriedades das transferências de calor convectiva e radiativa através da área $A\left(\mathrm{~m}^{2}\right)$ são calculadas, respectivamente, pelo coeficiente de convecção $h\left(\mathrm{~W} / \mathrm{m}^{2} / \mathrm{K}\right)$, pela emissividade $\varepsilon$ (adimensional) e pela constante de Stefan-Boltzmann $\sigma \quad\left(=5.670 \cdot 10^{-8} \mathrm{~W} / \mathrm{m}^{2} / \mathrm{K}^{4}\right)$. A condução de calor através do cabo do sensor foi desconsiderada, devido à área do fio ser desprezível. Admitindo que o meio radiativo envolve completamente o sensor, a equação que relaciona $T_{p r o c} \mathrm{e}$ $T_{\text {ind }}$ pode ser escrita como segue:

$$
M C \frac{d T_{\text {ind }}}{d t}-h A\left(T_{\text {proc }}-T_{\text {ind }}\right)-\varepsilon \sigma A\left(T_{\infty}^{4}-T_{\text {ind }}^{4}\right)=0
$$

onde $T_{\infty}$ denota a temperatura na qual ocorre a transferência radiativa, e ligada a temperatura de combustão do carvão no caso de um reator de leito fluidizado.

A equação (5.1) pode ser escrita em termos mais apropriados dividindo ambos os lados por $h A$ e reorganizando as potências de $T_{\infty}$ e $T_{\text {ind }}$ tem-se

$$
\tau \frac{d T_{\text {ind }}}{d t}-\left(T_{\text {proc }}-T_{\text {ind }}\right)-\gamma\left(T_{\infty}-T_{\text {ind }}\right)=0
$$


onde

$$
\begin{gathered}
\tau=\frac{M C}{h A} \\
\gamma \cong \frac{4 \varepsilon \sigma}{h}\left(\frac{T_{\infty}+T_{\text {ind }}}{2}\right)^{3}
\end{gathered}
$$

$\mathrm{Na}$ expressão (5.3), $\tau$ (s) representa a constante de tempo da sonda, isto é, o aumento de temperatura causado pelo acúmulo de calor sobre o calor transferido por convecção. O coeficiente de radiação $\gamma$, da equação (5.4), avalia a intensidade de transferência de calor radiativo em comparação com a transferência de calor convectivo.

A equação (5.2) expressa a relação entre a variável do processo (estímulo) e a variável indicada (resposta). O problema direto pode ser resolvido de maneira imediata, calculando a saída $\left(T_{\text {ind }}\right)$ da conhecida entrada $\left(T_{\text {proc }}\right)$. Entretanto, resolver o problema inverso correspondente é certamente uma tarefa difícil por causa de sua natureza intrínseca mal condicionada.

Em termos matemáticos, o problema inverso é intrinsecamente mal posto no sentido de Hadamard, como visto na Seção 3.5. A solução pode não existir ou, se existir, pode não ser única ou não contínua com respeito à entrada de dados. Na prática isto significa que o processo de solução de $T_{\text {proc }}$ a partir de $T_{\text {ind }}$ será fortemente afetado pela presença de erros experimentais na medida de $T_{\text {ind }}$.

Então, pelo método de diferenças finitas (Anexo A.1) a equação (5.2) pode ser discretizada no tempo. Definindo um passo no tempo $\Delta t$ e um esquema de discretização atrasado com índices $n$ e $n-1$ indicando que a variável se refere nos tempos $t=n \Delta t$ e $t=(n-1) \Delta t$, respectivamente. É possível obter

$$
\frac{\tau_{n}}{\Delta t}\left(T_{i n d, n}-T_{i n d, n-1}\right)-\left(T_{p r o c, n}-T_{i n d, n}\right)-\gamma_{n}\left(T_{\infty}-T_{i n d, n}\right)=0
$$

Assim os problemas diretos e inversos são expressos como: 


$$
\begin{aligned}
T_{i n d, n}= & \frac{1}{\frac{\tau_{n}}{\Delta t}+1+\gamma_{n}}\left(T_{p r o c, n}+\gamma_{n} T_{\infty}+\frac{\tau}{\Delta t} T_{i n d, n-1}\right) \\
T_{p r o c, n}= & \frac{\tau_{n}}{\Delta t}\left(T_{i n d, n}-T_{i n d, n-1}\right)+T_{i n d, n}-\gamma_{n}\left(T_{\infty}-T_{i n d, n}\right)
\end{aligned}
$$

\subsection{Algoritmo de reconstrução}

Os problemas inversos relacionados com condução de calor têm sido objeto de estudo de vários pesquisadores e por isso existem vários métodos capazes de reconstruir a temperatura do processo, mas são métodos de aplicação posterior como a regularização de Tikhonov e Arsenin (1977) que trabalha com coeficientes específicos que devem ser determinados previamente. A principal desvantagem do método de Tikhonov é que os termos de regularização devem ser ponderados por coeficientes específicos os quais devem ser determinados previamente e são dependentes da situação (JANICKI, ZUBERT e NAPIERALSKI 1999).

Outra interessante aproximação posterior é a técnica de deconvolução iterativa de Van-Cittert, baseada na formação de sucessivas aproximações de um sistema desconhecido de resposta impulsivo usando a equação de convolução, (RIAD 1986 e BENNIA e RIAD 1992). Esta técnica trabalha notavelmente bem, mas é restrita a sistemas lineares e não é apropriada em processamento em tempo real. Filtragem adaptativa por wavelets (SELEGHIM e MILIOLI 2001) e medidas redundantes (ROLNIK e SELEGHIM 2002) podem também ser empregada em problemas nãolineares com bons resultados, mas ainda restrita a aplicações posteriores.

A reconstrução da temperatura do processo em tempo real deve ser baseada num número finito de operações realizadas nas últimas poucas temperaturas indicadas, uma vez que o algoritmo correspondente deve ser implementado em hardware dedicado.

Uma aproximação adotada neste trabalho é baseada na técnica de alisamento Savitzky-Golay (método dos mínimos quadrados simplificado) para calcular os termos mais complexos da equação (5.2), entre os quais a derivada temporal é seguramente a mais importante. 
Esta derivada atua como um filtro passa-alta e conseqüentemente os componentes de baixa freqüência presentes no sinal original da temperatura indicada são atenuados enquanto há um ganho elevado dos componentes de alta frequiência, onde muito do ruído está contido.

A idéia básica é ajustar um polinômio de baixo grau $N$ para as últimas $m+1$ temperaturas indicadas e substituir $d T_{\text {ind }} / d t$ e $T_{\text {ind }}$ na equação (5.2) por valores suavizados ou regularizados obtidos deste polinômio. Considerando que $T_{\text {suave }}(x)$ indique tal polinômio, onde $x$ é um eixo de suporte centrado na última temperatura adquirida e de forma oposta orientada no tempo, Figura 5.2.

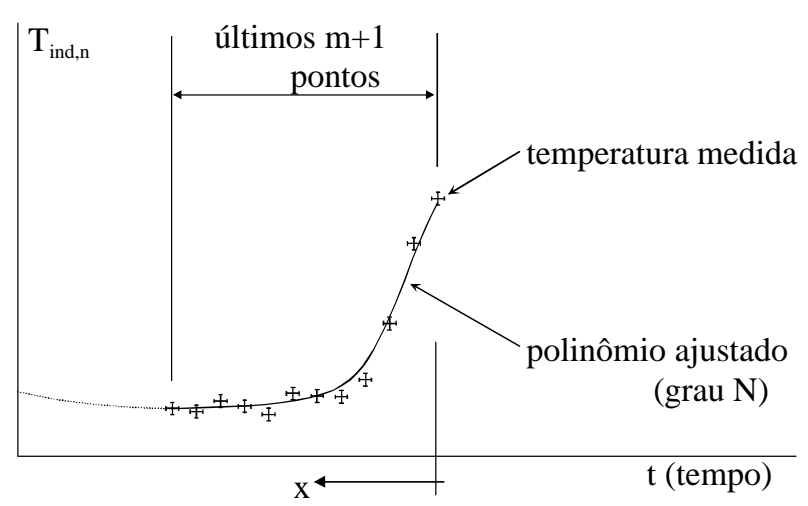

Figura 5. 2: $T_{\text {ind }}$ e $d T_{\text {ind }} / d t$ da equação (5.2) são calculadas através de um polinômio ajustado sobre os últimos $m+1$ pontos de temperatura

Assim, as equações seguintes devem ser resolvidas:

$$
\left\{\begin{array}{l}
T_{\text {ind }, n} \cong T_{\text {suave }}(x=0)=a_{0}+a_{1}(0)+a_{2}(0)^{2}+\cdots+a_{N}(0)^{N} \\
T_{\text {ind }, n-1} \cong T_{\text {suave }}(x=1 \Delta t)=a_{0}+a_{1}(1 \Delta t)+a_{2}(1 \Delta t)^{2}+\cdots+a_{N}(1 \Delta t)^{N} \\
T_{\text {ind }, n-2} \cong T_{\text {suave }}(x=2 \Delta t)=a_{0}+a_{1}(2 \Delta t)+a_{2}(2 \Delta t)^{2}+\cdots+a_{N}(2 \Delta t)^{N} \\
\vdots \\
T_{\text {ind }, n-m} \cong T_{\text {suave }}(x=m \Delta t)=a_{0}+a_{1}(m \Delta t)+a_{2}(m \Delta t)^{2}+\cdots+a_{N}(m \Delta t)^{N}
\end{array}\right.
$$

Com o intuito de ajustar-se ao sinal, a técnica residual com ponderação (ou mínimos quadrados ponderado) associada ao método dos mínimos quadrados simplificado foi usada neste trabalho. As principais razões para isto são a possibilidade de definir diferentes valores de peso e enfatizar diferentes partes do sinal da temperatura 
indicada. A possibilidade de escolher diferentes valores resulta em um conjunto de coeficientes que variam com necessidades específicas. Em notação matricial a solução da equação (5.8) pode ser escrita como segue:

$$
\left(\begin{array}{c}
a_{0} \Delta t^{0} \\
a_{1} \Delta t^{1} \\
\vdots \\
a_{N} \Delta t^{N}
\end{array}\right)=[G]^{-1}\left(\begin{array}{c}
\sum_{k=0}^{m} w_{k} T_{\text {ind }, k} k^{0} \\
\sum_{k=0}^{m} w_{k} T_{\text {ind }, k} k^{1} \\
\vdots \\
\sum_{k=0}^{m} w_{k} T_{\text {ind }, k} k^{N}
\end{array}\right)
$$

onde $w_{k}$ denota os valores dos pesos e $[G]$ está associada a matriz de Gram dada por

$$
[G]=\left[\begin{array}{cccc}
\sum_{k=0}^{m} w_{k} k^{0} & \sum_{k=0}^{m} w_{k} k^{1} & \cdots & \sum_{k=0}^{m} w_{k} k^{N} \\
\sum_{k=0}^{m} w_{k} k^{1} & \sum_{k=0}^{m} w_{k} k^{2} & \cdots & \sum_{k=0}^{m} w_{k} k^{N+1} \\
\vdots & \vdots & \cdots & \vdots \\
\sum_{k=0}^{m} w_{k} k^{N+1} & \sum_{k=0}^{m} w_{k} k^{N+2} & \cdots & \sum_{k=0}^{m} w_{k} k^{2 N}
\end{array}\right]
$$

A principal vantagem desta aproximação é que a matriz de Gram na equação (5.9) pode ser previamente invertida por causa de sua dependência somente com $w_{k} \mathrm{e}$ com os $m+1$ pontos de temperaturas ajustados. Além disso, não é necessário implementar todas estas operações por completo desde que somente $T_{i n d, n}$ e a primeira derivada são exigidas em $x=0$ para serem repetidas na equação (5.2). De acordo com a equação (5.8) estes valores podem ser calculados por

$$
\begin{gathered}
T_{\text {ind }}(n \Delta t) \cong T_{\text {suave }}(0)=a_{0} \\
\frac{d T_{\text {ind }}}{d t}(n \Delta t) \cong-\frac{d T_{\text {suave }}}{d x}(0)=-a_{1}
\end{gathered}
$$

e da equação (5.7) tem-se 


$$
T_{p r o c, n}=-\tau_{n} a_{1, n}+a_{0, n}-\gamma_{n}\left(T_{\infty}-a_{0, n}\right)
$$

onde o índice $n$ foi introduzido para enfatizar o fato que $a_{0}$ e $a_{1}$ referem-se a $t=n \Delta t$ e devem ser recalculados em todos os passos no tempo. Sinteticamente estas operações podem ser resumidas nas seguintes linhas de instruções:

1. $\quad$ seja $m, N$ e $w_{k}$

2. calcule $G^{-1}$ na equação (5.9) e obtém a primeira e segunda linhas, isto é,

$$
\begin{aligned}
& \left(A_{0}, A_{1}, \ldots, A_{N}\right)=\left.[G]^{-1}\right|_{\text {linha }=1} \\
& \left(B_{0}, B_{1}, \ldots, B_{N}\right)=\left.[G]^{-1}\right|_{\text {linh } a=2}
\end{aligned}
$$

3. inicie o laço temporal com valores adequados para $T_{i n d, n}, T_{i n d, n-1}, \ldots, T_{i n d, n-m}$

4. calcule $a_{0}$ e $a_{1}$ através das fórmulas

$$
\begin{gathered}
a_{0}=\left(A_{0}, A_{1}, \ldots, A_{N}\right)\left(\begin{array}{c}
\sum_{k=0}^{m} w_{k} T_{\text {ind }, n-k} k^{0} \\
\sum_{k=0}^{m} w_{k} T_{i n d, n-k} k^{1} \\
\vdots \\
\sum_{k=0}^{m} w_{k} T_{\text {ind }, n-k} k^{N}
\end{array}\right) \\
a_{1}=\left(B_{0}, B_{1}, \ldots, B_{N}\right)\left(\begin{array}{c}
\sum_{k=0}^{m} w_{k} T_{i n d, n-k} k^{0} \\
\sum_{k=0}^{m} w_{k} T_{i n d, n-k} k^{1} \\
\vdots \\
\sum_{k=0}^{m} w_{k} T_{i n d, n-k} k^{N}
\end{array}\right)
\end{gathered}
$$


5. calcule $T_{p r o c, n}$ da equação (5.13)

6. faça $n=n+1$ e obtenha a nova temperatura indicada atualizando todos os valores prévios de acordo com as regras dadas por

$$
\left\{\begin{array}{l}
T_{i n d, n-m} \leftarrow T_{i n d, n-m+1} \\
T_{i n d, n-m+1} \leftarrow T_{i n d, n-m+2} \\
\vdots \\
T_{i n d, n-1} \leftarrow T_{i n d, n} \\
T_{i n d, n} \leftarrow T_{i n d, n+1}
\end{array}\right.
$$

7. volte ao passo 4 . 


\section{Capítulo 6}

\section{Testes numéricos e experimentais}

Neste capítulo estão os testes numéricos e experimentais realizados. Os testes numéricos demonstram as discrepâncias introduzidas pela inércia térmica, convecção e radiação, bem como a extrema sensibilidade da presença de ruídos quando o problema inverso é resolvido. Já os testes experimentais foram conduzidos para validar o algoritmo de reconstrução sob condições práticas.

\subsection{Testes numéricos}

Considere um escoamento a bolhas gás-sólidos reagente, cuja temperatura varia entre níveis característicos ao redor de $900 \mathrm{~K}$ e $1000 \mathrm{~K}$. Estes níveis de temperatura são respectivamente associados com o gás inerte no interior das bolhas e com as partículas de sólidos reagente na fase de emulsão. Por simplicidade, é assumido que a temperatura varia de acordo com uma onda quadrada.

Assim, $T_{\infty}=1000 \mathrm{~K}$ e parâmetros adicionais foram adotados representando valores tipicamente experimentais: $\quad M=4.712 \times 10^{-6} \mathrm{~kg}, \quad C=380 \mathrm{~J} / \mathrm{kg} / \mathrm{K}$, $h=550 \mathrm{~W} / \mathrm{m}^{2} / \mathrm{K}, A=3.142 \times 10^{-6} \mathrm{~m}^{2}$ e $\varepsilon=0.9$, o qual implica numa constante de tempo média de 1.1 segundo adotados nas equações (5.6) e (5.7); para facilitar $\left(\tau_{n}=\bar{\tau}=1.1 \mathrm{~s}\right)$. 
O sinal medido foi gerado pela resolução da equação (5.6), foi adicionado um ruído uniforme centrado com amplitude de $0.01 \mathrm{~K}$ e o período da amostragem foi de $0.001 \mathrm{~s}$.

A reconstrução de $T_{\text {proc }}$ com valores de $T_{\text {ind }}$ com ruído foi efetuado através da equação (5.7). Vale notar que, apesar do coeficiente de radiação variar no tempo devido à dependência com a temperatura indicada, o qual está explicito nas equações (5.5), (5.6) e (5.7), $\gamma_{n}$ foi substituído pelo seu valor médio. Mais precisamente, um coeficiente de radiação médio e constante $\bar{\gamma}$ pode ser determinado através da equação (5.4) pela substituição de valores instantâneos de $T_{\text {ind }}$ pelo valor médio $\bar{T}_{\text {ind }}$, o qual pode ser obtido na prática por um filtro passa-baixa na saída do sinal da sonda. Isto é vantajoso quando $T_{\infty}$ é constante, ou varia pouco em comparação com a temperatura do processo, porque a recorrência intrínseca na definição do coeficiente de radiação é eliminado e não há a necessidade de um método iterativo para calcular simultaneamente $T_{\text {proc }}$ e $T_{\infty}$.

Neste exemplo, $\gamma_{n}$ varia entre 0.339 e 0.364 , enquanto o valor médio é $\bar{\gamma}=0.352$. O erro entre os sinais do processo reconstruído usando $\gamma_{n}$ e $\bar{\gamma}$ tem um valor médio de $0.091 \mathrm{~K}$ com um desvio padrão de $0.271 \mathrm{~K}$, o qual é desprezível em comparação com $950 \mathrm{~K}$ do valor médio da $T_{\text {proc }}$ correspondente.

Na Figura 6.1 é mostrado o sinal do processo reconstruído obtido de uma $T_{\text {ind }}$ com valores perturbados pela aplicação da equação (5.7) sem nenhuma preocupação pela natureza mal condicionada intrínseca do problema inverso.

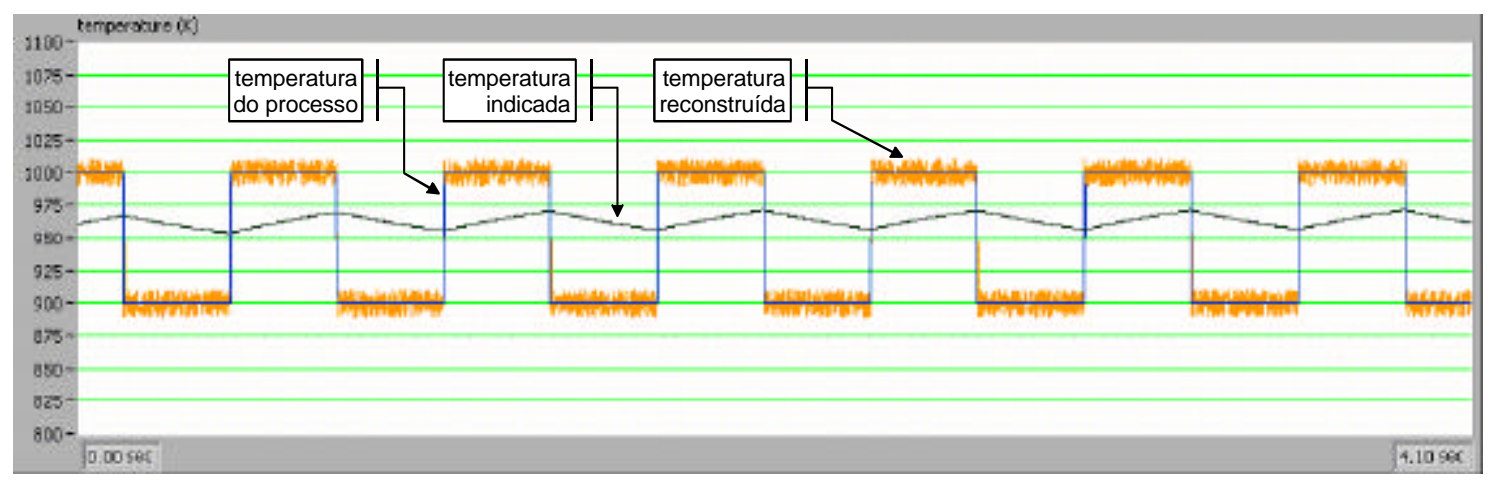

Figura 6. 1: Temperatura do processo, temperatura indicada e temperatura do processo reconstruída obtida da equação (5.7) sem regularização a priori (o nível de erro da temperatura indicada é de $0.01 \mathrm{~K}$ ) 
Pode ser visto que, apesar do nível de ruído extremamente baixo e irreal de $0.01 \mathrm{~K}$ sobre $950 \mathrm{~K}$, o erro entre o sinal do processo correto e o sinal do processo reconstruído tem um valor médio de $0.091 \mathrm{~K}$ e um desvio padrão de $8.503 \mathrm{~K}$, o qual corresponde a uma ampliação de aproximadamente 2.5 mil vezes.

A efetividade do algoritmo descrito na Seção 5.2 pode ser observada neste exemplo numérico, mas com um aumento no nível de ruído para $0.1 \mathrm{~K}$, Figura 6.2. Em tal caso o sinal reconstruído obtido pela equação (5.7) é extremamente degradado e apesar de um erro médio relativamente pequeno $(0.9 \mathrm{~K})$, o desvio padrão correspondente é inaceitável (59.6 K), se as extremidades do sinal forem identificadas.

Uma reconstrução muito melhor pode ser obtida da equação (5.13) com o ajuste polinomial linear sobre os últimos 45 pontos da temperatura indicada, como mostra a Figura 6.2. O erro médio associado é igual a $0.2 \mathrm{~K}$ e o desvio padrão associado é $8.2 \mathrm{~K}$ ou $0.86 \%$ da média do sinal da temperatura do processo.

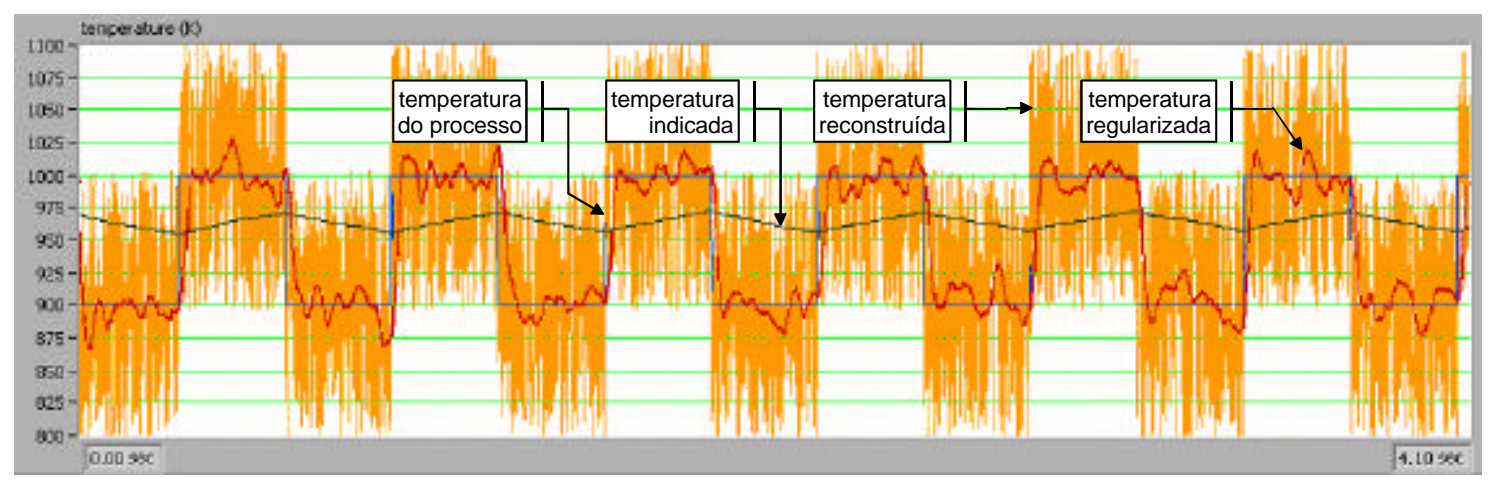

Figura 6. 2: Temperaturas do processo, indicada, reconstruída (equação (5.7)) e regularizada (equação (5.13)) (o nível de ruído da temperatura indicada é $0.1 \mathrm{~K}$ )

É importante enfatizar que a escolha da parametrização intrínseca do algoritmo de reconstrução proposto (o número de pontos de temperatura ajustada e coeficientes de ponderação) é de grande importância para aplicações que exigem a obtenção dos valores em tempo real porque envolve um compromisso entre regularização e custo computacional.

No que diz respeito às aplicações consideradas neste trabalho, os aspectos mais importantes para serem otimizados são a semelhança e o atraso entre a temperatura reconstruída e a temperatura do processo real.

A semelhança entre a temperatura reconstruída e a temperatura do processo é importante, pois pela análise da função de densidade de probabilidade (PDF) (Anexo 
A.2) do sinal reconstruído pode-se definir os níveis de corte. Posteriormente, por exemplo, o sinal indicador de fase associado pode ser reconstruído para obter o histograma de corda e, com premissas, o diâmetro da bolha correspondente.

Adicionalmente, um pequeno atraso é vantajoso para aplicações envolvendo monitoramento e controle em tempo real, porque medidas de correção podem ser realizadas em pouco tempo e, conseqüentemente, todo o processo trabalha durante longos períodos mais perto do estado ótimo.

O polinômio de ajuste na equação (5.8), o número de pontos de temperaturas ajustadas e o coeficiente de ponderação influenciam nas semelhanças e atrasos entre os sinais das temperaturas do processo e regularizado. A determinação apropriada do número de temperaturas ajustadas $(m+1)$ é necessária para que $a_{0, n}$ e $a_{1, n}$ sejam calculados nas equações (5.16) e (5.17). Já a escolha dos coeficientes de ponderação $\left(w_{k}\right)$ é importante com relação às propriedades dinâmicas da temperatura reconstruída, tal como limites excedidos, e o polinômio ajustado é convenientemente escolhido como linear, isto é, $N=1$ na equação (5.8), a fim de otimizar a quantidade de memória necessária para implementar o método de reconstrução.

Para demonstrar o comportamento de semelhança e de atraso com respeito ao número de temperaturas ajustadas, simulações numéricas foram realizadas considerando a mesma onda quadrada da temperatura do processo das Figuras 6.1 e 6.2.

Para cada teste o número total de amostras geradas foram de $2^{14}=16384$, correspondendo a todo intervalo de 16.4 segundos. Em todos os casos a amplitude do erro aleatório adicionado na temperatura indicada correspondente foi de $0.1 \mathrm{~K} \mathrm{e} m+1$ estava variando entre 3 e 400, o que corresponde ao intervalo de tempo de 0.003 e 0.4 segundos respectivamente.

$\mathrm{O}$ atraso entre a temperatura do processo e a temperatura reconstruída obtida da equação (5.13) foi estimada da posição do primeiro pico em sua função de correlação transversal. A semelhança foi estimada pelo cálculo do desvio padrão da diferença entre os sinais, depois se moveu a temperatura reconstruída para cancelar o atraso associado.

A Figura 6.3 está dividida em três figuras ( $a, b$ e c), sendo que cada uma delas corresponde ao número de temperaturas ajustadas: a-) $m+1=10$; b-) $m+1=60$ e c-) $m+1=300$. Em cada figura tem-se acima os sinais da temperatura do processo $\left(T_{\text {proc }}\right)$ em azul, da temperatura reconstruída regularizada $\left(T_{\text {reg }}\right)$ em vermelho (equação (5.13)) 
e da temperatura reconstruída $\left(T_{\text {rec }}\right.$ ) em alaranjado (equação (5.7)). Abaixo estão as PDF's das $T_{\text {proc }}, T_{\text {reg }}$ e $T_{\text {rec }}$ respectivamente à esquerda, centro e direita. Pesos unitários foram usados.

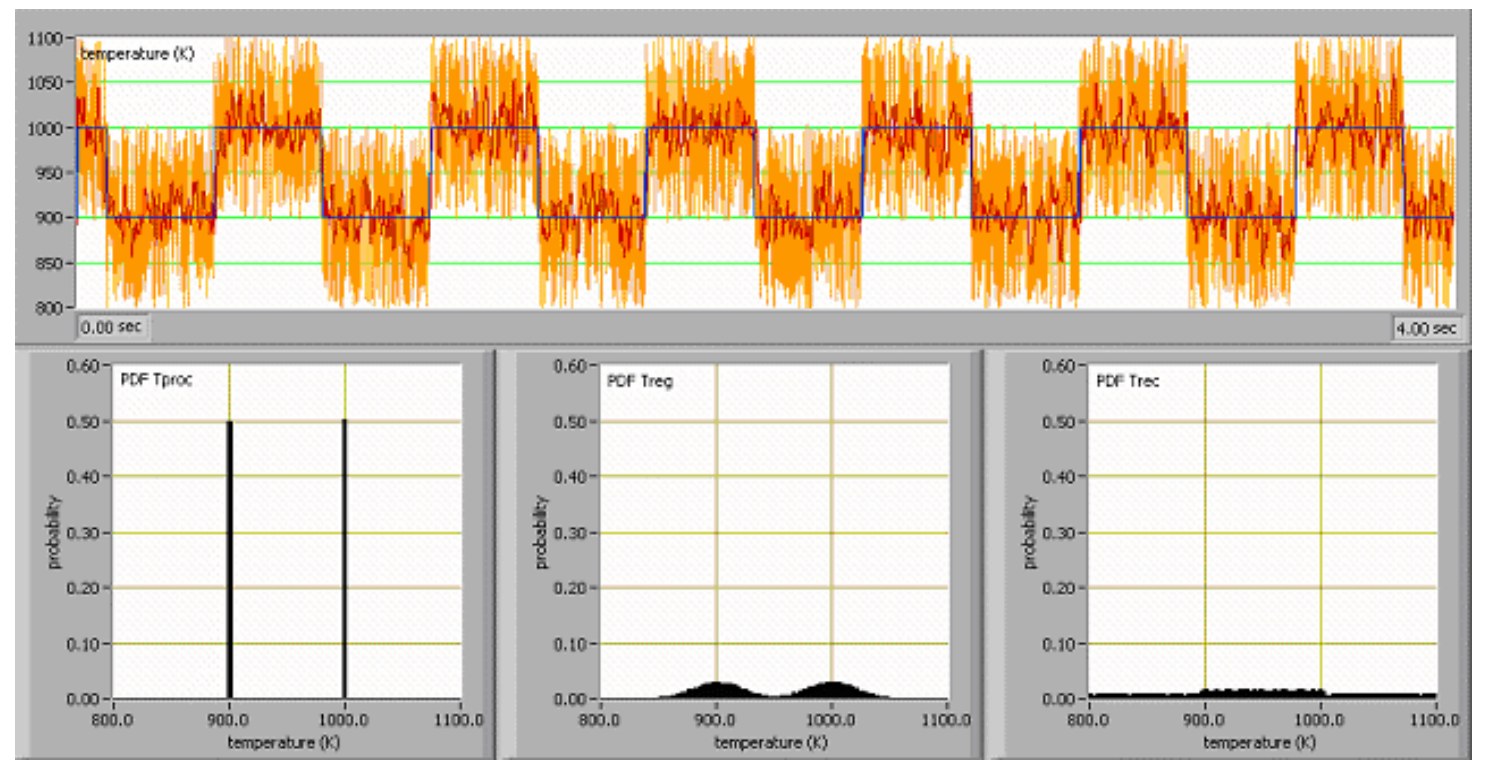

a-) $m+1=10$

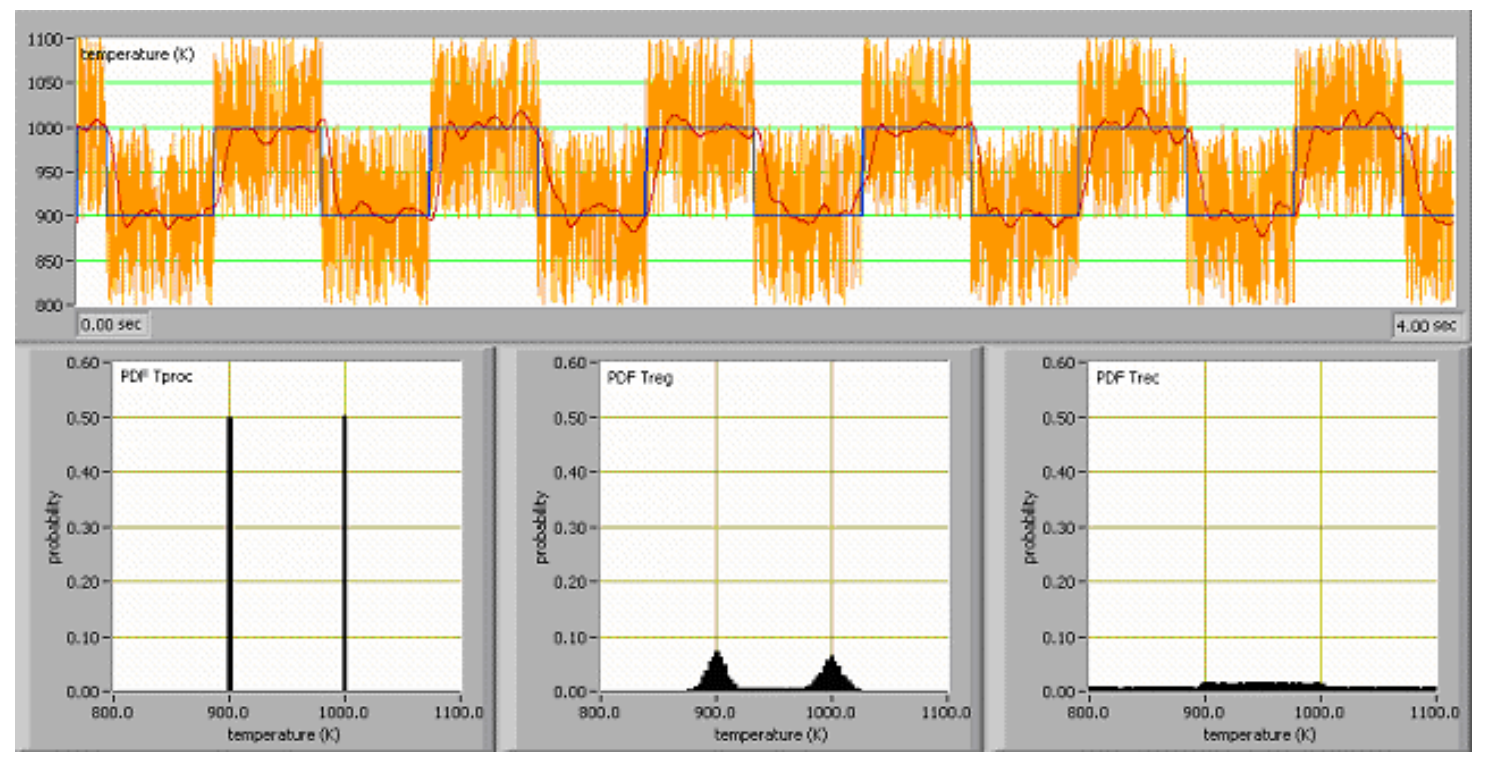

b-) $m+1=60$

Figura 6.3 - continua... 


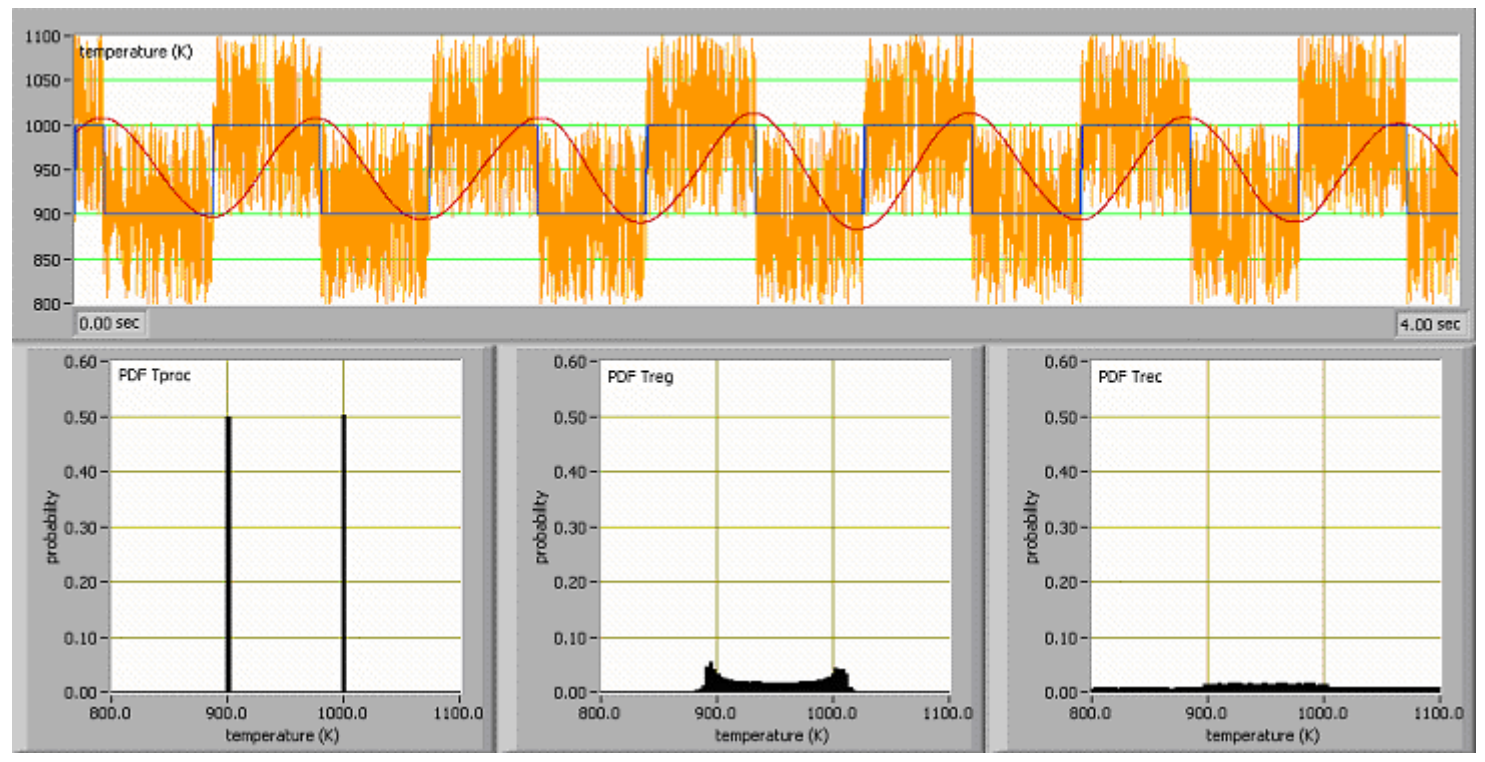

c-) $m+1=300$

Figura 6. 3: Sinais das temperaturas do processo (azul), reconstruída (alaranjado) e regularizada (vermelho) para diferentes números de temperaturas ajustadas ( $\mathrm{a}, \mathrm{b}$ e c) e PDF's da temperatura do processo, regularizada e reconstruída (esquerda, centro e direita)

Nas Figuras 6.3 a, b e c, comparando as PDF's, a $T_{r e c}$ não define as temperaturas máxima e mínima da $T_{p r o c}$. Então, fica claro que a reconstrução sem regularização prévia é inútil para determinar as características dos níveis de temperatura da PDF. Já a PDF da $T_{r e g}$ especifica com maior transparência as temperaturas máxima e mínima da $T_{\text {proc }}$. Mas é evidente que a PDF da temperatura do processo e a PDF da temperatura reconstruída regularizada para $m+1=60$ tem melhor harmonia, da qual as características dos níveis de temperatura podem ser facilmente extraídos.

Outra importante conclusão que pode ser tirada da Figura 6.3 é que uma escolha conveniente de parametrização intrínseca (número de pontos de temperatura ajustados e coeficientes de ponderação) é de crucial importância para o sucesso do método de reconstrução proposto. Estes parâmetros devem ser escolhidos de modo a proporcionar a melhor semelhança e o menor atraso possível, considerando-se que as respostas devem ser obtidas em tempo real.

Doze simulações foram executadas com o mesmo sinal da onda quadrada dos exemplos anteriores, mas considerando um grande número de diferentes temperaturas ajustadas e os seguintes pesos nas equações (5.14) até (5.17): 


$$
\begin{gathered}
w_{k}=1, \quad k=0,1,2, \ldots, m \\
w_{k}=\frac{m}{k+m}, \quad k=0,1,2, \ldots, m
\end{gathered}
$$

Os resultados correspondentes são mostrados na Figura 6.4 onde os pontos em forma de quadrados pretos e losangos azuis denotam os pesos de acordo com as equações (6.1) e (6.2), respectivamente. Estes resultados mostram que as semelhanças ótimas são obtidas por volta de 20 a 60 pontos de temperaturas ajustadas em ambos os casos, apesar da variação hiperbólica dos coeficientes na equação (6.2) produzir razoável semelhança com poucos pontos ajustados, $m+1 \cong 10$ por exemplo, o que é vantajoso em termos de minimização do atraso associado.

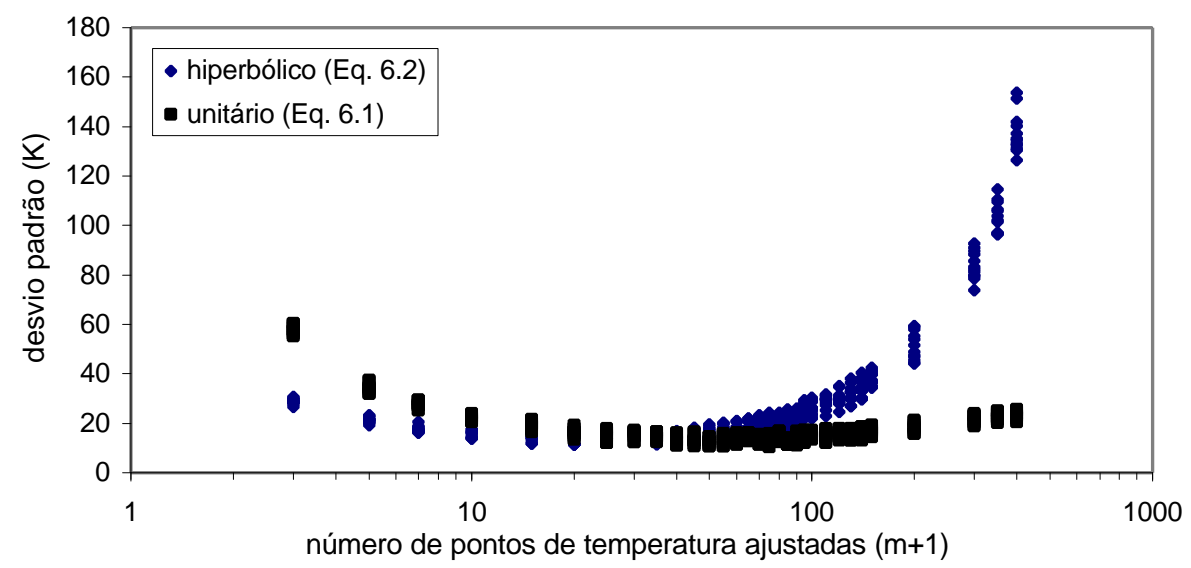

Figura 6. 4: Desvio padrão do erro entre o sinal do processo real e do sinal reconstruído regularizado em função do número de pontos de temperatura ajustada e por coeficientes de ponderação dada pelas equações (6.1) e (6.2) (pontos quadrados pretos e losangos azuis respectivamente)

\subsection{Testes experimentais}

Testes experimentais foram conduzidos para validar o algoritmo de reconstrução proposto sob condições práticas. Foram realizados três diferentes testes, de maneira que deu-se maior ênfase ao tratamento estatístico conforme o avanço do projeto, o que possibilitou melhores comparações entre os sinais real e reconstruído. No Apêndice A é 
apresentado um quarto teste que usou um hardware dedicado para a aquisição e reconstrução da temperatura.

Um sistema de aquisição de dados da National Instruments foi usado para obter as amostras do sinal da temperatura numa freqüência de $30 \mathrm{~Hz}$, o qual é suficiente para evitar os efeitos de aliasing e para ter certeza que os dados do sinal do processo foram obtidos corretamente. O sistema de aquisição é composto de um chassi PXI-1000B equipado com um controlador embutido NI 8176 PXI (Pentium III 1.26 GHz) e uma placa I/O multi-função PXI-6025E por $200 \mathrm{kS} / \mathrm{s}$ 12-bit de amostragem. Todas as conexões foram cuidadosamente blindadas, incluindo os cabos dos termopares, a fim de minimizar a influência de ruídos externos.

\subsubsection{Primeiro teste}

O primeiro teste realizado teve como objetivo a reconstrução do sinal em altas temperaturas, já que a finalidade do projeto é a reconstrução do sinal em leitos fluidizados. $\mathrm{O}$ experimento consistia de dois termopares tipo $\mathrm{K}$, sendo que um deles foi encapsulado por um tubo de aço inox e o outro não recebeu proteção, fornecendo, assim, a temperatura indicada e do processo, respectivamente. Os termopares foram posicionados sob um chama de bico de Bunsen, atingindo uma temperatura máxima de $1012.8{ }^{\circ} \mathrm{C}$ e temperatura mínima de $453.4{ }^{\circ} \mathrm{C}$. A constante de tempo foi calculada em $\bar{\tau}=114 \mathrm{~s}$.

A Figura 6.5 mostra a temperatura do processo, indicada e reconstruída. O sinal foi reconstruído usando $w_{k}=1 / k+1$ como o vetor de ponderação para a regularização do sinal da temperatura reconstruída, sendo o polinômio de ajuste de grau $N=4$ e número de pontos ajustados de $m+1=6$.

Como pode ser observada na Figura 6.5, a temperatura reconstruída se aproxima da temperatura do processo, mas com um certo atraso e uma diferença com relação à amplitude. 


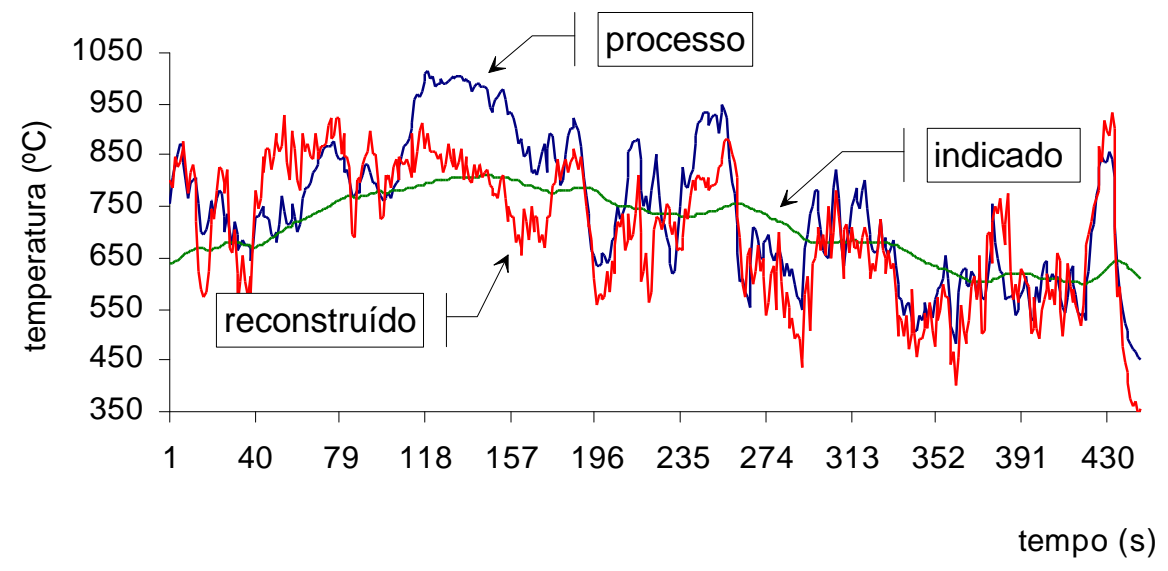

Figura 6. 5: Temperaturas do processo, indicada e reconstruída do teste da chama

\subsubsection{Segundo teste}

O segundo teste consistiu em mergulhar um termopar encapsulado, com borracha de silicone, em água quente $\left(93.1^{\circ} \mathrm{C}\right)$ e fria $\left(-0.1^{\circ} \mathrm{C}\right)$, respectivamente, para simular um processo, no qual a temperatura varia de acordo com uma onda quadrada. A constante de tempo do termopar foi previamente calculada em uma série de testes nos dados de entrada e resultou em $\bar{\tau}=13.04$ s. Um termopar não encapsulado foi usado para obter a temperatura do processo instantânea.

Depois de um intervalo de tempo inicial necessário para todos os transientes desaparecerem, a reconstrução é executada em tempo real na mesma razão que as medidas são adquiridas. A Figura 6.6 mostra a temperatura do processo instantânea obtida pelo termopar não encapsulado, a temperatura indicada dada pelo termopar encapsulado e a temperatura reconstruída correspondente.

Embora tenha alguma oscilação, está claro na Figura 6.6 que a temperatura reconstruída está consideravelmente mais perto da temperatura do processo real.

O desempenho do algoritmo de reconstrução depende fortemente dos parâmetros intrínsecos, tal como o grau do polinômio $(N)$ na equação (5.8) e o número de pontos da temperatura no qual o polinômio está sendo ajustado $(m+1)$. O vetor de ponderação $w_{k}$ também tem uma significante influência no todo. Para estimar estas influências o erro entre a temperatura reconstruída regularizada obtida pela equação (5.13), $T_{\text {reg }}$, e a 
temperatura do processo dada pelo termopar não encapsulado, $T_{\text {proc }}$, foram quantificados por:

$$
e=\sqrt{\frac{\sum_{j=0}^{k}\left(T_{r e g, j}-T_{p r o c, j}\right)}{k}}
$$

A Tabela 6.1 mostra a evolução deste erro. O menor erro ocorre quando o grau do polinômio é $N=4$ e o número de pontos $m+1=20$.

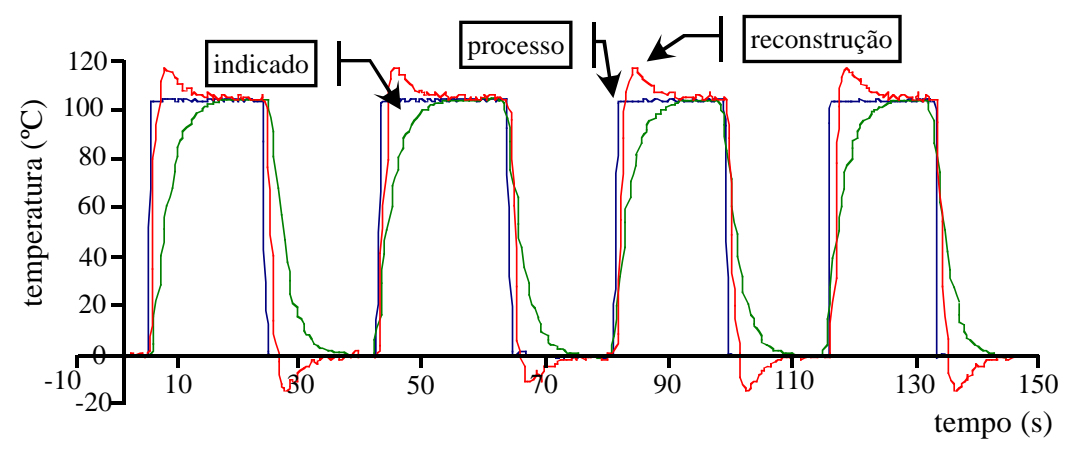

Figura 6. 6: Temperaturas do processo, indicada e reconstruída

Tabela 6. 1: Erro médio entre a temperatura do processo real e reconstruída regularizada de acordo com a equação (6.3) em ${ }^{\circ} \mathrm{C}$ (vetor de ponderação: $w_{k}=e^{-k}$ )

\begin{tabular}{|c|c|c|c|c|c|c|c|c|c|}
\hline \multirow{2}{*}{$\begin{array}{c}\text { Número de pontos } \\
(\mathrm{m}+1)\end{array}$} & \multicolumn{9}{|c|}{ Grau do polinômio (N) } \\
\cline { 2 - 9 } & 2 & 3 & 4 & 5 & 6 & 7 & 8 & 9 & 10 \\
\hline 3 & 16.351 & & & & & & & \\
4 & 16.385 & 17.346 & & & & & & \\
5 & 16.756 & 16.352 & 20.136 & & & & & \\
6 & 17.135 & 16.102 & 17.899 & 25.541 & & & & \\
7 & 17.447 & 16.072 & 17.037 & 21.108 & 35.534 & & & \\
8 & 17.680 & 16.123 & 16.606 & 19.319 & 26.978 & 53.659 & & & \\
9 & 17.841 & 16.200 & 16.368 & 18.358 & 23.468 & 37.547 & 86.084 & & \\
10 & 17.946 & 16.276 & 16.232 & 17.769 & 21.572 & 30.815 & 56.347 & 143.809 & \\
11 & 18.011 & 16.344 & 16.150 & 17.385 & 20.395 & 27.175 & 43.729 & 89.478 & 246.487 \\
12 & 18.048 & 16.398 & 16.103 & 17.114 & 19.615 & 24.911 & 36.888 & 66.233 & 147.677 \\
13 & 18.070 & 16.438 & 16.077 & 16.919 & 19.063 & 23.403 & 32.642 & 53.606 & 105.267 \\
14 & 18.081 & 16.466 & 16.063 & 16.776 & 18.655 & 22.340 & 29.804 & 45.800 & 82.234 \\
15 & 18.087 & 16.485 & 16.056 & 16.669 & 18.346 & 21.558 & 27.802 & 40.587 & 68.063 \\
20 & 18.093 & 16.513 & 16.050 & 16.427 & 17.558 & 19.606 & 23.113 & 29.309 & 40.628 \\
30 & 18.093 & 16.515 & 16.050 & 16.370 & 17.263 & 18.708 & 20.893 & 24.258 & 29.578 \\
40 & 18.093 & 16.515 & 16.050 & 16.369 & 17.256 & 18.650 & 20.633 & 23.432 & 27.476 \\
50 & 18.093 & 16.515 & 16.050 & 16.369 & 17.256 & 18.649 & 20.626 & 23.381 & 27.229 \\
\hline
\end{tabular}




\subsubsection{Terceiro teste}

O terceiro teste consistiu de uma corrente de ar quente produzida com a ajuda de um ventilador de PC e uma resistência elétrica conectada a um transformador variável para controlar o fornecimento de potência. A temperatura máxima atingida foi de aproximadamente $325 \mathrm{~K}$.

Dois termopares em miniatura e idênticos $(\phi=0.6 \mathrm{~mm}$ de raio) foram usados para medir a temperatura da vazante do escoamento aquecido pela resistência. Um dos termopares foi encapsulado com borracha de silicone para distorcer e atrasar o sinal da temperatura indicada. Ambos os termopares foram estatisticamente calibrados num banho quente considerando a leitura do termopar não encapsulado como a temperatura de referência ou do processo real $\left(T_{\text {ref }}\right)$. A constante de tempo $\tau$ do termopar encapsulado foi determinada por uma série de testes com temperaturas variando de $310 \mathrm{~K}$ até $325 \mathrm{~K}$.

Este teste foi realizado no projeto experimental esquematizado na Figura 6.7.

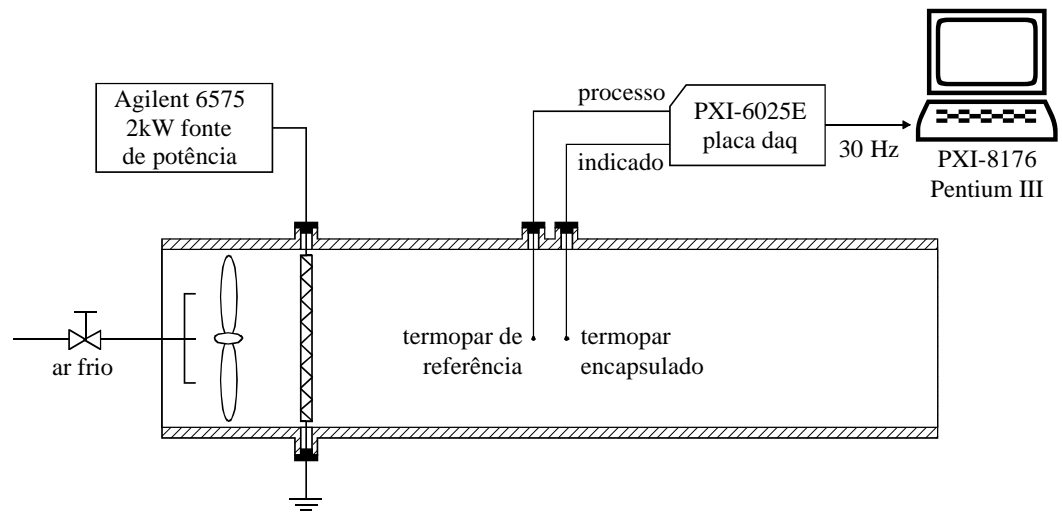

Figura 6. 7: Projeto experimental (termopares tipo K estão localizados lado a lado perpendicularmente a direção do escoamento para minimizar os efeitos de rastro)

Ar comprimido foi periodicamente injetado na corrente de ar quente principal para alterar, o mais rápido possível, o equilíbrio da temperatura ao redor, fazendo com que a temperatura do processo oscile por causa da turbulência.

Para conseguir calcular as variações do coeficiente de convecção com a temperatura local, o qual é de no mínimo uma ordem de magnitude num reator de leito fluidizado por exemplo, a dependência linear de $\tau$ e $T_{\text {ind }}$ foi assumida como se segue: 


$$
\tau_{n}\left(T_{i n d, n}\right)=\tau_{0}+\lambda\left(T_{i n d, n}-317.5\right)
$$

onde $\tau_{0}$ e $\lambda$ são parâmetros representando, respectivamente, a constante de tempo em 317.5 K (a temperatura média entre $310 \mathrm{~K}$ e $325 \mathrm{~K}$ ) e a medida flutuante térmica correspondente $(\mathrm{s} / \mathrm{K})$. Estes parâmetros foram obtidos através da minimização da seguinte função de erro:

$$
e\left(\tau_{0}, \lambda\right)=\sum_{n}\left(T_{p r o c, n}-T_{r e f, n}\right)^{2}
$$

onde $T_{r e f, n}$ é a temperatura instantânea dada pelo termopar não encapsulado e $T_{p r o c, n}$ é a temperatura reconstruída obtida da temperatura indicada $T_{i n d, n}$ e a constante de tempo associada $\tau_{n}$ (equação (6.4)).

É importante notar que a determinação de $\tau_{0}$ e $\lambda$ constitui um problema inverso à parte e, portanto, os problemas já discutidos a respeito do mau condicionamento são esperados. De acordo com a formulação adotada neste trabalho, este mau condicionamento é caracterizado por aspectos patológicos associados à superfície de minimização $e\left(\tau_{0}, \lambda\right)$, mostrado na Figura 6.8 .
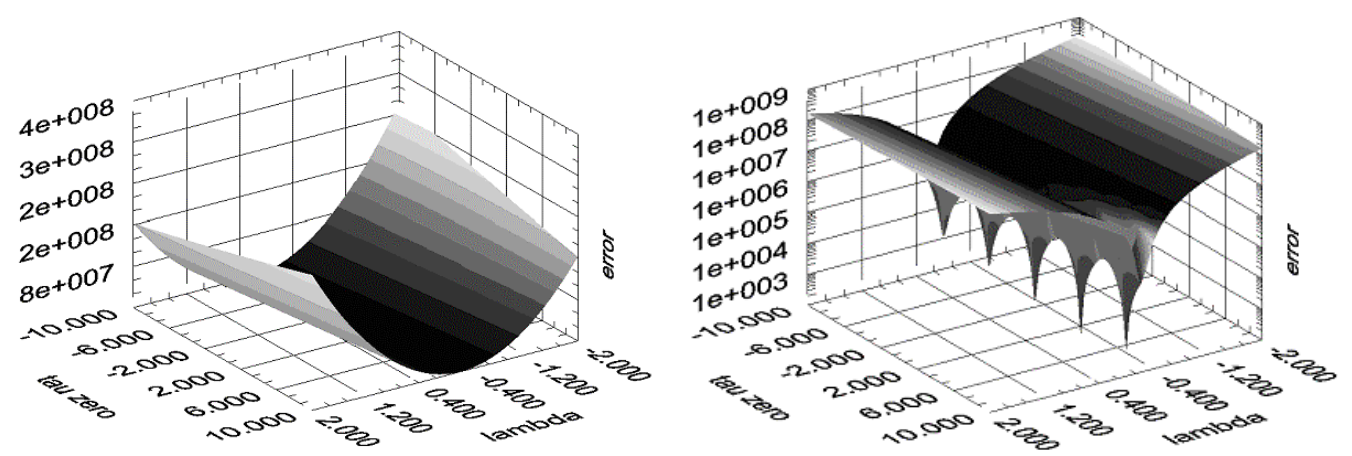

Figura 6. 8: Superfície de otimização dada pela equação (6.5) (esquerda = escala linear e direita $=$ escala logarítmica)

O principal aspecto relativo é que $\partial e / \partial \tau_{0}$ é desprezível quase em todo domínio se comparado com $\partial e / \partial \lambda$, exceto para algumas poucas regiões específicas vistas somente quando o gráfico é representado na escala logarítmica (múltiplos mínimos 
locais). Isto significa que o processo de minimização baseado na inclinação local deve convergir rapidamente para um vale paralelo no eixo $\tau_{0}$ e deve muito provavelmente ficar preso num mínimo local, perdendo a solução dada pelo mínimo global.

Se $\tau$ depende de $T_{\text {ind }}$ em um caminho não-linear implicando num grande número de parâmetros para serem ajustados, o procedimento de minimização deve provavelmente ser impraticável sem procedimentos numéricos especiais ou regularização anterior de um funcional de erro tal como o método de Tikhonov, por exemplo.

A fim de controlar este problema de determinação do melhor $\tau_{0}$ e $\lambda$ foi efetuado uma exaustiva pesquisa no intervalo $\left(\tau_{0}, \lambda\right) \in[-10,10] \times[-2,2]$. Cada intervalo foi dividido em $10^{4}+1$ passos, com resultado em aproximadamente $10^{8}$ cálculos da equação (6.5) levando 8 horas em um PC Pentium de $2.76 \mathrm{GHz}$. Uma série de 12 passos de temperaturas testada foi executada e os resultados correspondentes são mostrados na Tabela 6.2. Os valores médios de $\tau_{0}=6.186 \mathrm{~s}$ e $\lambda=-0.148 \mathrm{~s} / \mathrm{K}$ foram subseqüentemente adotados.

Tabela 6. 2: Temperaturas testadas a fim de determinar $\tau_{0}$ e $\lambda$ na equação (6.4)

\begin{tabular}{|cccc|}
\hline $\mathbf{m i n} \mathbf{T}_{\text {proc }}(\mathbf{K})$ & $\mathbf{m a x} \mathbf{T}_{\text {proc }}(\mathbf{K})$ & $\tau_{\mathbf{0}}(\mathbf{s e g})$ & $\lambda(\mathbf{s e g} / \mathbf{K})$ \\
\hline 312.4 & 324.9 & 6.182 & -0.154 \\
310.5 & 322.6 & 6.181 & -0.153 \\
313.3 & 322.9 & 6.175 & -0.141 \\
310.8 & 326.4 & 6.187 & -0.146 \\
311.0 & 325.1 & 6.181 & -0.148 \\
311.6 & 324.7 & 6.190 & -0.151 \\
314.1 & 323.9 & 6.191 & -0.138 \\
311.0 & 325.6 & 6.192 & -0.154 \\
312.4 & 327.0 & 6.185 & -0.152 \\
311.1 & 325.2 & 6.194 & -0.151 \\
310.8 & 326.4 & 6.182 & -0.139 \\
312.1 & 323.8 & 6.187 & -0.153 \\
\hline \multicolumn{5}{c}{ Médias } \\
\hline 311.8 & 324.9 & $\mathbf{6 . 1 8 6}$ & $-\mathbf{0 . 1 4 8}$ \\
\hline
\end{tabular}

Depois de ter determinado a constante de tempo do termopar dependente da temperatura local e o melhor coeficiente de ponderação (hiperbólico), uma série de testes com temperaturas pulsadas foi executado a fim de validar o procedimento de reconstrução em tempo real em condições experimentais similares àquelas encontradas num reator de leito fluidizado. 
Os pulsos de temperaturas foram obtidos injetando rajadas de ar frio no fluxo quente principal. $\mathrm{O}$ sinal de temperatura resultante é então similar àqueles encontrado num escoamento gás-sólidos com bolhas reagente, isto é, oscila entre níveis característicos associados com as regiões mais quentes (emulsão reagente) e mais frias (bolhas de gás inertes) do escoamento.

A preocupação básica é obter uma temperatura do processo reconstruída estatisticamente equivalente a temperatura do processo real dada pelo termopar de referência e, em adição a isto, com o mínimo de atraso possível entre elas. A Figura 6.9 mostra os resultados obtidos nestes testes para diferentes números de temperaturas ajustadas $(m+1)$ num intervalo ideal determinado previamente, Figura 6.4.

A Figura 6.9 está dividida em quatro figuras (a,b,c e d), sendo que cada uma delas corresponde ao número de temperaturas ajustadas: a-) $m+1=3$; b-) $m+1=25$; c-) $m+1=45$ e d-) $m+1=60$. Em cada figura tem-se acima os sinais da temperatura do processo $\left(T_{\text {proc }}\right)$ em azul, da temperatura reconstruída regularizada $\left(T_{\text {reg }}\right)$ em vermelho (calculada da equação (5.13)) e da temperatura indicada $\left(T_{\text {ind }}\right)$ em preto. A temperatura reconstruída ( $\left.T_{\text {rec }}\right)$ obtida pela equação (5.7), isto é, sem regularização, foi omitida para facilitar a identificação dos sinais. Abaixo estão as PDF's das $T_{p r o c}, T_{r e g}$ e $T_{\text {rec }}$ respectivamente à esquerda, centro e direita.

Para cada teste, a semelhança estatística foi avaliada calculando os primeiros quatro momentos (média, desvio padrão, skewness e kurtosis (Anexo A.3)) da função de densidade de probabilidade (PDF) associada e os valores médios correspondentes são dados na Tabela 6.3.

Tabela 6. 3: Momentos estatísticos médios da temperatura de referência e da temperatura reconstruída para diferentes valores de $m+1$ nas equações (5.16) e (5.17)

\begin{tabular}{|c|c|c|c|c|c|}
\hline \multirow{2}{*}{$\begin{array}{c}\text { Momento } \\
\text { estatítico }\end{array}$} & \multirow{2}{*}{$\mathrm{T}_{\text {ref }}$} & \multicolumn{4}{|c|}{$\mathrm{T}_{\text {proc }}$ (equação (5.13)) } \\
\cline { 3 - 6 } & & $\mathrm{m}+1=3$ & $\mathrm{~m}+1=25$ & $\mathrm{~m}+1=45$ & $\mathrm{~m}+1=60$ \\
\hline média $(\mathrm{K})$ & 317.6 & 317.2 & $317.9^{*}$ & 318.6 & 318.3 \\
desvio padrão $(\mathrm{K})$ & 2.126 & 1.881 & 2.307 & $2.213^{*}$ & 2.368 \\
skewness $\left(\mathrm{K}^{3}\right)$ & -12.53 & -3.130 & $-13.08^{*}$ & -14.68 & -17.27 \\
kurtosis $\left(\mathrm{K}^{4}\right)$ & 89.82 & 41.52 & 100.9 & $97.68^{*}$ & 143.3 \\
\hline
\end{tabular}

* melhor resultado 


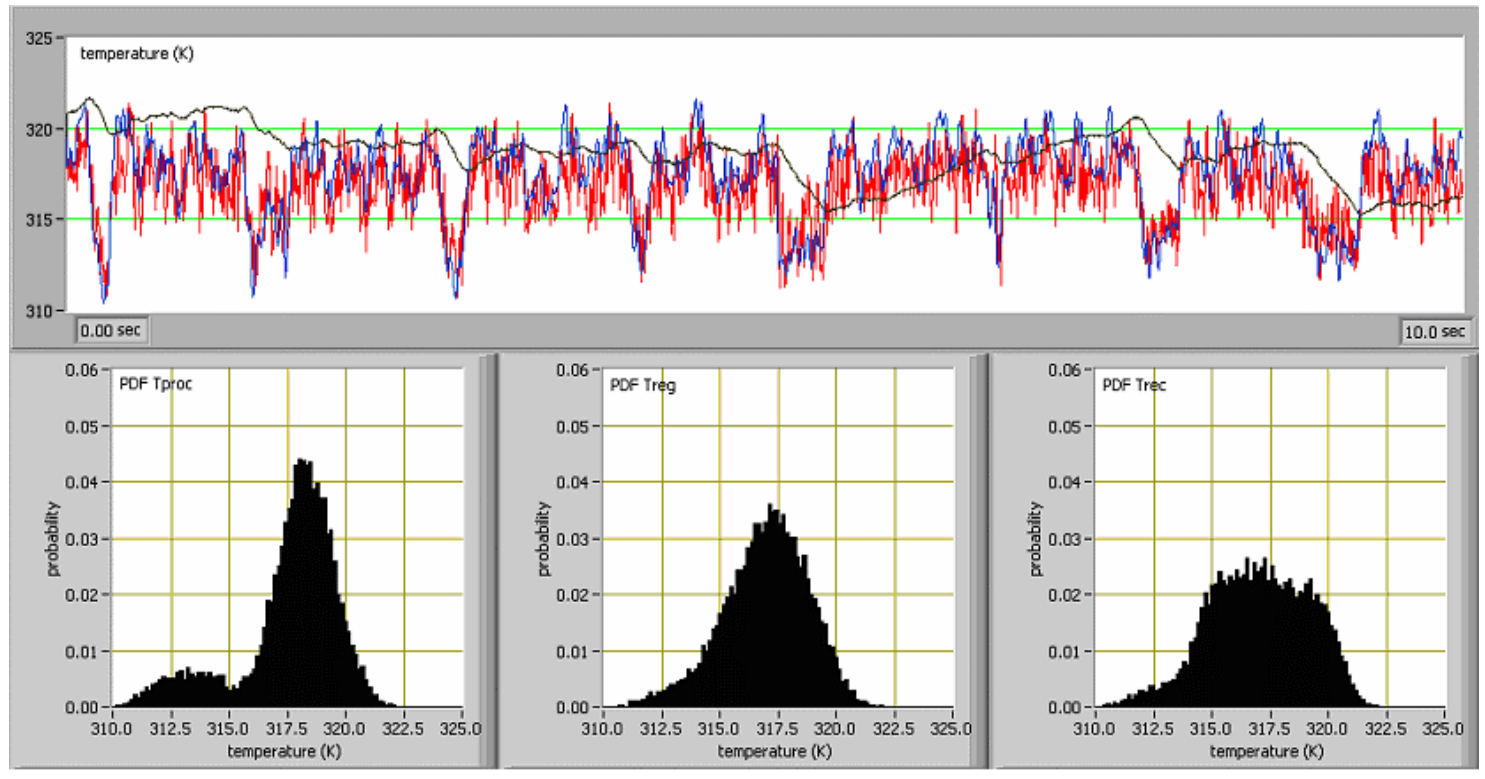

a-) $m+1=3$

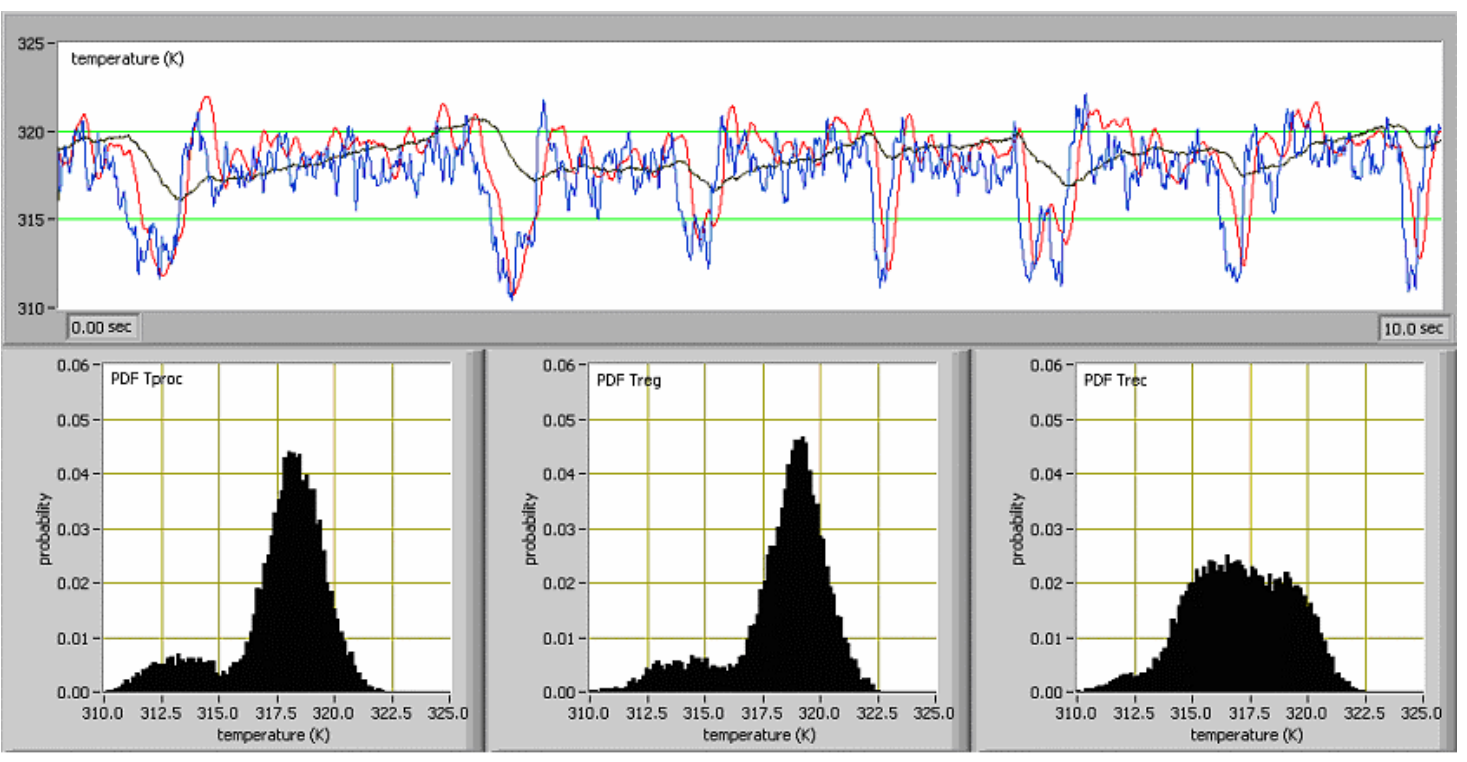

b-) $m+1=25$

Figura 6.9 - continua... 


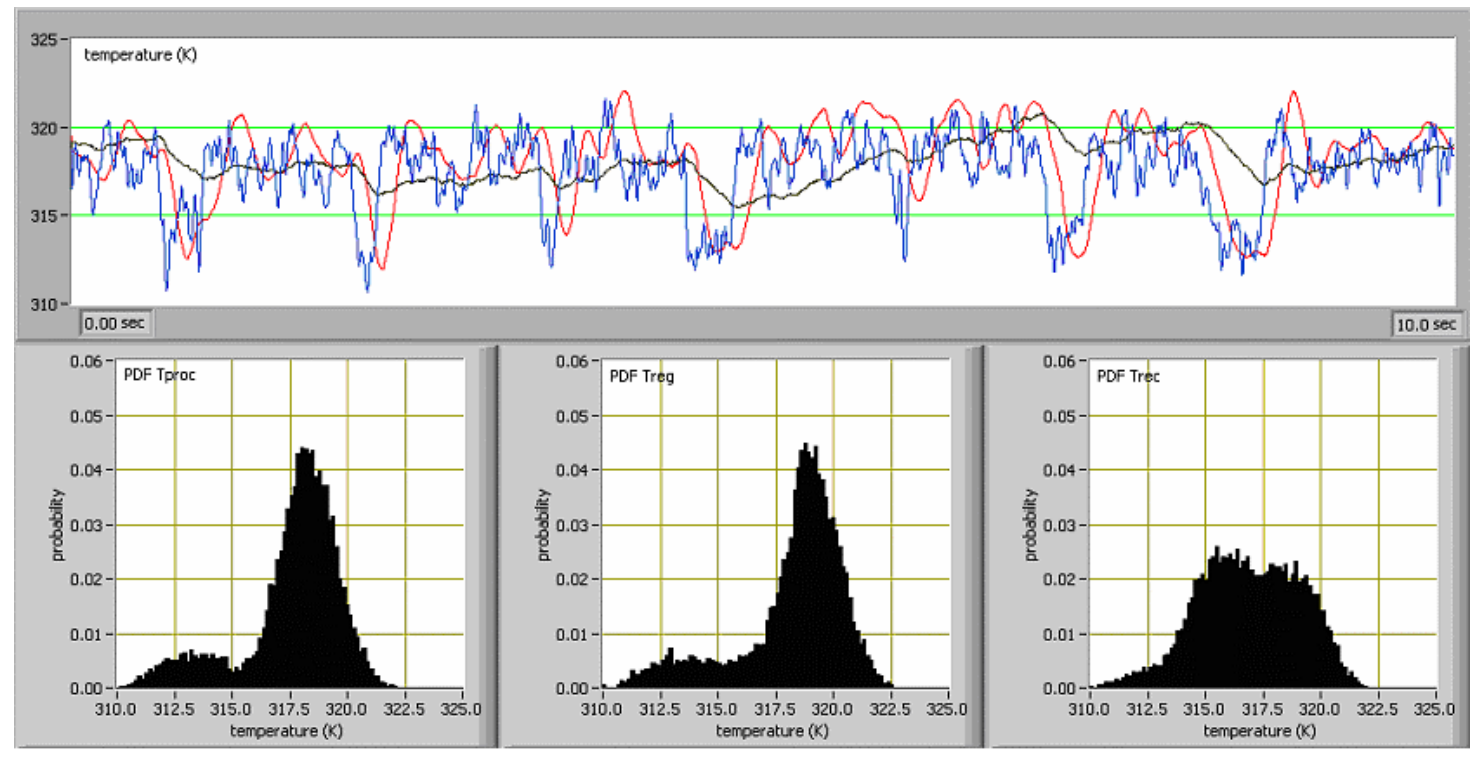

c-) $m+1=45$

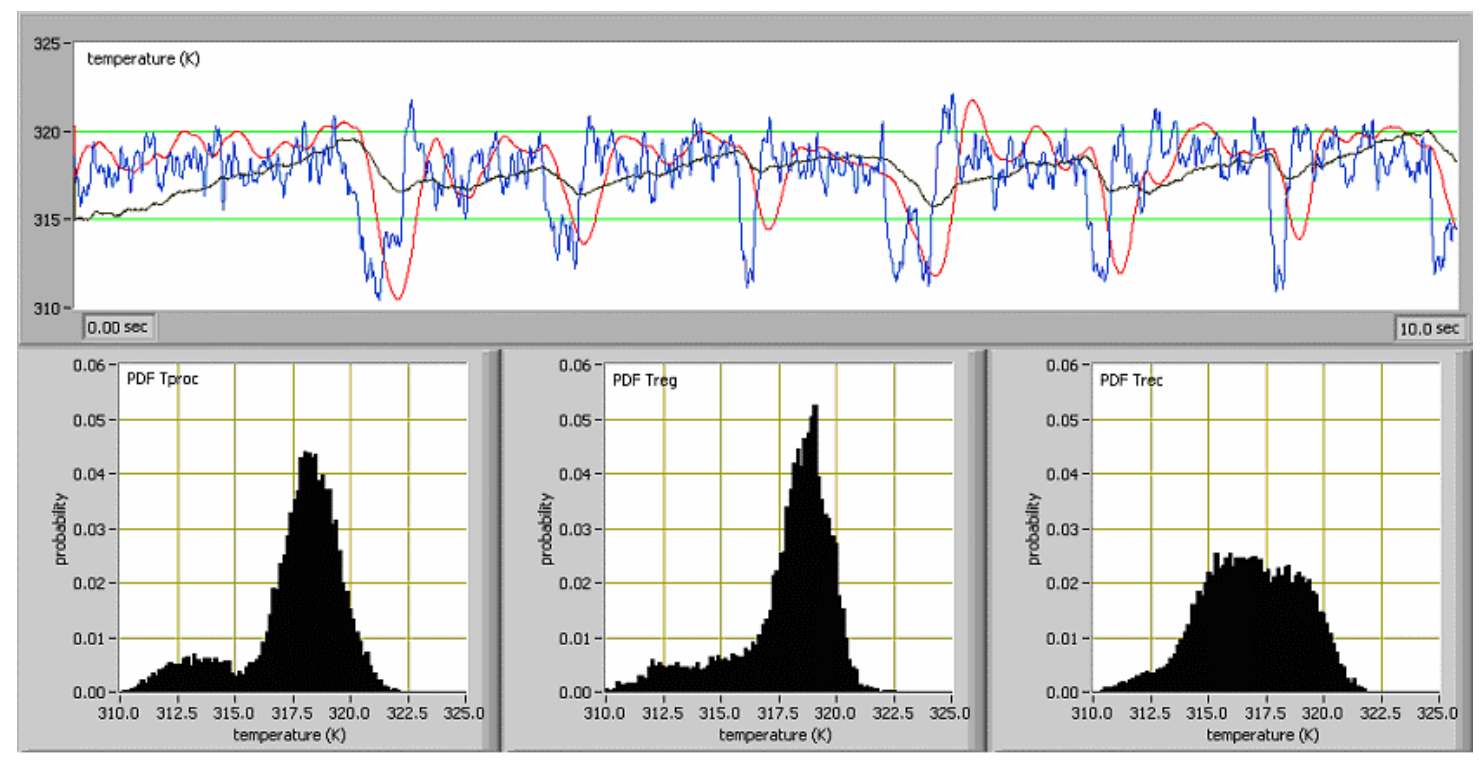

d-) $m+1=60$

Figura 6. 9: Sinais experimentais das temperaturas do processo (azul), indicada (preto) e regularizada (vermelho) para diferentes números de temperaturas ajustadas (a, b, c e d) e PDF's das temperaturas do processo, regularizada e reconstruída (esquerda, centro e direta)

Nas Figuras 6.9 a, b, c e d, a PDF da $T_{\text {rec }}$ não caracteriza a PDF da $T_{p r o c}$. Então, a reconstrução sem regularização prévia não é aconselhável para determinar as características dos níveis de temperatura da PDF. Já a PDF da $T_{\text {reg }}$ se assemelha com a PDF da $T_{p r o c}$. 
Ainda analisando a Figura 6.9, está claro nos sinais, e também pela correlação cruzada do sinal de referência e reconstruído (equação (5.13)), que o atraso entre eles é proporcional a $m+1$ (número de temperaturas ajustadas). Embora $m+1=3$ resulta numa reconstrução aceitável os valores médios e o desvio padrão são interessantes, o ruído em alta frequiência está ainda sendo amplificado e comprometendo significativamente os momentos estatísticos com ordem mais elevadas. Do ponto de vista da aplicação um exemplo seria controlar um processo de pasteurização industrial. Neste caso se o sinal reconstruído está sendo usado para monitorar se a temperatura do processo está dentro dos valores limites, então, $m+1=3$ deve ser uma escolha satisfatória porque as temperatura máximas e mínimas são constantemente determinadas com um atraso menor do que 0.1 segundos.

Resultados melhores são obtidos com $m+1=25$ e 45, como indicado pelo asterisco na Tabela 6.3. Isto pode ser visto nos traços da Figura 6.9, o sinal reconstruído com $m+1=25$ tende superficialmente superar o limite do sinal do processo, enquanto para $m+1=45$ esta tendência é muito menos evidente. Por outro lado, os atrasos correspondentes são de 0.83 e 1.5 segundos, respectivamente.

Finalmente, o sinal reconstruído com $m+1=60$ comporta-se como um filtro passa-baixa do sinal do processo real com um atraso de 2 segundos. Apesar da média e do desvio padrão ainda estarem aceitáveis, skewness e kurtosis mostram grandes desvios dos valores corretos devido a uma assimetria mais forte e picos das PDF's. 


\section{Capítulo 7}

\section{Conclusões e perspectivas}

Este trabalho teve por objetivo principal o desenvolvimento de uma técnica de processamento numérico capaz de reconstruir o sinal da temperatura do processo original a partir do sinal distorcido, atrasado e ruidoso, medido através de uma sonda intrusiva. O algoritmo é baseado num modelo discreto inverso da equação de transdução, seguido por um procedimento de regularização, já que o problema inverso é intrinsecamente mal condicionado.

A técnica de regularização adotada foi o método dos mínimos quadrados simplificado, no qual ajusta por polinômios as últimas poucas temperaturas indicadas e faz a correção da temperatura atual e da derivada temporal pelos valores dos coeficientes do polinômio. Este procedimento é apropriado para uma implementação em tempo real devido ao número reduzido de operações matemáticas associadas.

Testes numéricos demonstraram que o método de regularização adotado é capaz de reconstruir a temperatura do processo a partir do modelo matemático inverso constituído da inércia térmica, convecção e radiação mesmo sob forte influência de ruídos. E permitiram o estudo de importantes parâmetros para a reconstrução da temperatura em tempo real, que são o número de pontos de temperaturas ajustadas e os coeficientes de ponderação adotados, parâmetros estes que atrasam e afetam na semelhança entre a temperatura reconstruída e a temperatura do processo real.

Os teste experimentais foram conduzidos para validar o algoritmo de reconstrução sob condições práticas. Os resultados dos três testes experimentais mostraram uma boa reconstrução da temperatura do processo realizada a partir do sinal obtido por um termopar encapsulado. 
Com o avanço do projeto deu-se maior ênfase ao tratamento estatístico dos resultados, possibilitando melhores comparações entre os sinais real e reconstruído. A semelhança estatística entre os sinais real e reconstruído foi avaliada calculando os primeiros quatro momentos da função de densidade de probabilidade e os valores médios correspondentes.

A determinação da constante de tempo da sonda e do coeficiente de radiação foi determinada pela minimização de um funcional de erro, que consistiu num problema inverso a parte e seus problemas de mau condicionamento é caracterizado por aspectos patológicos associados à superfície de minimização.

Algumas das dificuldades encontradas no transcorrer deste trabalho encontra-se em determinar os parâmetros de regularização, a constante de tempo da sonda e o coeficiente de radiação, no qual os dois últimos parâmetros dependem do coeficiente de convecção. Assim, trabalhos futuros podem incluir:

- $\quad$ estudar mais detalhadamente os parâmetros de regularização: consiste em aplicar diferentes coeficientes de ponderação e assim tentar contornar alguns dos problemas do método dos mínimos quadrados simplificado como, limites excedidos o que são desvantagens em algumas aplicações;

- pesquisar outros procedimentos numéricos: consiste em implementar métodos que tenham características semelhantes ao método dos mínimos quadrados simplificado, ou seja, um método rápido e com código computacional pequeno, que admite a regularização em tempo real, mas que conduza na determinação dos parâmetros de regularização mais facilmente;

- monitorar em tempo real os coeficientes de convecção dos processos industriais: consiste em realizar este monitoramento de duas maneira. A primeira é baseada na medida da temperatura por dois termopares com a mesma geometria externa, mas com diferentes constante de tempo. Cada termopar indica uma temperatura distorcida e atrasada que pode ser reconstruída por um modelo regularizado inverso apropriado. Assumindo que a convecção é aproximadamente análoga em ambos os termopares, o modelo correspondente pode ser usado para calcular o coeficiente de convecção comum. A segunda é baseada em medidas redundantes que consiste na realização de medidas redundantes do coeficiente de convecção e de combiná-las todas juntas em um mesmo funcional de erro convenientemente definido de maneira que a sua minimização leve ao 
coeficiente de convecção comum. O processamento de medidas redundantes reduz os efeitos dos erros experimentais e dos ruídos, pois se admite que os erros e ruídos introduzidos no processo sejam aleatórios, então se espera que a informação degradada em uma medida possa ser restaurada por outras. 


\section{Referência bibliográfica}

BARTELS, R.H.; BEATTY, J.C.; BARSKY, B.A. (1997). An introduction to splines for use in computer graphics and geometric modelling. San Francisco: Morgan Kaufmann.

BENNIA, A.; RIAD, S.M. (1992). Filtering capabilities and convergence of the VanCittert deconvolution technique. IEEE Transactions on Instrumentation and Measurement, New York, v.41, n.2, p.246-250.

BIANCHI, R.A.; SANTOS, F.V.; KARMA, J.M.; COURTOIS, B.; PRESSECQ, F.; SIFFLET, S. (1998). CMOS-compatible smart temperature sensors. Microeletronics Journal, London, v.29, n.9, p.627-636, Sept.

BOKAR, J.C.; ÖZISIK, M.N. (1995). An inverse analysis for estimating the timevarying inlet temperature in laminar flow inside a parallel plate duct. International Journal of Heat and Mass Transfer, London, v.38, n.1, p.39-45, Jan.

BROMBA, M.U.A.; ZIEGLER, H. (1981). Application hints for savitzky-golay digital smoothing filters. Analytical Chemistry, Washington, v.53, n.11, p.1583-1586, Feb.

CAMPOS VELHO, H.F. (2001). Problemas inversos: conceitos básicos e aplicações, mini-curso. 17p. In: ENCONTRO DE MODELAGEM COMPUTACIONAL, 4., 12-14 Nov, Nova Friburgo.

CARTELLIER, A.; ACHARD, J.L. (1991). Local phase detection probes in fluid/fluid two-phase flows. Review of Scientific Instruments, Rochester, v.62, n.2, p.279-303, Feb. 
CHALHOUB, E.S.; CAMPOS VELHO, H.F. (2002). Estimation of internal sources in natural waters using remote sensing data. In: INTERNATIONAL CONFERENCE ON INVERSE PROBLEMS IN ENGINEERING, 4., 26-31 May, Rio de Janeiro, 1 CDROM.

CHEN, B.S.; YANG, T.Y. (1992). Design of optimal digital differentiator using algebric methods. Signal Processing, Amsterdam, v.28, n.2, p.213-223, Aug.

CHEN, R.C.; KADAMBI, J.R. (1995). Discrimination between solid and liquid velocities in slurry flow using laser Doppler velocimeter, Powder Tecnology, Lausanne, v. 85 , n. 2 , p. $127-134$, Nov.

DOICU, A.; SCHREIER, F.; HESS, M. (2004). Interative regularization methods for atmospheric remote sensing. Journal of quantitative Spectroscopy and Radiative Transfer, New York, v.83, n.1, p.47-61, Jan.

DOLENKO, S.A.; FILIPPOV, A.V.; PAL, A.F.; PERSIANTSEV, I.G.; SEROV, A.O. (2003). Use of neural network based auto-associative memory as a data compressor for pre-processing optical emission spectra in gas thermometry with the help of neural network. Nuclear Instruments and Methods in Physics Research, section A, Amsterdam, v.502, n.213, p.523-525, Apr.

ESSADKI, H.; NIKOV, I.; DELMAS, H. (1997). Electrochemical probe for bubble size prediction in a bubble column. Experimental Thermal and Fluid Science, New York, v.14, n.3, p.243-250, Apr.

FAN, L.S. (1996). Summary paper on fluidization and transport phenomena. Powder Technology, Lausanne, v.88, n.3, p.245-253, Sept.

FORTUNA, A.O. (2000). Técnicas computacionais para dinâmica dos fluidos. São Paulo: EDUSP. p.73-80.

GABOR, D. (1946). Theory of communication. Journal of IEE, part III, London, p.429-457. 
GARCÍA-GUZMÁN J.; ULIVIERI, N.; COLE, M.; GARDNER, J.W. (2003). Design and simulation of a smart ratiometric ASIC chip for VOC monitoring. Sensor and Actuators B: Chemical, Lausanne, v.95, n.1-3, p.232-243, Oct.

GRASSLER, T.; WIRTH, K.E. (2000). X-ray computer tomography - potential and limitation for the measurement of local solids distribution in circulating fluidized beds, Chemical Engineering Journal, Lausanne, vol. 77, n. 1-2, p.65-72, Apr.

GROSSMAN, A.; MORLET, J.; PAUL, T. (1985). Transform associated to square integrable group representations I: general results. Journal of Mathematical Physics, New York, v.26, n.10, p.2473-2479, Oct.

HOGSETT, S.; ISHII, M. (1997). Local two-phase flow measurements using sensor techniques. Nuclear Engineering and Design, Amsterdam, v.175, n.1/2, p.15-24, Nov.

HONG, M.; CARTELLIER, A.; HOPFINGER, E.J. (2004). Characterization of phase detection optical probes for the measurement of the dispersed phase parameters in sprays. International Journal of Multiphase Flow, Oxford, v.30, n.6, p.615-648, June.

HUANG, C.H.; YUAN, I.C.; AY, H. (2003). A three-dimensional inverse problem in imaging the local heat transfer coefficients for plate finned-tube heat exchangers. International Journal of Heat and Mass Transfer, London, v.46, n.19, p.3629-3638, Sept.

JANICKI, M.; ZUBERT, M.; NAPIERALSKI, A. (1999). Application of inverse problem algorithms for integrated circuit temperature estimation. Microelectronics Journal, Luton, v.30, n.12, p.1099-1107, Dec.

JOHNSSON, H.; JOHNSSON, F. (2001). Measurements of local solids volumefraction in fluidized bed boilers. Powder Technology, Lausanne, v.115, n.1, p.13-26, Mar. 
JOSHI, J.B.; VITANKAR, V.S.; KULKARNI, A.A.; DHOTRE, M.T.; EKAMBARA, K. (2002). Coherent flow structures in bubble column reactors. Chemical Engineering Science, London, v.57, n.17, p.3157-3183, Sept.

KANTARCI, N.; BORAK, F.; ULGEN, K.O. (2005). Bubble column reactors. Process Biochemistry, Oxford, v.40, n.7, p.2263-2283, June.

KATAOKA, I.; ISHII, M.; SERIZAWA, A. (1994). Sensitivity analysis of bubble size and probe geometry on the measurements of interfacial area concentration in gas-liquid two-phase flow. Nuclear Engineering and Design, Amsterdam, v.146, n.1/3, p.53-70, Feb.

KIM, M.C.; KIM, S.; LEE, H.J.; LEE, Y.J.; KIM K.Y. (2002). An experimental study of electrical impedance tomography for the two-phase flow visualization, International Communications In Heat And Mass Transfer, New York, v. 29, n. 2, p.193-202, Feb.

LAGIER, G.L.; LEMONNIER, H.; COUTRIS, N. (2004). A numerical solution of the linear multidimensional unsteady inverse heat conduction problem with the boundary element and the singular value decomposition. International Journal of Thermal Sciences, Paris, v.43, n.2, p.145-155, Feb.

LEBLOND, J.; JAVELOT; LEBRUN, D.; LEBON, L. (1998). Two-phase flow characterization by nuclear magnetic resonance, Nuclear Engineering and Design, Amsterdam, v. 184, n. 2-3, p. 229-237, Aug.

LOUIS, A.K.; MAAB, P.; RIEDER, R. (1997). Wavelets: theory and applications. Chichester; New York: John Wiley.

LUO, J.; YING, K.; BAI, J. (2005). Savitzky-Golay smoothing and differentiation filter for even number data. Signal Processing, Amsterdam, v.85, n.7, p.1429-1434, July. 
MALINEN, M.; HUTTUNEN, T.; KAIPIO, J.P. (2002). Optimal control for the ultrasound induced heating of a tumor. In: INTERNATIONAL CONFERENCE ON INVERSE PROBLEMS IN ENGINEERING, 4., 26-31 May, Rio de Janeiro, 1 CDROM.

MARCHAND, P.; MARMET, L. (1983). Binomial smoothing filter: a way to avoid some pitfalls of least-squares polynomial smoothing. Review of Scientific Instruments, Rochester, v.54, n.8, p.1034-1041, Aug.

MARTINS, R.C.; SILVA, C.L.M. (2004). Inverse problem methodology for thermalphysical properties estimation of frozen green bean. Journal of Food Engineering, London, v.63, n.4, p.383-392, Aug.

MCLLROY, S.J.; EVANS, N.E. (1994). An encoding telemeter for climatic temperature monitoring using a single chip microcontroller. Microprocessors and Microsystems, Guildford, v.18, n.8, p.473-479, Oct.

MEIJER, G.C.M. (1994). Concepts and focus point for intelligent sensor systems. Sensors and Actuators A: Physical, Lausanne, v.41-42, n.1-3, p.183-191, Apr.

MEIJER, G.C.M.; KERKVLIET, H.M.M.; TOTH, F.N. (1994). Non-invasive detection of micro-organisms using smart temperature sensors. Sensors and Actuators B: Chemical, Lausanne, v.18-19, n.1-3, p.276-281, Mar.

MEJÍA, C.E.; MURIO, D.A. (1996). Numerical solution of generalized IHCP by discrete mollification. Computers and Mathematics With Applications, Oxford, v.32, n.2, p.33-50, July.

METCALFE, A.V. (1994). Statistics in engineering: a practical approach. London: Chapman \& Hall. p.75-78; p.389.

MILLER, N.; MITCHIE, R.E. (1970). Measurement of local voidage in liquid/gas two phase flow systems using a universal probe. Journal of the British Nuclear Energy Society, London, v.2, p.94-100. 
MORLET, J.; ARENS, G.; FOURGEAU, E.; GIARD, D. (1982). Wave propagation and sampling theory - part II: sampling theory and complex waves. Geophysics, Houston, v.47, n.2, p.222-236, Feb.

NATIONAL INSTRUMENTS (2005). Disponível em <http://www.ni.com/labview/>. Acesso em: 24 May.

PALACIO, C.; PASCUAL, C.; SUAREZ, F.; LLORET, I. (2002). Smoothing of digital spectroscopic data by using a Chebyshev filter. Vacuum, London, v.64, n.3-4, p.481485, Jan.

PAPOULIS, A. (1965). Probability, random variables, and stochastic processes. New York: McGraw-Hill. p.94.

PERRY, R.H.; CHILTON, C.H. (1980). Manual de engenharia química. 5.ed. Rio de Janeiro: Guanabara Dois.

PRESS, W.H.; TEUKOLSKY, S.A.; VETTERLING, W.T.; FLANNERY, B.P. (1992). Numerical recipes in $C$ : the art of scientific computing. $2^{\text {nd }}$ ed. Cambridge: Cambridge University Press.

PROCTOR, A.; SHERWOOD, P.M.A. (1980). Smoothing of digital X-ray photoelectron spectra by an extended sliding least-squares approach. Analytical Chemistry, Washington, v.52, n.14, p.2315-2321, Dec.

REIS, A.M. (1999). Desenvolvimento de técnica de medição de temperatura e velocidade com termopares em escoamentos turbulentos de baixa freqüência. 134p. Tese (Doutorado) - Escola Politécnica, Universidade de São Paulo, São Paulo, 1999.

RIAD, S.M. (1986). The deconvolution problem: an overview. Proceedings of the IEEE, New York, v.74, n.1, p.82-85, Jan.

ROCO, M.C. (1996). Multiphase flow: summary paper. Powder Technology, Lausanne, v.88, n.3, p.275-284, Sept. 
ROLNIK, V.P. (2003). Contribuição ao desenvolvimento de uma nova técnica de reconstrução tomográfica para sondas de visualização direta. 128p. Tese (Doutorado) - Escola de Engenharia de São Carlos, Universidade de São Paulo, São Carlos, 2003.

ROLNIK, V.P.; SELEGHIM JR., P. (2002). On-site calibration of a phase fraction meter by an inverse technique. Journal of the Brazilian Society of Mechanical Sciences, Rio de Janeiro, v.24, n.4, p.266-270, nov.

SAVITZKY, A.; GOLAY, M.J.E. (1964). Smoothing and differentiation of data by simplified least square procedures. Analytical Chemistry, Washington, v.36, n.8, p.1627-1639, July.

SCHÄFER, R.; MERTEN, C.; EIGENBERGER, G. (2002). Bubble size distributions in a bubble column reactor under industrial conditions. Experimental Thermal and Fluid Science, New York, v.26, n.6/7, p.595-604, Aug.

SELEGHIM JR,. P. (1992). Caracterisation des changements de configuration d'un ecoulement diphasique horizontal par l'application de methods d'analyse tempsfrequence. Thèse - Institut National Polytechnique de Grenoble, Grenoble, 1992. p.6373

SELEGHIM JR., P. (1993). Analyse temps-fréquence appliquée aux ecoulements diphasiques. Mémoire de DEA - Institut National Polytechnique de Grenoble, Grenoble, 1993. p.28-31.

SELEGHIM JR., P. (2002). Criação de uma linha de pesquisa em instrumentação e controle de escoamentos multifásicos industriais. 130p. Tese (Livre-docência) - Escola de Engenharia de São Carlos, Universidade de São Paulo, São Carlos, 2002.

SELEGHIM JR., P.; MILIOLI, F.E. (2001). Improving the determination of bubble size histograms by wavelet de-noising techniques. Powder Technology, Lausanne, v.115, n.2, p.114-123, Apr. 
SGURA, I.; BOZZINI, B. (2005). Numerical issues related to the modelling of electrochemical impedance data by non-linear least-squares. International Journal of Non-Linear Mechanics, New York, v.40, n.4, p.557-570, May.

SHARMA, M.D. (2002). Group velocity along general direction in a general anisotropic medium. International Journal of Solids an Structures, New York, v.39, n.12, p.3277-3288, June.

SILVA NETO, A.J.; MOURA NETO, F.D. (2000). Problemas inversos em engenharia. In: CONGRESSO BRASILEIRO DE ENGENHARIA E CIÊNCIAS TÉRMICAS, 8., 2000, Porto Alegre. MERCOFRIO 2000 [recurso eletrônico]... Porto Alegre: UFRGS. 1 CD-ROM.

SILVA NETO, A.J.; ÖZISIK, M.N. (1995). An inverse problem of simultaneous estimation of radiation phase function, albedo and optical thickness. Journal of Quantitative Spectroscopy and Radiative Transfer, New York, v.53, n.4, p.397-409 Apr.

TERMOPARES (2005). Disponível em <http://www.iope.com.br/index_port.htm>. Acesso em: 09 May.

TESSLER, A.; SPANGLER, J.L. (2005). A least-squares variational method for fullfield reconstruction of elastic deformations in shear-deformable plates and shells. Computer Methods in Applied Mechanics and Engineering, Amsterdam, v.194, n.2/5, p.327-339, Feb.

TILLWICK, J.; UHLENWINKEL, V.; BAUCKHAGE, K. (1999). Analysis of the spray forming process using backscattering phase-Doppler anemometry, International Journal of Heat and Fluid Flow, Guildford, v. 20, n.5, p.530-537, Oct.

TIKHONOV, A.N.; ARSENIN, V.Y. (1977). Solutions of ill-posed problems. Washington; New York, Winston. 
VAN LARE, C.E.J.; PIEPERS, H.W.; SCHOONDERBEEK, J.N.; THOENES, D. (1997). Investigation on bubble characteristics in a gas fluidized bed. Chemical Enginnering Science, London, v.52, n.5, p.829-841, Mar.

VILLE, J. (1948). Théorie et applications de la notion de signal analytique. Cables et Transmission, Paris, v.2a, n.1, p.61-74.

VINCE, M.; MOREIRA, S.H.; LAHEY JR., R.T. (1980). Derivative signal thresholding for a local void impedance probe. American Nuclear Society Transactions, New york, v.34, p.872-873.

WANG, J.; ZABARAS, N. (2004). A Bayesian inference approach to the inverse heat conduction problem. International Journal of Heat and Mass Transfer, London, v.47, n.17/18, p.3927-3941, Aug.

WEISSTEIN, E.W. (2005a). Cubic spline, from MathWorld--a wolfram web resource. Disponível em:<http://mathworld.wolfram.com/CubicSpline.html>. Acesso em: 17 May.

WEISSTEIN, E.W. (2005b). Finite difference, from MathWorld--a wolfram web resource. Disponível em:<http://mathworld.wolfram.com/FiniteDifference.html $>$. Acesso em: 15 June.

ZIEGLER, H. (1981). Properties of digital smoothing polynomial (DISPO) filters. Aplied Spectroscopy, Bound Brook, v.35, n.1, p.88- 92.

ZUN, I.; FILIPIC, B.; PERPAR, M.; BOMBAC, A. (1995). Phase discrimination in void fraction measurement via genetic algorithms. Review of Scientific Instruments, Rochester, v.66, n.10, p.5055-5064, Oct. 


\section{Apêndice A - Termopar inteligente}

Um teste final foi conduzido substituindo o sistema de aquisição e o microcomputado por um hardware dedicado (PIC 18F252) e a eletrônica associada ao sinal condicionado. Todo o processo de reconstrução e parâmetros relevantes, tais como a constante de tempo dependente da temperatura indicada dada pela equação (6.4) ou os coeficientes de ponderação, por exemplo, foram programados em menos de três Kbytes.

O sensor de temperatura inteligente teve o código desenvolvido pelo Engenheiro Jorge Nicolau dos Santos, técnico do Núcleo de Engenharia Térmica e Fluidos da Escola de Engenharia de São Carlos da Universidade de São Paulo (NETeF-EESCUSP). A implementação foi realizada em ANSI C, a Figura A.1 mostra o diagrama esquemático correspondente e a Figura A.2 é a foto da montagem do termopar inteligente no protoboard.

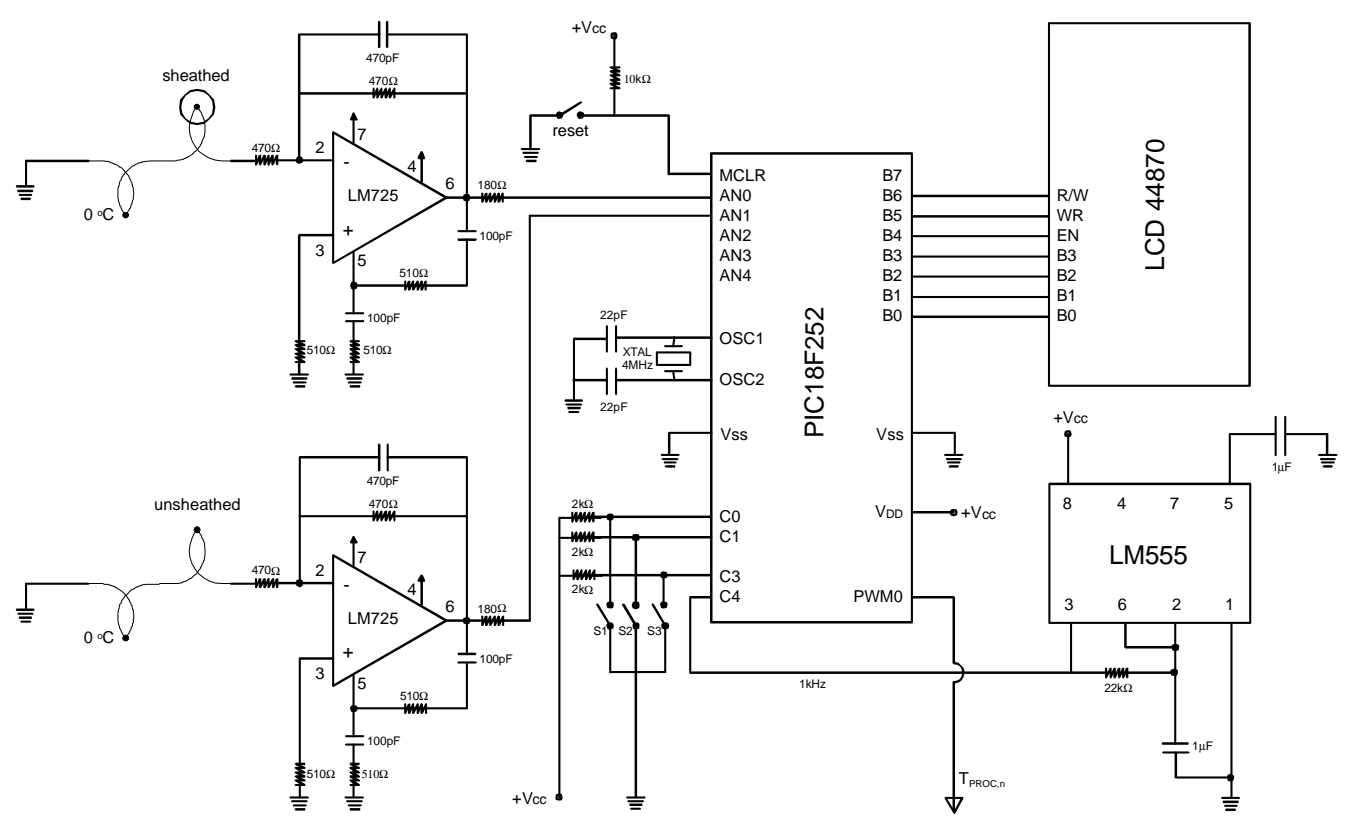

Figura A. 1: Hardware dedicado (PIC 18F252) e a eletrônica associada ao sinal condicionado 


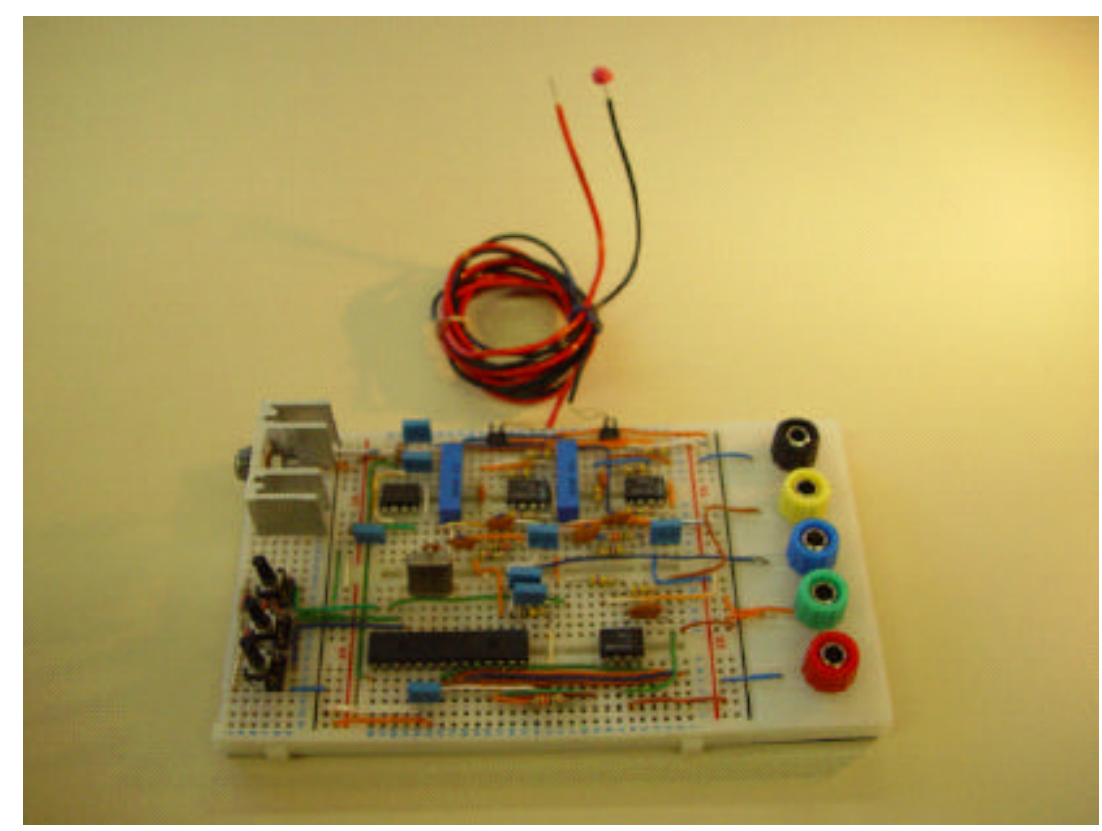

Figura A. 2: Foto da montagem do termopar inteligente no protoboard

Os resultados obtidos pelo termopar inteligente foram essencialmente equivalentes aqueles já mencionados, exceto pelo aumento do nível de ruído, muito provavelmente devido à interferência da parte digital do circuito nos termopares. 


\section{Apêndice B - LabVIEW}

LabView é uma linguagem de programação da National Instruments (NATIONAL INSTRUMENTS 2005) para aquisição, análise e apresentação de dados.

A programação no LabVIEW é feita através de ícones ao invés de linhas de texto para criar aplicações. Em comparação com as linguagens de programação textuais, onde as instruções determinam o programa de execução, o LabVIEW usa programação em fluxogramas, onde o fluxo de dados determina a execução.

No LabVIEW faz-se a interface do usuário, painel frontal, com um conjunto de ferramentas e objetos. Então o usuário adiciona o código, diagrama de blocos, usando representações gráficas de funções para controlar os objetos do painel frontal. $\mathrm{O}$ software permite o desenvolvimento de novas funções gráficas com aplicações específicas que se integram perfeitamente às outras funções e arquivos.

Os programas do LabVIEW são chamados de instrumentos virtuais, ou VIs, porque aparecem e operam imitando instrumentos físicos, tal como osciloscópios e multímetros. Toda VI usa funções que manipulam a entrada dos dados pela interface do usuário ou arquivos e apresentam os resultados no painel frontal ou movem para outros arquivos ou outros computadores.

Neste projeto o software LabVIEW foi usado para a reconstrução dos sinais, simulação e aquisição dos dados. Segue abaixo a listagem completa dos programas implementados.

Primeiramente, tem-se a listagem do programa de aquisição de dados. Na Figura B.1 é apresentado o painel frontal e na Figura B.2 o diagrama de bloco correspondente. 


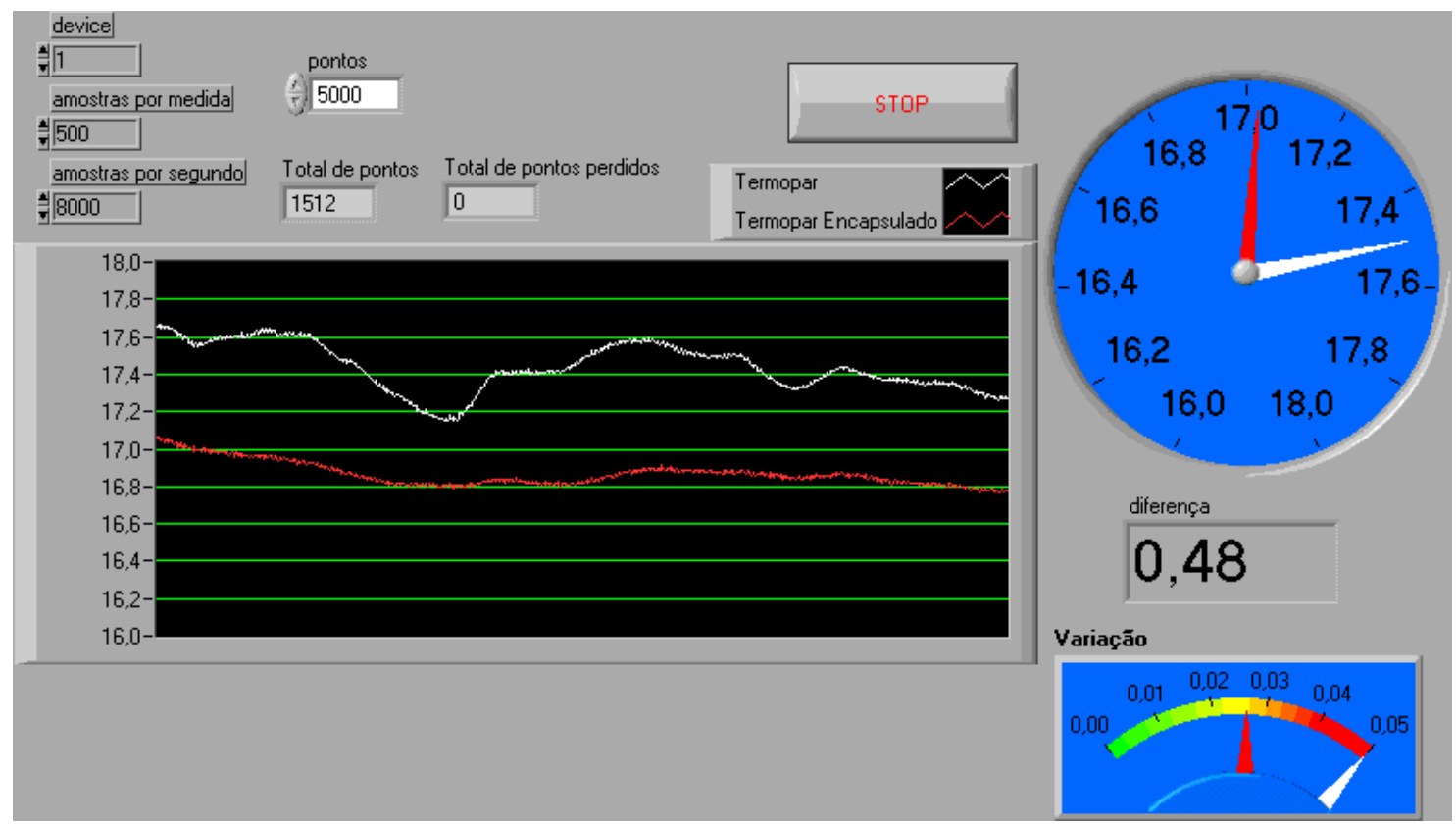

Figura B. 1: Painel frontal do programa de aquisição de dados

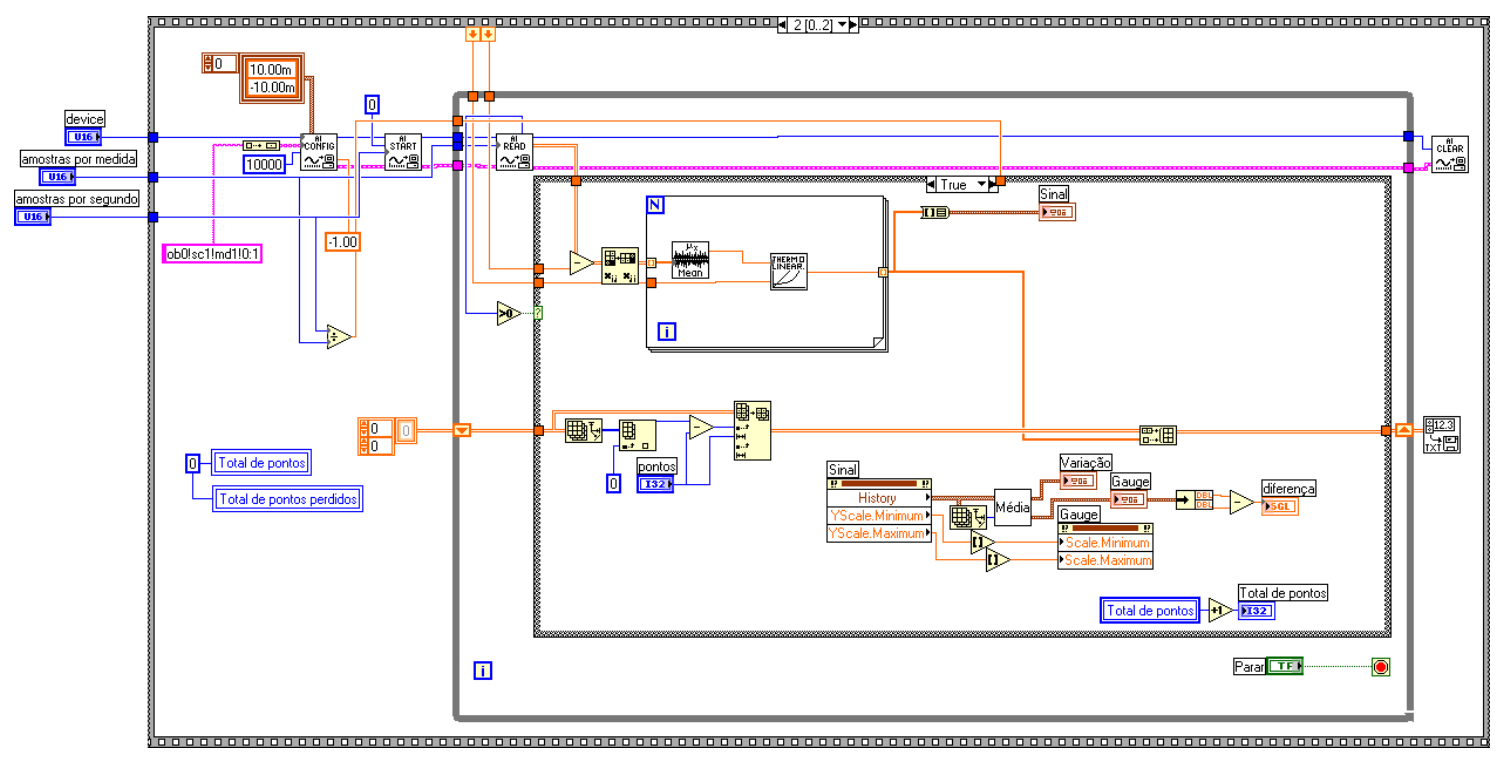

Figura B. 2: Diagrama de bloco do programa de aquisição de dados

A seguir está a listagem do programa de reconstrução dos sinais e simulação. $\mathrm{O}$ painel frontal e o diagrama de bloco correspondente estão representados na Figura B.3 e Figura B.4, respectivamente. 


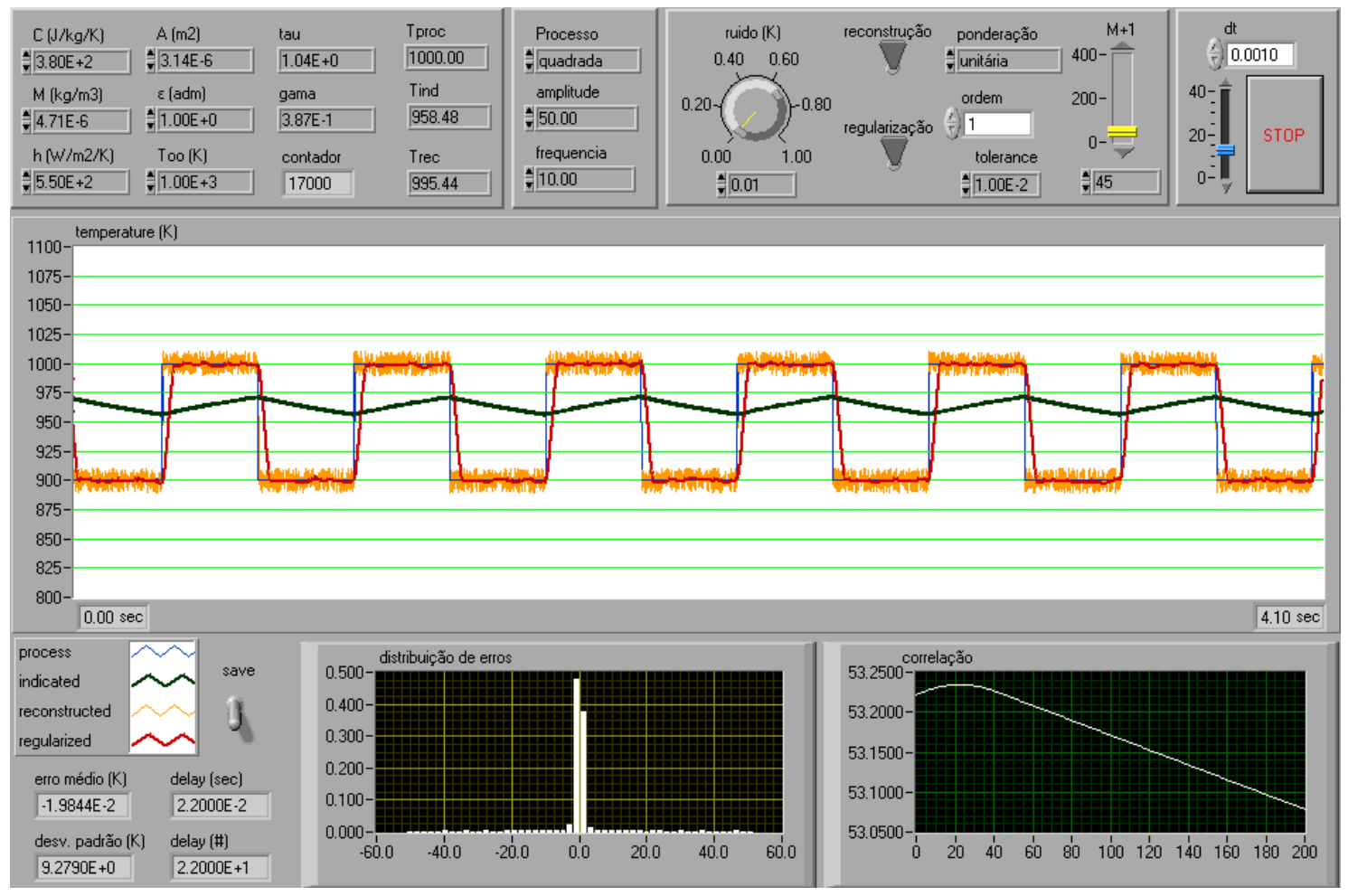

Figura B. 3: Painel frontal do programa de reconstrução dos sinais e simulação

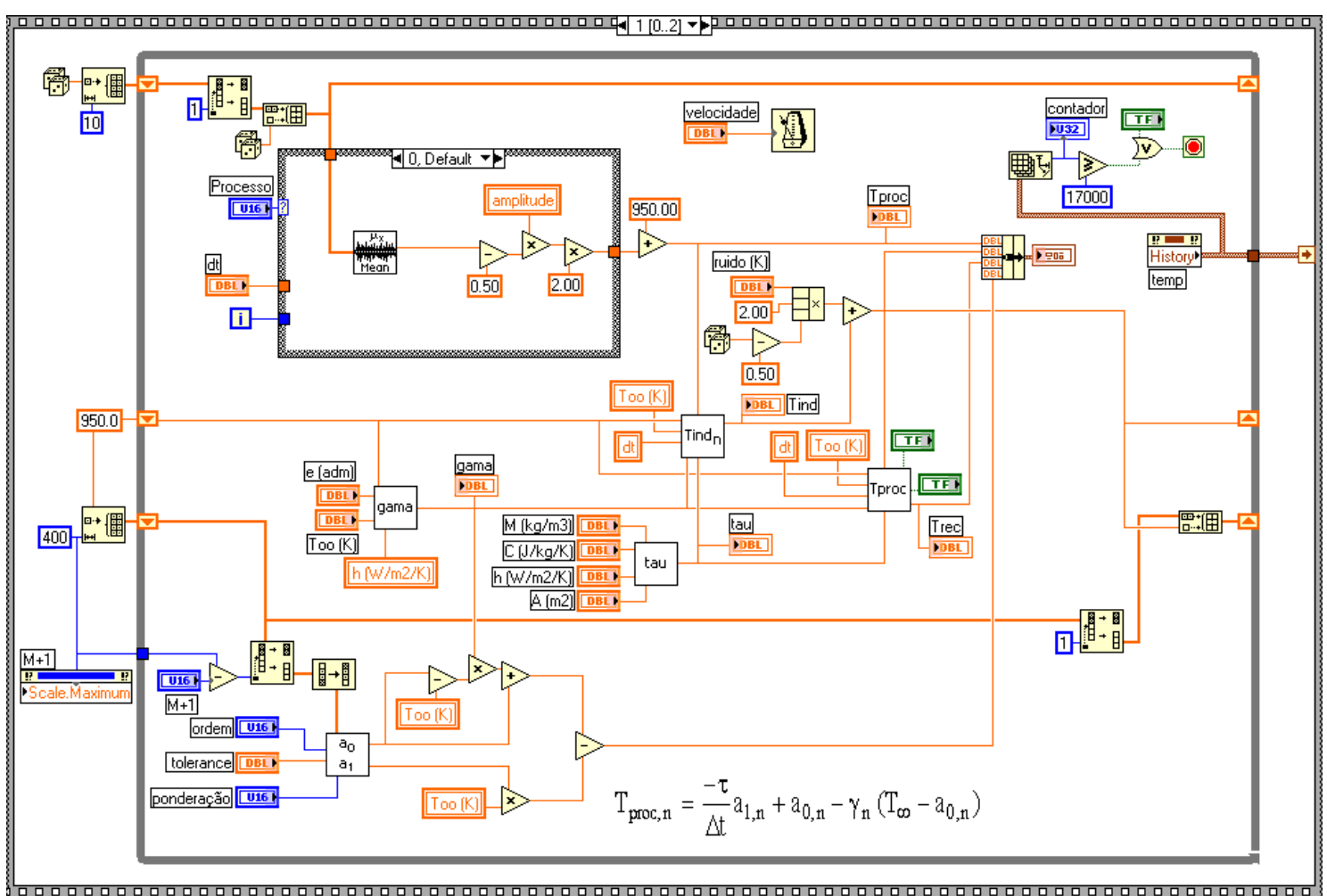

Figura B. 4: Diagrama de bloco do programa de reconstrução dos sinais e simulação 
As subVIs do programa de reconstrução dos sinais e simulação são: "gama", "tau", " $a_{0}$ e a ", "Tind" e "Tproc".

Nas subVIs "gama", "tau", "Tind ${ }_{n}$ e "Tproc ${ }_{n}$ " são calculados $\gamma$ da equação (5.4), $\tau$ da equação (5.3), $T_{\text {ind }}$ da equação (5.6) e $T_{p r o c}$ (temperatura reconstruída) da equação (5.7), respectivamente. Abaixo estão os respectivos diagramas de bloco nas Figuras B.5, B.6, B.7 e B.8.

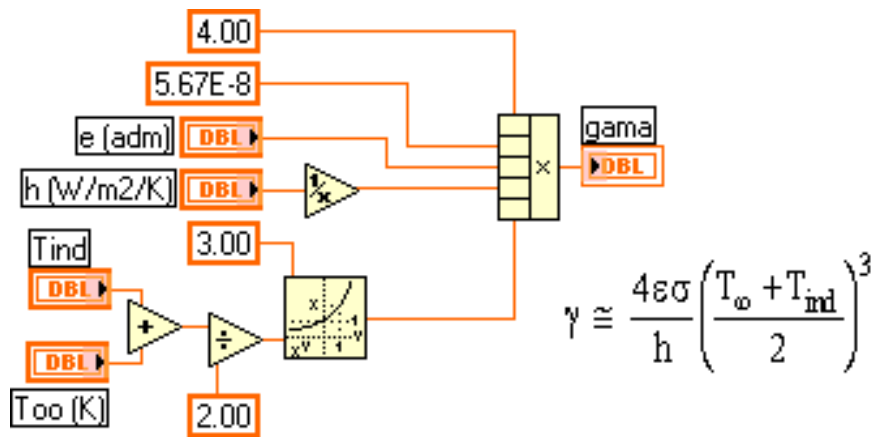

Figura B. 5: Diagrama de bloco da subVI "gama"

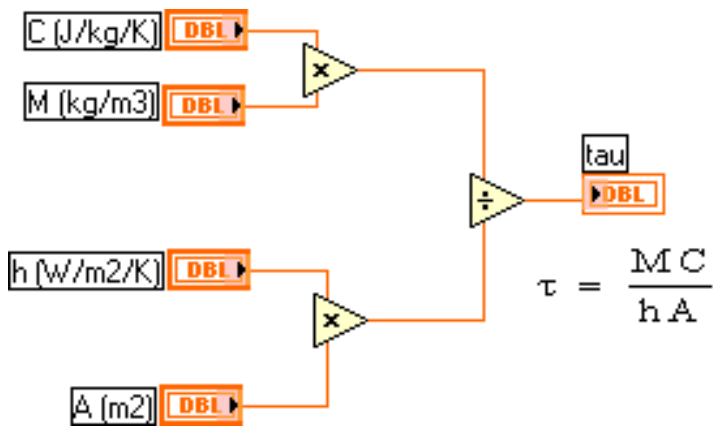

Figura B. 6: Diagrama de bloco da subVI "tau" 


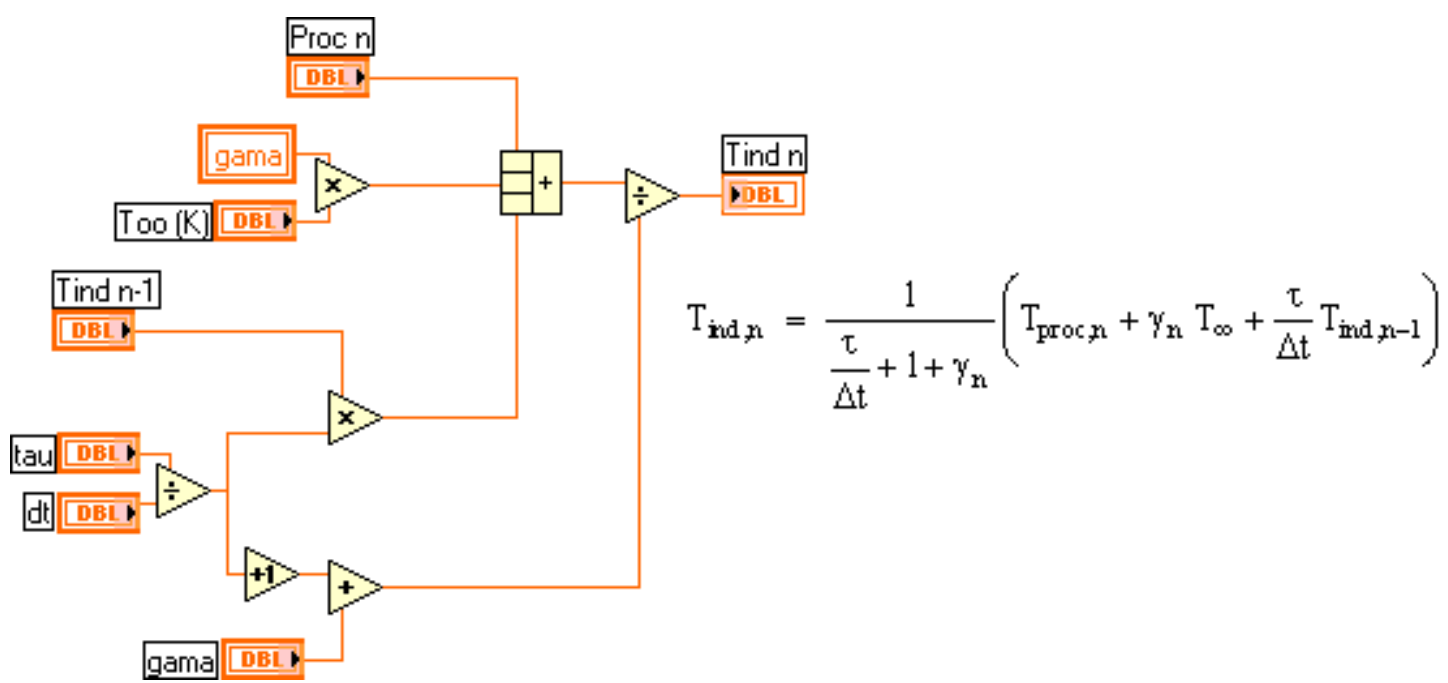

Figura B. 7: Diagrama de bloco da subVI "Tind,"

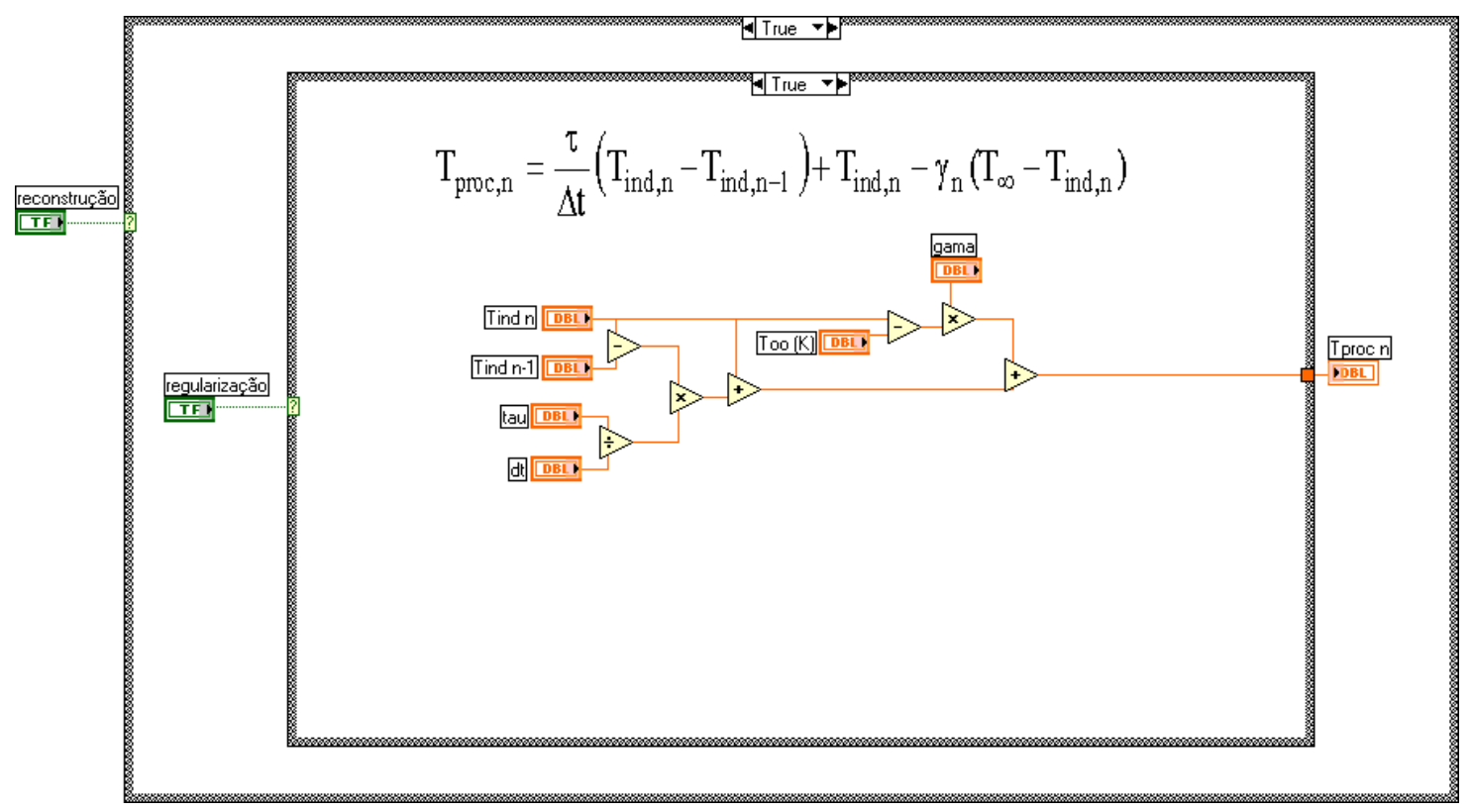

Figura B. 8: Diagrama de bloco da subVI "Tproc "

E por fim, o diagrama de bloco da subVI " $a_{0} e a_{l}$ " onde são calculados $a_{0} \mathrm{e}$ $a_{1}$ das equações (5.16) e (5.17) e conseqüentemente a temperatura reconstruída regularizada, Figura B.9. A subVI " $a_{0} e$ e $a_{l}$ " possui duas subVIs, " $G^{-1}$ " e "gera vet $b$ " (Figuras B.10 e B.11, respectivamente), onde são calculados a inversa da matriz de Gram (equação (5.10)) e o vetor independente do sistema. 


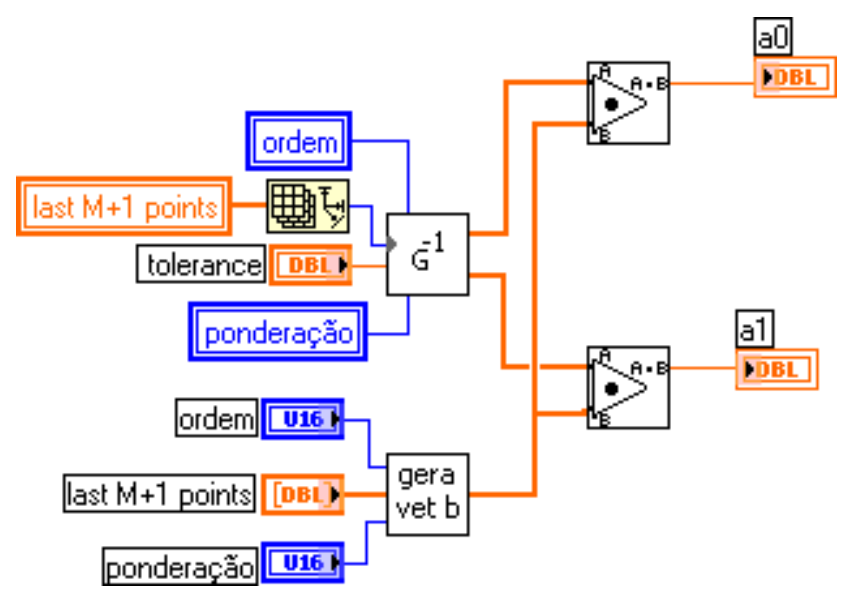

Figura B. 9: Diagrama de bloco da subVI " $a_{0} e a_{l}$ "

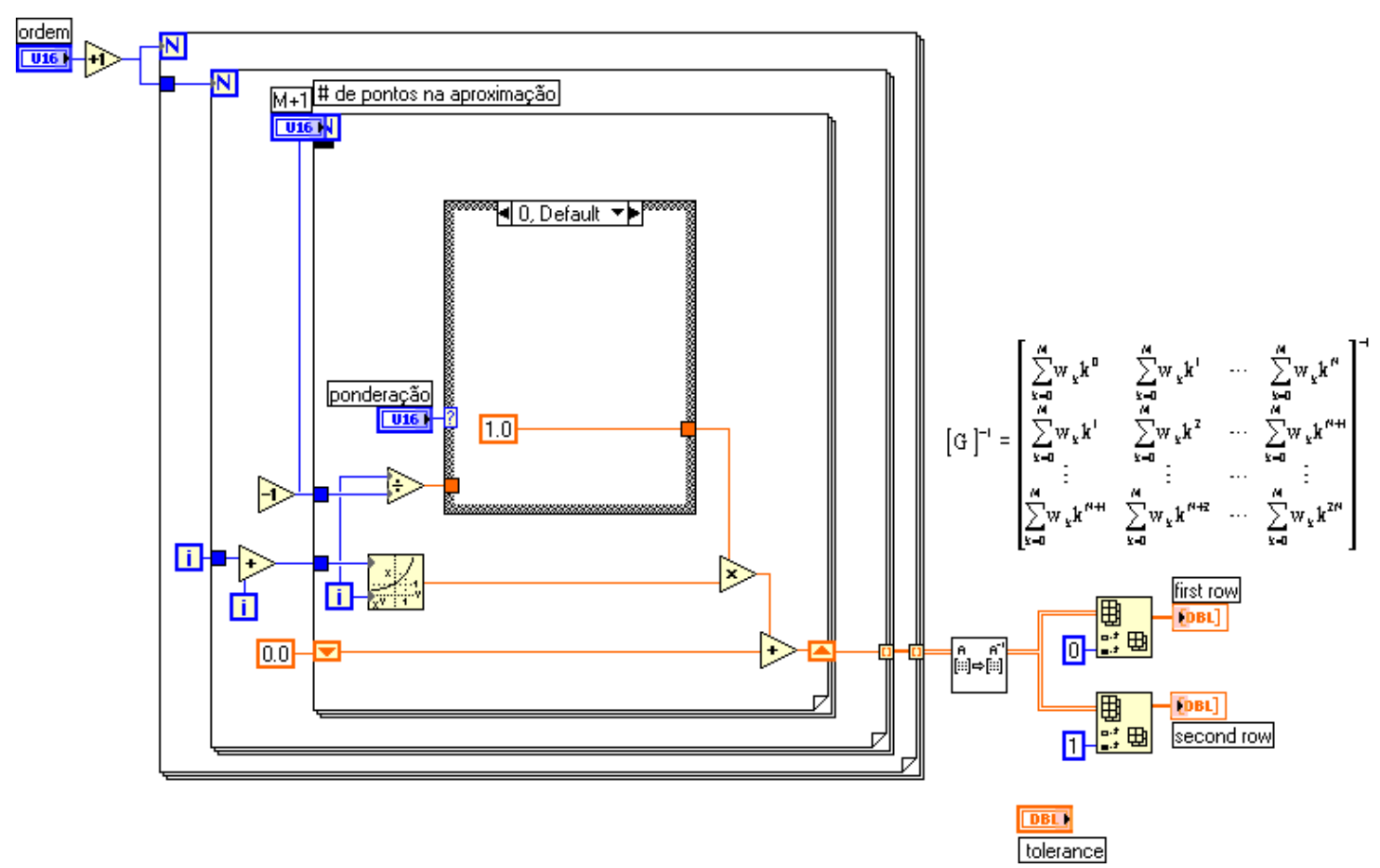

Figura B. 10: Diagrama de bloco da subVI " $G^{-1}$ ”, 


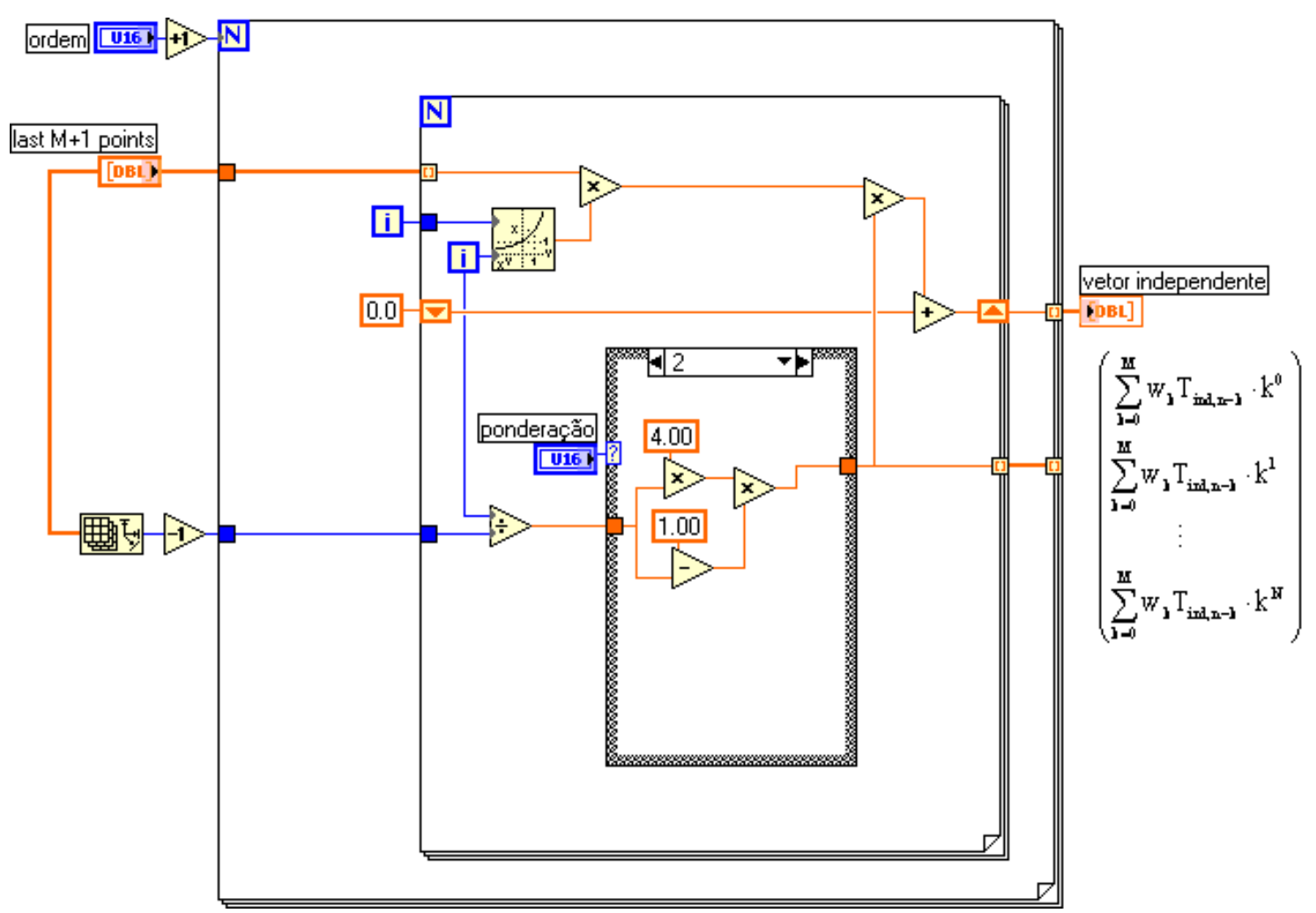

Figura B. 11: Diagrama de bloco da subVI "gera vet b" 


\section{Apêndice C - Termopar}

Os termopares são sensores para medição de temperatura de maior uso industrial. Cobrem uma faixa bastante extensa de temperaturas que vai de -200 a $2300{ }^{\circ} \mathrm{C}$ aproximadamente e possui baixo custo se comparado com outros tipos de sensores.

A medição de temperatura por termopares data de 1821, quando T. J. Seebeck descobriu que uma corrente elétrica é gerada em um circuito contínuo formado por dois fios metálicos de materiais distintos quando as duas soldas (juntas) estão em temperaturas diferentes (PERRY e CHILTON 1980). Os termopares são sensores de temperatura baseados no princípio de que, enquanto dois metais diferentes forem unidos, uma tensão pré-estabelecida será gerada, relacionando a diferença de temperatura entre a junção de medição e a junção de referência.

Quando as junções de dois metais diferentes formando um circuito fechado são expostas a diferentes temperaturas, uma força eletromotriz (f.e.m.) é gerada, induzindo uma corrente elétrica contínua (efeito Seebeck). Quando este circuito é interrompido, a tensão do circuito aberto torna-se uma função das temperaturas das junções e da composição dos dois metais, chamado assim de tensão Seebeck (TERMOPARES 2005).

O termopar pode ser representado graficamente conforme a Figura C.1. Os dois metais são A e B, e $T_{1}$ e $T_{2}$ são as temperaturas das junções. Quando $T_{1}$ é a temperatura da junta fria (junção de referência) e $T_{2}$ é a temperatura da junta quente (junção de medição) a corrente termoelétrica $i$ flui na direção indicada na Figura C.1. 


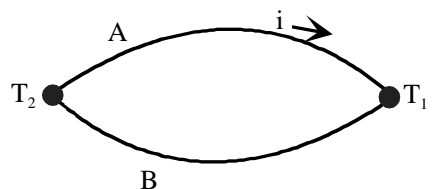

Figura C. 1: Circuito simples de termopar (PERRY e CHILTON 1980)

A medida de temperatura por meios termoelétricos é baseada inteiramente na aplicação das leis termoelétricas (REIS 1999 e TERMOPARES 2005):

- $\quad$ lei do circuito homogêneo: dois materiais diferentes são necessários para formar um termopar;

- lei dos metais intermediários: a f.e.m. gerada por um par termoelétrico não será alterada se for introduzido em qualquer ponto do circuito, um metal genérico diferente dos que compõem o sensor, desde que as novas junções formadas sejam mantidas na mesma temperatura;

- lei das temperaturas intermediárias: um termopar pode ser usado em qualquer temperatura de referência.

Para se usar o termopar como sensor de temperatura, é necessário conhecer a f.e.m. gerada e a temperatura da junção de referência $T_{1}$, assim tem-se a temperatura $T_{2}$ da junção de medição. Uma forma de se determinar a temperatura de referência é colocar a extremidade da junção fria numa mistura de água e gelo a $0{ }^{\circ} \mathrm{C}$ e a tensão gerada será de zero $\mathrm{mV}$, assim o sinal gerado pelo sensor só dependerá da temperatura da junção quente do meio a ser medido. Há outras maneiras, como dispositivos alternativos (resistor, termistor, etc), que simulam automaticamente a temperatura de referência.

Os termopares geram a f.e.m. na faixa de $\mathrm{mV}$, então, é necessário converter estes dados em temperatura. A relação f.e.m. x temperatura de um termopar não é linear. O instrumento indicador deve de algum modo converter o sinal gerado pelo sensor. Várias tabelas dão as relações f.e.m. x temperatura para os tipos mais comuns de termopares usados na indústria. Alternativamente, um polinômio pode ser aproximado descrevendo a curva do sensor, cujos coeficientes são determinados para intervalos de temperatura apropriados. A Figura C.2 mostra um gráfico da relação f.e.m. x temperatura para os vários tipos de termopares existentes. 


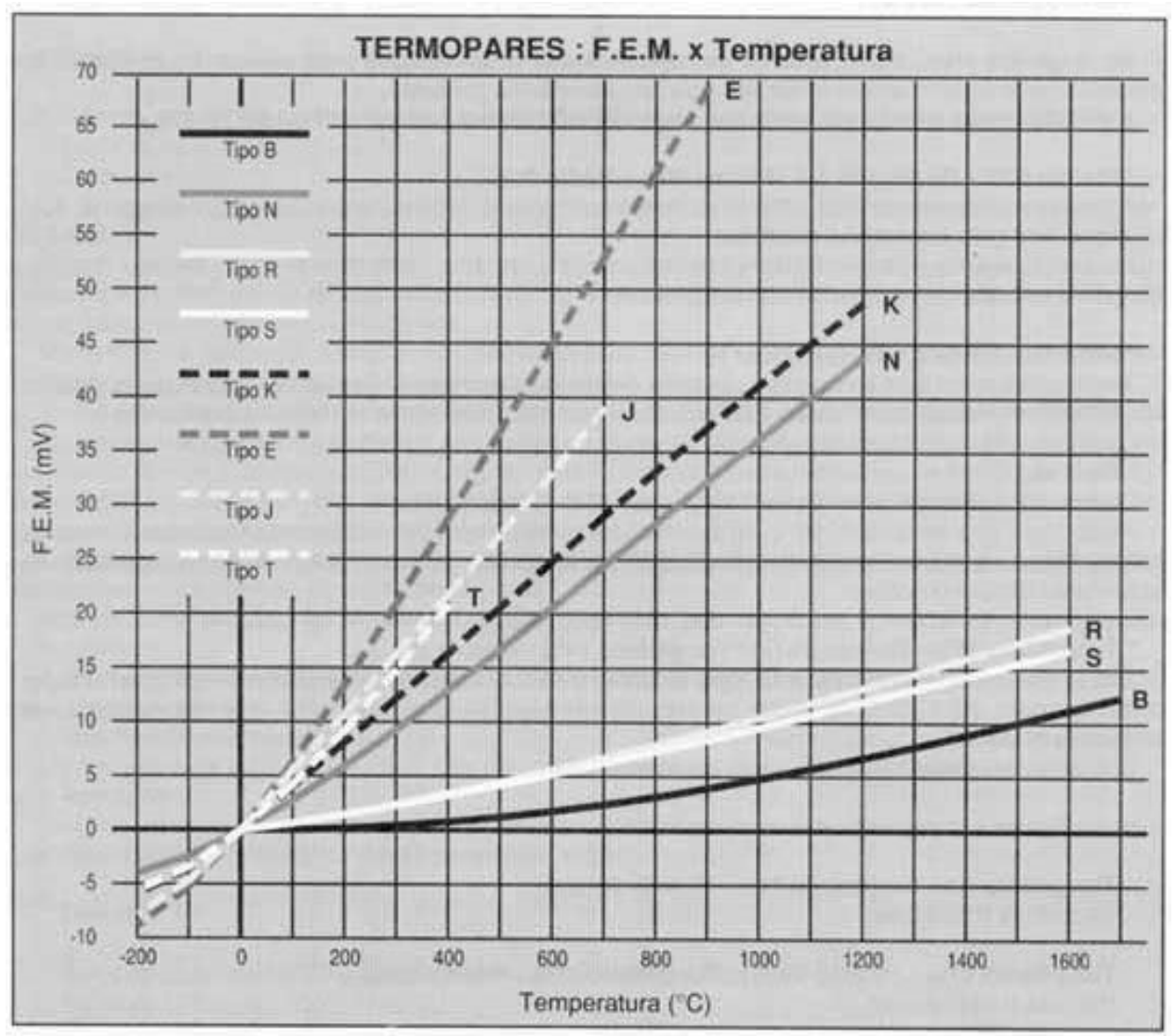

Figura C. 2: Gráfico da relação f.e.m. x temperatura de vários tipos de termopares (TERMOPARES 2005)

Alguns erros na medida devem-se a termopares descalibrados, provocando desvios de centésimos ou até décimos de graus. A calibração é feita comparando a temperatura indicada pelo termopar por um termômetro, ambos no mesmo meio de forma que as temperaturas possam ser comparadas. A correção é feita determinando um polinômio que aproxima os dados fornecidos pelo termopar em $\mathrm{mV}$ e a temperatura obtida pelo termômetro.

A seleção do melhor tipo de termopar é baseada na temperatura de aplicação, características ambientais, comprimento exigido para a execução do serviço, precisão e custo. A Tabela C.1 relaciona os tipos de termopares mais comuns, a faixa de temperatura de trabalho e suas características de utilização. 
Tabela C. 1: Relação de tipos de materiais utilizados na construção de termopares e suas faixas de atuação

\begin{tabular}{|c|c|c|c|}
\hline Tipo & Composição & Variação & Característica \\
\hline B & $\begin{array}{l}\text { Platina-30\% } \\
\text { Ródiol(+) } \\
\text { Platina-6\% } \\
\text { Ródiol(-) }\end{array}$ & 600 a $1700^{\circ} \mathrm{C}$ & $\begin{array}{l}\text { Recomendáveis em atmosferas oxidantes ou inertes; } \\
\text { não devem ser usados abaixo de zero grau, no vácuo, } \\
\text { em atmosferas redutoras ou atmosferas com vapores } \\
\text { metálicos; mais adequado para altas temperaturas que } \\
\text { os tipos S e R. }\end{array}$ \\
\hline $\mathrm{E}$ & $\begin{array}{c}\text { Níquel- } \\
\text { Cromo(+) } \\
\text { Cobre-Níquel(-) }\end{array}$ & -200 a $900^{\circ} \mathrm{C}$ & $\begin{array}{l}\text { Podem ser usados em atmosferas oxidantes e inertes; } \\
\text { em ambientes redutor ou vácuo perdem suas } \\
\text { características termoelétricas; adequado para uso em } \\
\text { temperaturas abaixo de zero grau. }\end{array}$ \\
\hline $\mathrm{J}$ & Cobre-Níquel(-) & -40 a $750{ }^{\circ} \mathrm{C}$ & $\begin{array}{l}\text { Podem ser usados em atmosferas oxidantes, redutoras, } \\
\text { inertes e no vácuo; não deve ser usado em atmosferas } \\
\text { sulfurosas e não se recomenda o uso em temperaturas } \\
\text { abaixo de zero grau; apresenta baixo custo. }\end{array}$ \\
\hline $\mathrm{K}$ & $\begin{array}{l}\text { Níquel- } \\
\text { Cromo(+) } \\
\text { Níquel- } \\
\text { Alumínio(-) }\end{array}$ & -200 a $1200^{\circ} \mathrm{C}$ & $\begin{array}{l}\text { Recomendáveis em atmosferas oxidantes ou inertes; } \\
\text { ocasionalmente podem ser usados abaixo de zero grau; } \\
\text { não devem ser utilizados em atmosferas redutoras e } \\
\text { sulfurosas; seu uso no vácuo é por curto período de } \\
\text { tempo. }\end{array}$ \\
\hline $\mathrm{N}$ & $\begin{array}{l}\text { Platina-Cromo- } \\
\quad \text { Silício(+) } \\
\text { Níquel-Silício(-) }\end{array}$ & -200 a $1200^{\circ} \mathrm{C}$ & $\begin{array}{l}\text { Excelente resistência à oxidação até } 1200^{\circ} \mathrm{C} \text {; curva } \\
\text { f.e.m. x temperatura similar ao tipo K, porém possui } \\
\text { menor potência termoelétrica; apresenta maior } \\
\text { estabilidade e menor desvio por tempo. }\end{array}$ \\
\hline $\mathrm{R}$ & $\begin{array}{l}\text { Platina-13\% } \\
\text { Ródiol(+) } \\
\text { Platina(-) }\end{array}$ & 0 a $1600^{\circ} \mathrm{C}$ & $\begin{array}{l}\text { Recomendáveis em atmosferas oxidantes ou inertes; } \\
\text { não devem ser usados abaixo de zero grau, no vácuo, } \\
\text { em atmosferas redutoras ou atmosferas com vapores } \\
\text { metálicos; apresenta boa precisão em temperaturas } \\
\text { elevadas. }\end{array}$ \\
\hline $\mathrm{S}$ & $\begin{array}{l}\text { Platina-10\% } \\
\text { Ródiol(+) } \\
\text { Platina(-) }\end{array}$ & 0 a $1600^{\circ} \mathrm{C}$ & $\begin{array}{l}\text { Recomendáveis em atmosferas oxidantes ou inertes; } \\
\text { não devem ser usados abaixo de zero grau, no vácuo, } \\
\text { em atmosferas redutoras ou atmosferas com vapores } \\
\text { metálicos; apresenta boa precisão em temperaturas } \\
\text { elevadas. }\end{array}$ \\
\hline $\mathrm{T}$ & Cobre-Níquel(-) & -200 a $350^{\circ} \mathrm{C}$ & $\begin{array}{l}\text { Podem ser usados em atmosferas oxidantes, redutoras, } \\
\text { inertes e no vácuo; adequados para medições abaixo de } \\
\text { zero grau; apresenta boa precisão na sua faixa de } \\
\text { utilização. }\end{array}$ \\
\hline
\end{tabular}

Fonte: Termopares (2005)

Os termopares são transdutores robustos de medida e podem ser usados em condições severas de medida. Os sinais medidos são de nível baixo e por isso suscetíveis a ruídos. Portanto é aconselhável que sejam blindados para que tenha um bom desempenho. 


\section{Anexo A}

Neste anexo estão as teorias do método de diferenças finitas (FORTUNA 2000 e WEISSTEIN 2005b) usado para discretizar a equação de transdução, a função de densidade de probabilidade (METCALFE 1994 e PAPOULIS 1965) e dos quatro momentos estatísticos (PRESS et al. 1992) utilizados para comparação dos sinais estatisticamente.

\section{A.1 Diferenças finitas}

Diferença finita é o análogo discreto da derivada. Portanto, aproximações de diferenças finitas substituem o operador diferencial contínuo por uma aproximação discreta, calculada a partir dos valores de uma função $f$.

As aproximações por diferenças finitas para a primeira derivada podem ser feitas de três maneiras, a saber: diferenças avançadas, atrasadas e centrais, Figura A.1.1:

- $\quad$ diferenças avançadas: $\left.\frac{\partial f}{\partial x}\right|_{i}=\frac{f_{i+1}-f_{i}}{\Delta x}$

- diferenças atrasadas: $\left.\frac{\partial f}{\partial x}\right|_{i}=\frac{f_{i}-f_{i-1}}{\Delta x}$

- $\quad$ diferenças centrais: $\left.\frac{\partial f}{\partial x}\right|_{i}=\frac{f_{i+1}-f_{i-1}}{2 \Delta x}$

onde $\Delta x=x_{i}-x_{i-1}$, são pontos igualmente espaçados. Além disso, $f_{i \pm k}=f\left(x_{i} \pm k \Delta x\right)$, $k=0,1$. 


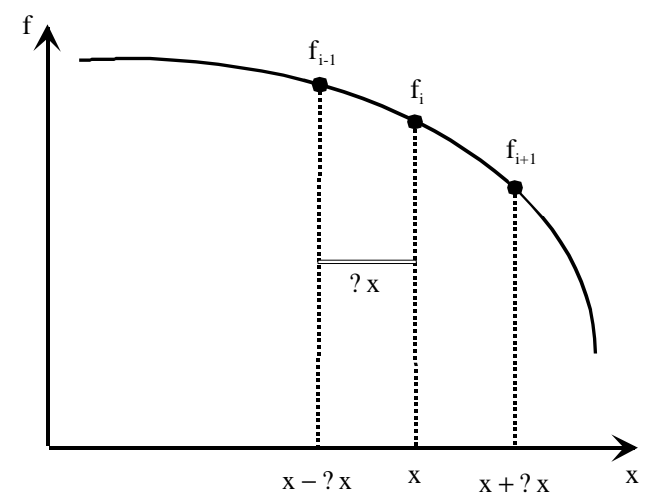

Figura A.1. 1: Pontos utilizados nas diferenças finitas avançadas, atrasadas e centrais

\section{A.2 Função de densidade de probabilidade}

Função densidade de probabilidade (PDF), também chamada de função de probabilidade ou função densidade, é uma curva cuja área entre dois valores representa a probabilidade de uma variável contínua estar entre estes valores, uma população análoga de um histograma.

A derivada

$$
f(x)=\frac{d F(x)}{d x}
$$

de uma função de distribuição $F(x), F(x)=P\{\mathbf{x} \leq x\}-\infty \leq x \leq \infty$, é chamada de função densidade da variável randômica $\mathbf{x}$ (também conhecida como função frequiência), Figura A.2.1.
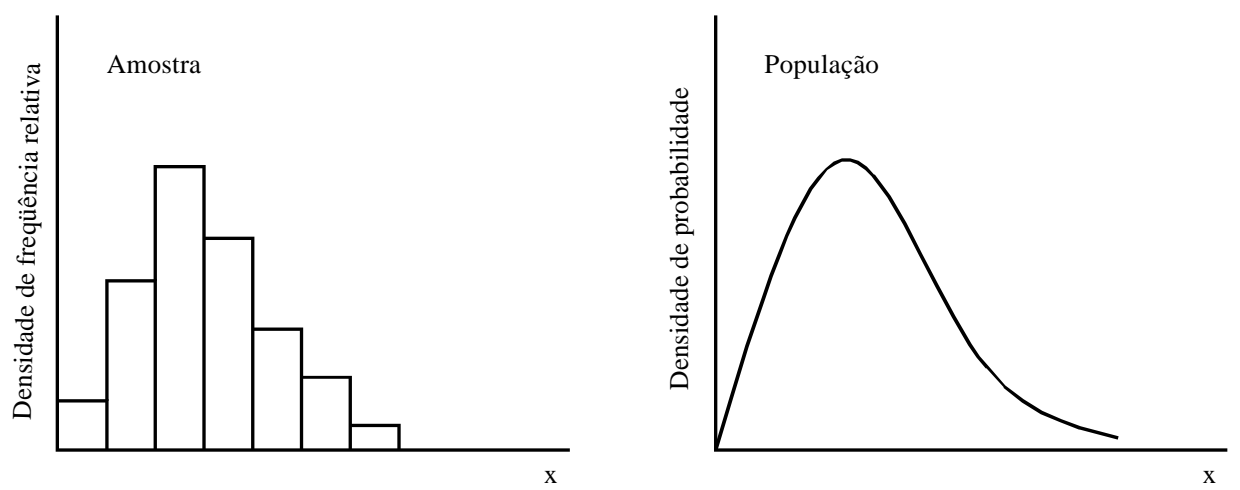

Figura A.2. 1: Relação entre a PDF e o histograma (METCALFE 1994) 


\section{A.3 Momentos estatísticos}

Quando um conjunto de valores tem uma tendência central forte, isto é, uma tendência de agrupar-se ao redor de algum valor em particular, pode-se usar para caracterizar este conjunto de poucos números por momentos que é a soma de potências inteiras dos valores.

A mais conhecida, ou o primeiro momento, é a média dos valores $x_{1}, \ldots, x_{N}$,

$$
\bar{x}=\frac{1}{N} \sum_{j=1}^{N} x_{j}
$$

o qual estima o valor ao redor da posição que ocorre o agrupamento central.

$\mathrm{O}$ segundo momento caracteriza a variabilidade ao redor dos valores. A mais comum é a variância, que estima o desvio quadrado da média de $x$ do valor médio

$$
\sigma^{2}=\frac{1}{N-1} \sum_{j=1}^{N}\left(x_{j}-\bar{x}\right)^{2}
$$

ou a raiz quadrada da variância, o desvio padrão

$$
\sigma=\sqrt{\frac{1}{N-1} \sum_{j=1}^{N}\left(x_{j}-\bar{x}\right)^{2}}
$$

O terceiro momento ou skewness caracteriza o grau de assimetria da distribuição ao redor da média, ou seja, o formato da distribuição, Figura A.3.1,

$$
\text { Skew }=\frac{1}{N} \sum_{j=1}^{N}\left[\frac{x_{j}-\bar{x}}{\sigma}\right]^{3}
$$

Se a distribuição tem uma assimetria cuja a parte final estende mais para os valores negativos de $x$, a função tem uma skewness negativa. Por outro lado, se a 
skewness tem valores positivos, a distribuição possui uma assimetria cuja a parte final estende mais para os valores positivos de $x$, Figura A.3.1.

O quarto momento é a kurtosis, mede os picos ou o nivelamento relativo a distribuição, Figura A.3.1. A definição convencional da kurtosis é

$$
\text { Kurt }=\left\{\frac{1}{N} \sum_{j=1}^{N}\left[\frac{x_{j}-\bar{x}}{\sigma}\right]^{4}\right\}-3
$$

sendo que o termo -3 faz o valor zero para uma distribuição normal. Uma distribuição com kurtosis positiva é chamada de leptokurtic, uma distribuição com kurtosis negativa é nomeada por platykurtic e uma distribuição entre os dois termos é denominado por mesokurtic, Figura A.3.1.
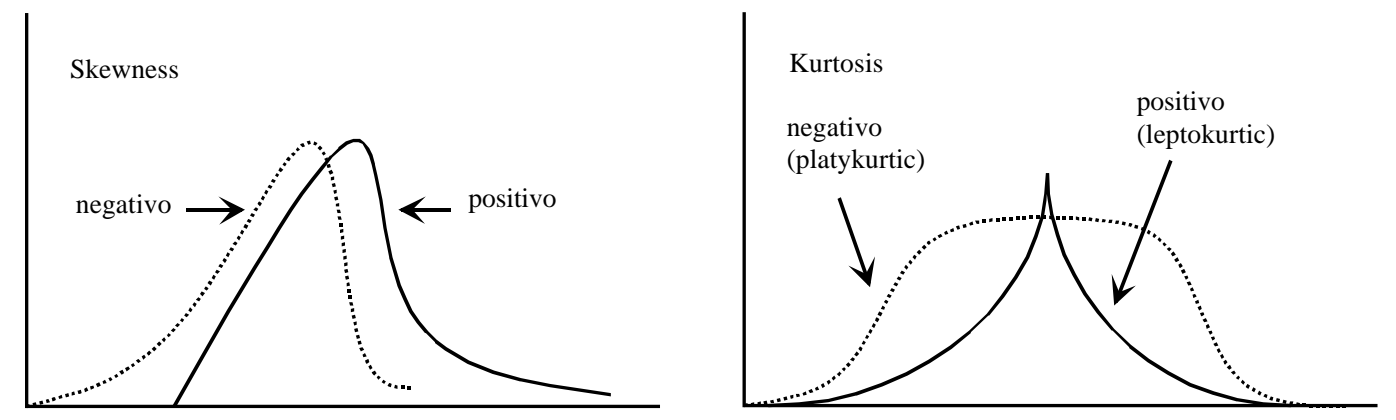

Figura A.3. 1: Distribuições cujo terceiro (esquerda) e quarto (direita) momentos são diferentes de uma distribuição normal (PRESS et al. 1992)

Dos quatro momentos, o primeiro e segundo momentos são quantidades dimensionais, isto é, tem alguma unidade como a quantidade de $x_{j}$ medidos. Já o terceiro e quarto momentos são adimensionais, isto é, um número puro que caracterizam o formato e os picos, respectivamente, da distribuição relativa a distribuição normal. 